\title{
A Global Ocean Oxygen Database and Atlas for Assessing and Predicting Deoxygenation and Ocean Health in the Open and Coastal Ocean
}

\begin{abstract}
Marilaure Grégoire 1*, Véronique Garçon ${ }^{2 *}$, Hernan Garcia ${ }^{3}$, Denise Breitburg ${ }^{4}$, Kirsten Isensee ${ }^{5}$, Andreas Oschlies 6 , Maciej Telszewski ${ }^{7}$, Alexander Barth ${ }^{8}$, Henry C. Bittig ${ }^{9}$, Jacob Carstensen ${ }^{10}$, Thierry Carval ${ }^{11}$, Fei Chai ${ }^{12}$, Francisco Chavez ${ }^{13}$, Daniel Conley ${ }^{14}$, Laurent Coppola ${ }^{15}$, Sean Crowe ${ }^{16}, K^{2}$ Currie ${ }^{17}$, Minhan Dai ${ }^{18}$, Bruno Deflandre ${ }^{19}$, Boris Dewitte ${ }^{20,21,22,}$ Robert Diaz ${ }^{23}$, Emilio Garcia-Robledo ${ }^{24}$, Denis Gilbert ${ }^{25}$, Alessandra Giorgetti26, Ronnie Glud ${ }^{27}$, Dimitri Gutierrez ${ }^{28}$, Shigeki Hosoda ${ }^{29}$, Masao Ishii ${ }^{30}$, Gil Jacinto ${ }^{31}$, Chris Langdon ${ }^{32}$, Siv K. Lauvset ${ }^{33}$, Lisa A. Levin ${ }^{34}$, Karin E. Limburg ${ }^{35}$, Hela Mehrtens', Ivonne Montes ${ }^{36}$, Wajih Naqvi37, Aurélien Paulmier', Benjamin Pfeilis, Grant Pitcher ${ }^{39}$, Sylvie Pouliquen ${ }^{11}$, Nancy Rabalais ${ }^{40}$, Christophe Rabouille ${ }^{41}$, Virginie Recape ${ }^{11}$, Michaël Roman ${ }^{42}$, Kenneth Rose ${ }^{43}$, Daniel Rudnick ${ }^{34}$, Jodie Rummer ${ }^{43}$, Catherine Schmechtig'5, Sunke Schmidtko ${ }^{6}$, Brad Seibel ${ }^{44}$, Caroline Slomp ${ }^{45}$, U. Rashid Sumalia ${ }^{46}$, Toste Tanhua ${ }^{6}$, Virginie Thierry ${ }^{47}$, Hiroshi Uchida ${ }^{29}$, Rik Wanninkhof $^{48}$ and Moriaki Yasuhara ${ }^{49}$
\end{abstract}

\section{OPEN ACCESS}

${ }^{1}$ Department of Astrophysics, MAST-FOCUS, Geophysics and Oceanography, University of Liège, Liège, Belgium, 2 Laboratoire d'Études en Géophysique et Océanographie Spatiales, CNRS/IRD/UPS/CNES, Toulouse, France, ${ }^{3}$ National Centers for Environmental Information, National Oceanic and Atmospheric Administration, Maryland, MD, United States, ${ }^{4}$ Smithsonian Environmental Research Center, Edgewater, MD, United States, ${ }^{5}$ Intergovernmental Oceanographic Commission of UNESCO, Paris, France, ${ }^{6}$ GEOMAR Helmholtz Centre for Ocean Research Kiel, Kiel, Germany, ${ }^{7}$ International Ocean Carbon Coordination Project, Institute of Oceanology of Polish Academy of Sciences, Sopot, Poland, ${ }^{8}$ Department of Astrophysics, GHER-FOCUS, Geophysics and Oceanography, University of Liège, Liège, Belgium, ${ }^{9}$ Leibniz Institute for Baltic Sea Research Warnemünde, Rostock, Germany, ${ }^{10}$ Department of Bioscience, Aarhus University, Roskilde, Denmark, ${ }^{11}$ Coriolis, IFREMER, Brest, France, ${ }^{12}$ School of Marine Sciences, University of Maine, Orono, ME, United States, ${ }^{13}$ Monterey Bay Aquarium Research Institute, Moss Landing, CA, United States, ${ }^{14}$ Department of Geology, Lund University, Lund, Sweden, ${ }^{15}$ CNRS, Laboratoire d'Océanographie de Villefranche, LOV, Sorbonne Université, Villefranche-sur-Mer, France, ${ }^{16}$ Laboratory of Microbiology and Immunology, Life Sciences Centre, Vancouver, BC, Canada, ${ }^{17}$ NIWA, Auckland, New-Zealand, ${ }^{18}$ Department of Oceanography, Xiamen University, Xiamen, China, ${ }^{19}$ CNRS, EPOC, EPHE, UMR 5805, Université de Bordeaux, Bordeaux, France, ${ }^{20}$ Centro de Estudios Avanzado en Zonas Áridas, La Serena, Chile,

${ }^{21}$ Departamento de Biología, Facultad de Ciencias del Mar, Universidad Católica del Norte, Coquimbo, Chile, ${ }^{22} \mathrm{CECl}$, Université de Toulouse, CERFACS/CNRS, Toulouse, France, ${ }^{23}$ Department of Biological Sciences, University of Virginia, Virginia, VA, United States, ${ }^{24}$ Department of Biology, University of Cadiz, Cadiz, Spain, ${ }^{25}$ Maurice-Lamontagne Institute, Fisheries and Oceans Canada, Mont-Joli, QC, Canada, ${ }^{26}$ Istituto Nazionale di Oceanografia e di Geofisica Sperimentale, Trieste, Italy, ${ }^{27}$ Department of Biology, Danish Institute for Advanced Study, Odense, Denmark, ${ }^{28}$ Dirección General de Investigaciones Oceanográficas y de Cambio Climático, Instituto del Perú, Callao, Peru, ${ }^{29}$ Japan Agency for Marine-Earth Science and Technology, Yokosuka, Japan, ${ }^{30}$ Department of Climate and Geochemistry, Meteorological Research Institute, Ibaraki, Japan, ${ }^{31}$ The Marine Science Institute, University of the Philippines, Quezon City, Philippines, ${ }^{32}$ Department of Marine Biology and Ecology, Rosenstiel School of Marine and Atmospheric Science, University of Miami, Miami, FL, United States, ${ }^{33}$ NORCE Norwegian Research Centre, Bjerknes Centre for Climate Research, Bergen, Norway, ${ }^{34}$ Integrative Oceanography Division, Scripps Institution of Oceanography, University of California, San Diego, La Jolla, CA, United States, ${ }^{35}$ State University of New York College of Environmental Science and Forestry, Syracuse, NY, United States, ${ }^{36}$ Instituto Geofísico del Perú, Lima, Peru, ${ }^{37}$ Council of Scientific and Industrial Research, New Delhi, India, ${ }^{38}$ Geophysical Research, Bjerknes Centre for Climate Research, University of Bergen, Bergen, Norway, ${ }^{39}$ Department of Biological Sciences, University of Cape Town, Cape Town, South Africa, ${ }^{40}$ Department of Oceanography and Coastal Sciences, Louisiana State University, Baton Rouge, LA, United States, ${ }^{41}$ Laboratoire des Sciences du Climat et de l'Environnement, CEA-CNRS-UVSQ, Gif-sur-Yvette, France, ${ }^{42}$ Horn Point Laboratory, University of Maryland Center for Environmental Science, Cambridge, MD, United States, ${ }^{43}$ ARC 
Centre of Excellence for Coral Reef Studies, James Cook University, Townsville, QLD, Australia, ${ }^{44}$ College of Marine Science, University of South Florida, St. Petersburg, FL, United States, ${ }^{45}$ Faculty of Geosciences, Utrecht University, Utrecht, Netherlands, ${ }^{46}$ Fisheries Economics Research Unit, University of British Columbia, Vancouver, BC, Canada, ${ }^{47}$ Ifremer, CNRS, IRD, LOPS, University of Brest, Plouzané, France, ${ }^{48}$ Atlantic Oceanographic and Meteorological Laboratory, NOAA, Miami, FL, United States, ${ }^{49}$ School of Biological Sciences, Division for Ecology and Biodiversity, Swire Institute of Marine Science, and State Key Laboratory of Marine Pollution, The University of Hong Kong, Hong Kong, Hong Kong SAR, China

In this paper, we outline the need for a coordinated international effort toward the building of an open-access Global Ocean Oxygen Database and ATlas $\left(\mathrm{GO}_{2} \mathrm{DAT}\right)$ complying with the FAIR principles (Findable, Accessible, Interoperable, and Reusable). $\mathrm{GO}_{2} \mathrm{DAT}$ will combine data from the coastal and open ocean, as measured by the chemical Winkler titration method or by sensors (e.g., optodes, electrodes) from Eulerian and Lagrangian platforms (e.g., ships, moorings, profiling floats, gliders, ships of opportunities, marine mammals, cabled observatories). $\mathrm{GO}_{2} \mathrm{DAT}$ will further adopt a community-agreed, fully documented metadata format and a consistent quality control (QC) procedure and quality flagging (QF) system. $\mathrm{GO}_{2} \mathrm{DAT}$ will serve to support the development of advanced data analysis and biogeochemical models for improving our mapping, understanding and forecasting capabilities for ocean $\mathrm{O}_{2}$ changes and deoxygenation trends. It will offer the opportunity to develop qualitycontrolled data synthesis products with unprecedented spatial (vertical and horizontal) and temporal (sub-seasonal to multi-decadal) resolution. These products will support model assessment, improvement and evaluation as well as the development of climate and ocean health indicators. They will further support the decision-making processes associated with the emerging blue economy, the conservation of marine resources and their associated ecosystem services and the development of management tools required by a diverse community of users (e.g., environmental agencies, aquaculture, and fishing sectors). A better knowledge base of the spatial and temporal variations of marine $\mathrm{O}_{2}$ will improve our understanding of the ocean $\mathrm{O}_{2}$ budget, and allow better quantification of the Earth's carbon and heat budgets. With the ever-increasing need to protect and sustainably manage ocean services, $\mathrm{GO}_{2} \mathrm{DAT}$ will allow scientists to fully harness the increasing volumes of $\mathrm{O}_{2}$ data already delivered by the expanding global ocean observing system and enable smooth incorporation of much higher quantities of data from autonomous platforms in the open ocean and coastal areas into comprehensive data products in the years to come. This paper aims at engaging the community (e.g., scientists, data managers, policy makers, service users) toward the development of $\mathrm{GO}_{2}$ DAT within the framework of the UN Global Ocean Oxygen Decade (GOOD) program recently endorsed by IOC-UNESCO. A roadmap toward $\mathrm{GO}_{2} \mathrm{DAT}$ is proposed highlighting the efforts needed (e.g., in terms of human resources).

Keywords: oxygen, atlas, database, observing, mapping, data-products, open and coastal ocean, deoxygenation

\section{INTRODUCTION}

Current evidence indicates that the coastal (i.e., most directly influenced by land) and open ocean is losing oxygen $\left(\mathrm{O}_{2}\right)$ since the middle of the last century (Figure 1), with consequences for living organisms and biogeochemical cycles that are not yet fully understood (e.g., Keeling et al., 2010; Breitburg et al., 2018). In the open ocean the $\mathrm{O}_{2}$ inventory has decreased by a few percent (i.e., 0.5-3\%) and the Oxygen Minimum Zones (OMZs) are expanding. Although observations and model simulations document a net decline of the global ocean $\mathrm{O}_{2}$ inventory, there is disagreement among analyses (Figure 2) resulting in inconsistent regional estimates of the rate of $\mathrm{O}_{2}$ loss (i.e., deoxygenation) (e.g., Oschlies et al., 2018). Uncertainties and differences between estimates could be attributable to the scarcity of accessible data, the use of different datasets (e.g., volume 


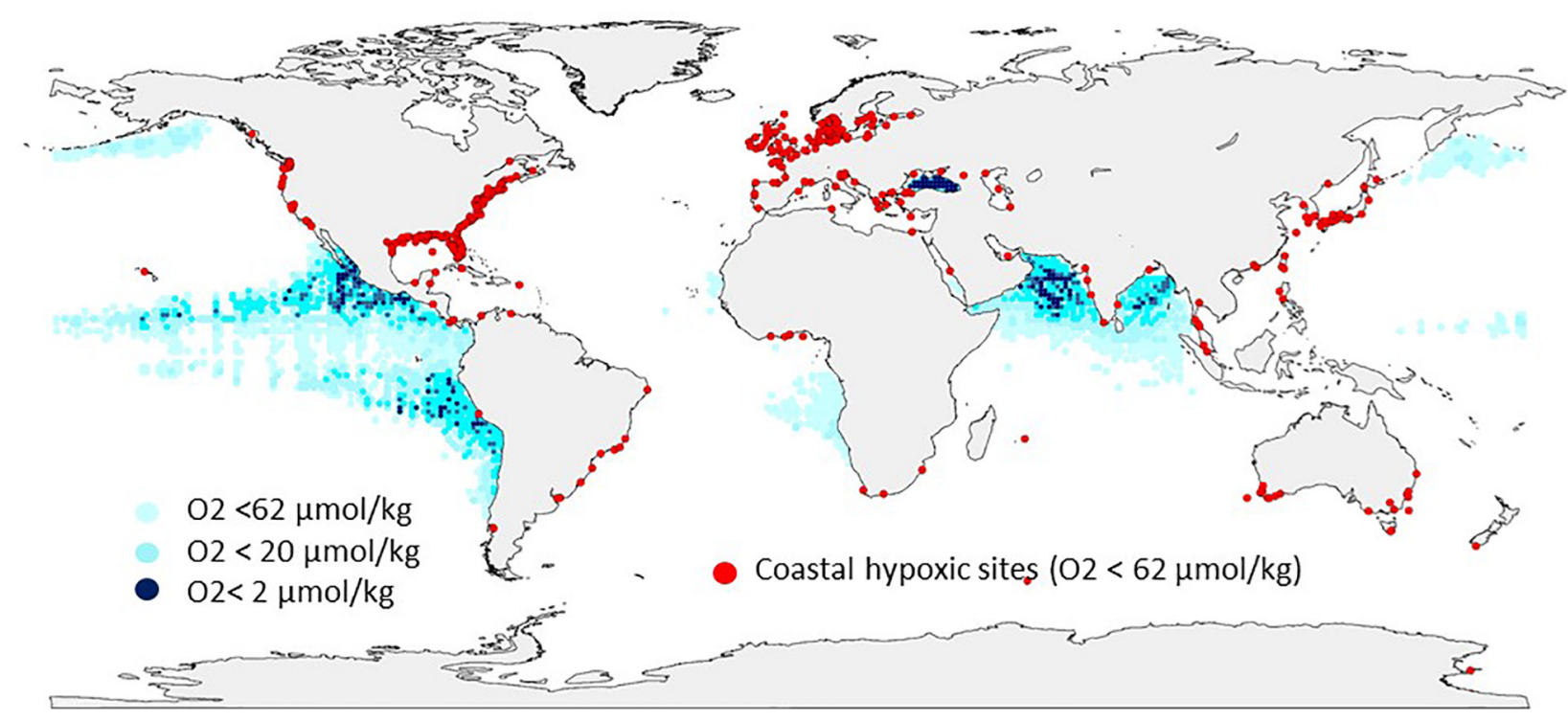

FIGURE 1 | Global distribution of low $\mathrm{O}_{2}$ areas (i.e., $\mathrm{O}_{2}<62 \mu \mathrm{mol} \mathrm{kg}^{-1}$ ) in the coastal and global ocean (from Breitburg et al., 2018 ). In the coastal area, more than 500 sites have been inventoried with low $\mathrm{O}_{2}$ conditions in the past half century (red dots) while in the open ocean the extent of low $\mathrm{O}_{2}$ waters amounts to several millions $\mathrm{km}^{3}$ (the blue dots refer to conditions at $300 \mathrm{~m}$ ).

and quality of data) and the employment of different mapping techniques and models.

In the global coastal ocean, $\mathrm{O}_{2}$ deficient zones are mostly intermittent features that essentially appear in the benthic boundary layer (BBL, i.e., the layer overlying the seabed where processes are influenced by the presence of the bottom) when the $\mathrm{O}_{2}$ consumption by respiration outpaces the $\mathrm{O}_{2}$ supply by ventilation and bottom photosynthesis (e.g., Pitcher et al., 2021). The number of coastal hypoxic sites has increased in response to worldwide eutrophication; yet a precise quantification of the $\mathrm{O}_{2}$ trend in the global coastal zone is still debated. The availability of $\mathrm{O}_{2}$ observations in international databases does not allow a comprehensive quantitative assessment of the severity of hypoxia (i.e., $\mathrm{O}_{2}<60 \mu \mathrm{mol} \mathrm{kg}{ }^{-1}$ ) at seasonal and interannual scales. This issue is particularly critical in regions with limited institutional infrastructure where the connection between National Oceanographic Data Centers (NODCs) and international oceanographic databases is not always wellestablished, or NODCs do not exist. Short-term (i.e., in terms of hours) and small-scale (i.e., in the BBL) variability and amplification of non-linearity in the coastal ocean require data of higher temporal and spatial resolution to characterize $\mathrm{O}_{2}$ dynamics and events of depletion. The reference distribution of hypoxic sites assembled by Diaz and Rosenberg (2008) (Figure 1) highlighted for the first time the worldwide extent of the coastal hypoxia phenomenon. This effort has been valuable but could be updated and amended with the large volume of (sometimes disparate) quantitative information on coastal $\mathrm{O}_{2}$ concentrations, including inventories of the frequency, timing, duration, intensity and spatial extension of the hypoxic events, and links to the original data contained in a globally accessible database. Tracking of the severity and evolution of coastal hypoxia requires access to coherent observational $\mathrm{O}_{2}$ datasets for the global coastal ocean that are amenable to global analysis.

Since the community white paper by Gruber et al. (2010) that called for the addition of $\mathrm{O}_{2}$ sensors on Argo floats, the number of Argo $\mathrm{O}_{2}$ profiles has increased considerably, up to 220,880 $\mathrm{O}_{2}$ profiles as of June 8th 2021. Profiling biogeochemical (BGC) Argo floats provide unprecedented vertical (i.e., at least one order of magnitude larger than the 12-36 points offered by Niskin bottles) and temporal ( each 5-10 days) resolution and coverage at regional and global scales down to a depth of $2000 \mathrm{~m}$. Currently $\sim 10 \%$ of the active Argo floats (i.e., 396 over 3828 floats) have $\mathrm{O}_{2}$ sensors $^{1}$. This percentage increases to more than $25 \%$ (i.e., 41 over 152 floats) when considering the Deep Argo floats only. This spurs initiatives like the GOOS strategy for BGC variables and the international BGC Argo program (Johnson and Claustre, 2016; Roemmich et al., 2019). This new program aims at operating a global array of 1000 BGC-floats that measure vertical profiles of all six core BGC and environmental variables including $\mathrm{O}_{2}$. In this context, the U.S. National Science Foundation has recently decided to add 500 BGC floats (all measuring $\mathrm{O}_{2}$ ) to the global Argo network in the next five years, and several other nations are increasing their contributions, which will boost the array to meet $50 \%$ of its target for global BGC sampling of the ocean.

The increasing number of observation platforms will improve our capabilities to monitor $\mathrm{O}_{2}$ in the open ocean and would remedy the chronic lack of $\mathrm{O}_{2}$ data compared to physical data for mapping and modeling marine systems. However, these several hundred thousand $\mathrm{O}_{2}$ profiles collected by profiling floats and gliders are not currently incorporated in a global compilation of data. Current gridded products and assessment of climate trends

\footnotetext{
${ }^{1}$ https://fleetmonitoring.euro-argo.eu/dashboard
} 


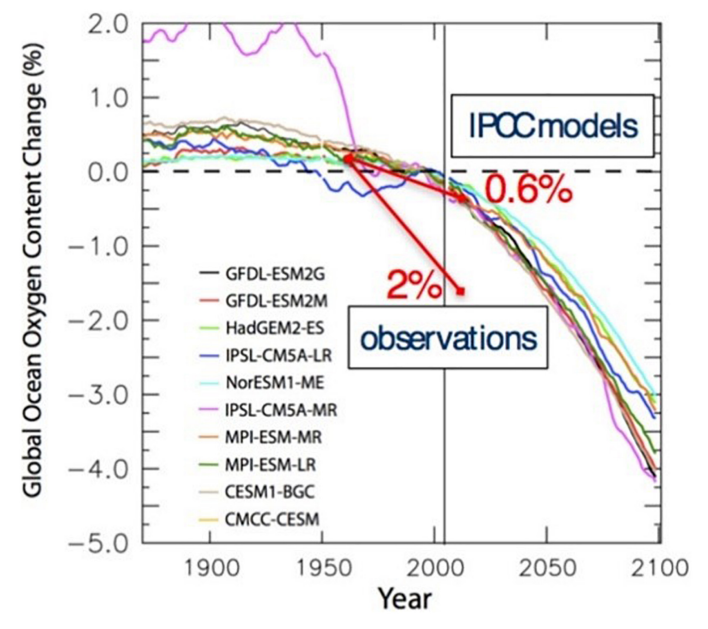

FIGURE 2 | Projected global ocean $\mathrm{O}_{2}$ content change from various models (IPCC AR5, taken from Bopp et al., 2013). Models indicate a 0.6\% decrease (1960-2000s) whereas compilations of observations, such as Schmidtko et al. (2017) indicate greater changes, by a factor of about 3. Figure from Oschlies (2018) and discussed in Oschlies et al. (2018).

(e.g., Garcia et al., 2005, 2013, 2019; Stramma et al., 2008; Lauvset et al., 2016; Schmidtko et al., 2017) are generally based on Winkler and CTD data. The lack of a community accepted data standard treatment (e.g., quality checks, adjustment procedures) and information to the users (e.g., quality flagging) across databases and platforms challenges the development of uniform-quality data-synthesis products that combine different data sources. The integration of sensor and Winkler data from different databases would offer the possibility to advance data-synthesis products at an increased resolution. It would also support the development of an $\mathrm{O}_{2}$ gridded product for the global coastal ocean facilitating a regular assessment of the evolution of coastal hypoxia in a warming climate.

This paper aims at outlining the need, establishing and proposing a roadmap toward the building of a Global Ocean Oxygen Database and ATlas $\left(\mathrm{GO}_{2} \mathrm{DAT}\right)$ for regional seas, coastal zones and open ocean. $\mathrm{GO}_{2} \mathrm{DAT}$ will integrate $\mathrm{O}_{2}$ data from both Eulerian and Lagrangian observations (i.e., Winkler titrations and $\mathrm{O}_{2}$ sensor measurements performed on conductivity-temperature-depth- $\mathrm{O}_{2}$ sondes, fixed moorings, autonomous platforms, and other emergent platforms). It will adopt a fully documented metadata format with traceable quality control (QC) procedures and assess uncertainty including quality flagging $(\mathrm{QF})$, that will be agreed upon by the scientific community. The $\mathrm{GO}_{2}$ DAT concept is aligned with the principles of the Framework for Ocean Observing (FOO, UNESCO, 2012). $\mathrm{GO}_{2}$ DAT will comply with the FAIR ${ }^{2}$ principles (Findable, Accessible, Interoperable, and Reusable, Wilkinson et al., 2016), be available free of charge and contribute to the motto "measure once-use many times." $\mathrm{GO}_{2} \mathrm{DAT}$ datasets and products are envisaged to support ocean research and societal needs and will be made available through a web-platform for scientific analysis,

${ }^{2}$ FAIR principles: https://www.go-fair.org/fair-principles/ decision making and education (Figure 3). In this paper, we aim at engaging the community (e.g., scientists, data managers, policy makers, service users) toward the development of $\mathrm{GO}_{2} \mathrm{DAT}$.

This paper is organized along the three pillars of the FOO value chain of $\mathrm{O}_{2}$ data from requirement setting, through data collection to product delivery. We first demonstrate the need for $\mathrm{GO}_{2} \mathrm{DAT}$ in support of scientific analyses and decision making and underline the requirements on the quality of $\mathrm{O}_{2}$ data to assess $\mathrm{O}_{2}$ state and variability. Next, we review the methodologies for observing ocean $\mathrm{O}_{2}$ concentrations. The basic principles underlying the most used techniques to measure $\mathrm{O}_{2}$, known technical challenges and possible solutions are described. For each observing platform, we synthetize the evolution of $\mathrm{O}_{2}$ measurements, calibration procedures and the existence of Data Assembly Centers (DACs) that centralize data processing according to an established protocol vetted by the oceanography community. The adequacy of current $\mathrm{O}_{2}$ data to assess variability at climate and weather scales and calibration procedures applied to collected $\mathrm{O}_{2}$ data (i.e., post-calibration or second order calibration) are discussed. Finally, a roadmap for achieving $\mathrm{GO}_{2} \mathrm{DAT}$ is presented.

\section{SCIENTIFIC RATIONALE}

\section{Physical and Biogeochemical Controls of Ocean $\mathrm{O}_{2}$ Dynamics}

The dynamics of $\mathrm{O}_{2}$ in the ocean is governed by both physical, biogeochemical and biological processes. The ocean gains $\mathrm{O}_{2}$ in the upper layer (i.e., $\sim 0-100 \mathrm{~m}$ ) due to photosynthesis by autotrophic organisms and dissolution from the atmosphere in undersaturated waters near the surface. Conversely, $\mathrm{O}_{2}$ is lost due to the diffusion of $\mathrm{O}_{2}$ to the atmosphere in over-saturated surface waters, and from the respiration of aerobic organisms and oxidation of chemical species in the water column and sediments. The surface mixed layer is well oxygenated in most of the ocean, but below the sunlit surface layer, there is no photosynthesis and, the renewal of the $\mathrm{O}_{2}$ consumed requires a physical mechanism (i.e., currents) that transports relatively well-oxygenated waters to regions of lower $\mathrm{O}_{2}$. This mechanism, called ocean ventilation, is responsible for the oxygenation of the ocean interior and modifies the distribution of $\mathrm{O}_{2}$ within the ocean. The distribution of $\mathrm{O}_{2}$ in the ocean interior thus offers information on physical and biogeochemical mechanisms in the ocean. For instance, physical oceanographers investigate the circulation and mixing of water masses from its distribution (e.g., Körtzinger et al., 2004; Coppola et al., 2017; Racapé et al., 2019; Li and Tanhua, 2020; Ulses et al., 2021), marine biogeochemists infer the balance of biological and chemical processes from its variability (e.g., Emerson et al., 1997; Keeling and Manning, 2014; Resplandy et al., 2018) and the $\mathrm{O}_{2}$ content is an indicator of ocean health.

In some subsurface regions where the renewal of $\mathrm{O}_{2}$ by physical transport is low, the $\mathrm{O}_{2}$ concentration can reach levels that are too low to support the survival of many aerobically respiring organisms. Organisms that are found in these areas can exhibit reduced growth and reproduction, avoidance, and, in extreme cases and for non-mobile species, experience low- $\mathrm{O}_{2}$ 


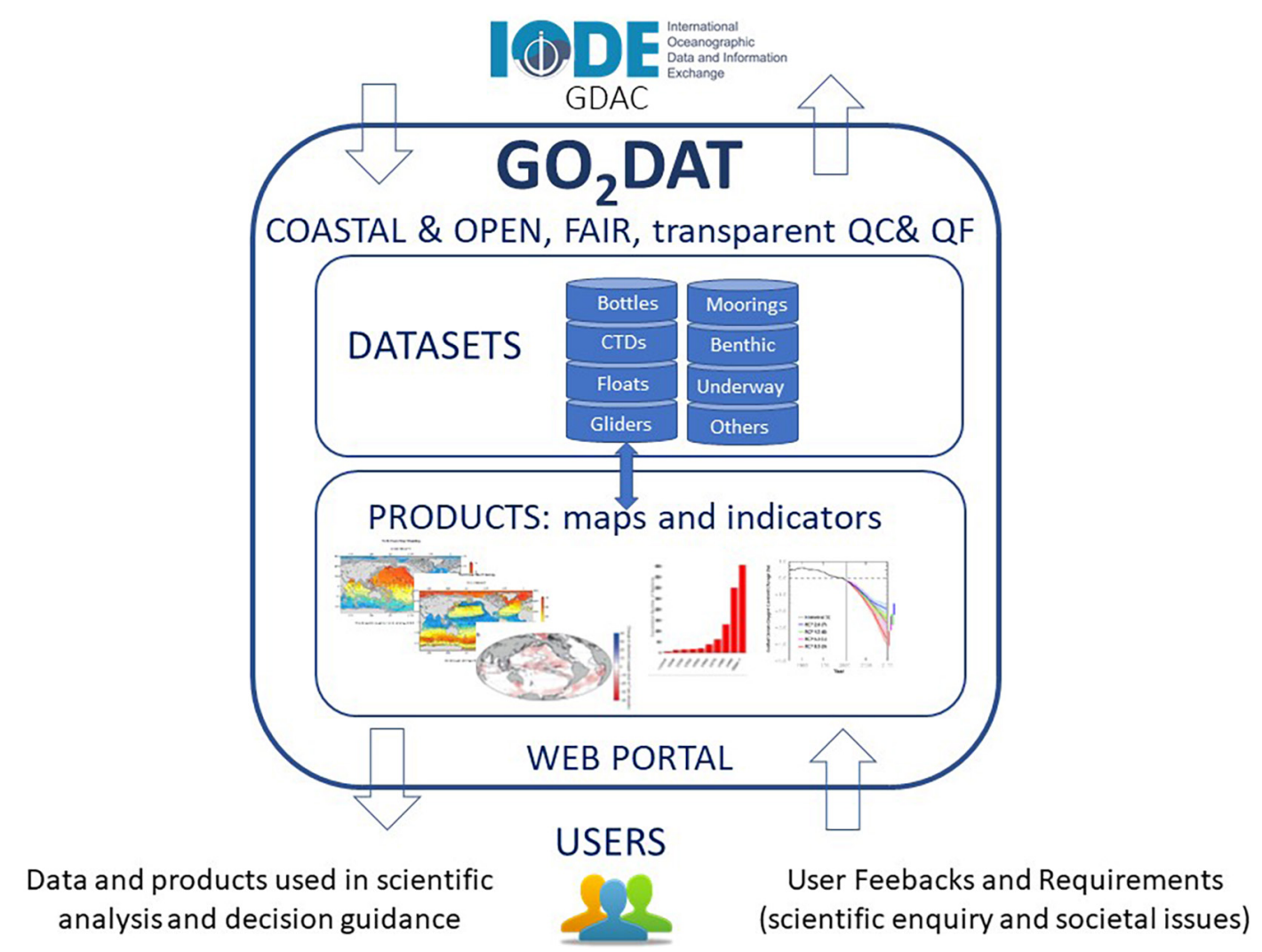

FIGURE 3 | $\mathrm{GO}_{2}$ DAT general concept.

induced mortality (e.g., Levin, 2003; Levin et al., 2009). In the open ocean, OMZs are mainly found in the Eastern boundary upwelling systems in the tropical Pacific and Atlantic, and in the northern Indian Ocean (Figure 1) and extend from $\sim 100$ to $1000 \mathrm{~m}$ (e.g., Helly and Levin, 2004; Paulmier and Ruiz-Pino, 2009). In these OMZs, the degradation of the organic material sinking from the surface takes place through denitrification leading to a consumption of fixed nitrogen and production of $\mathrm{N}_{2}$ and potentially $\mathrm{N}_{2} \mathrm{O}$ (Figure 4). Observational analysis and model results indicate that OMZs have expanded during recent decades (e.g., Stramma et al., 2012; Schmidtko et al., 2017).

$\mathrm{O}_{2}$ dynamics in the coastal ocean can be highly variable over small spatial and temporal scales, from diel cycles with nighttime hypoxia developing in productive coastal systems (Tyler et al., 2009) to episodic events developing over days, to seasonal and multiannual scales (Rabalais et al., 2002; Conley et al., 2009; Carstensen and Conley, 2019). Coastal hypoxia occurs when $\mathrm{O}_{2}$ consumption outpaces its supply, (e.g., during the period of stratification), driving concentrations below thresholds critical for living aerobic communities that cannot escape and have not developed adaptation process. Since the middle of the last century, the worldwide eutrophication ${ }^{3}$ process has increased the level of primary production in the coastal

${ }^{3}$ The enrichment of water by nutrients causing an accelerated growth of algae and higher forms of plant life to produce undesirable disturbance to the balance of zone, promoting bottom $\mathrm{O}_{2}$ depletion with consequences for living marine communities (e.g., Conley et al., 2009; Rabalais et al., 2010; Yasuhara et al., 2012, 2017; Breitburg et al., 2018). Scientific papers and technical reports document the widespread occurrence of coastal hypoxia around the world (Diaz and Rosenberg, 2008; Breitburg et al., 2018; Pitcher et al., 2021), although some regions are still poorly investigated (Altieri et al., 2017).

\section{Why Is a Global $\mathrm{O}_{2}$ Database and Atlas Needed?}

The need for a standardized, well-documented, high-quality, and comprehensive database integrating $\mathrm{O}_{2}$ data and other environmental variables from multiple sources is growing rapidly with the increasing threat of ocean deoxygenation for marine ecosystems and delivery of their associated services to society.

The decision-making process aimed at sustaining a healthy, productive and resilient ocean as prioritized by international policies and initiatives (e.g., UN SDG 14, the EU MFSD, the UN Decade of Ocean Science for Sustainable Development) requires sound environmental mapping and modeling capabilities of known quality.

organisms present in the water and to the quality of the water concerned (OSPAR definition). 


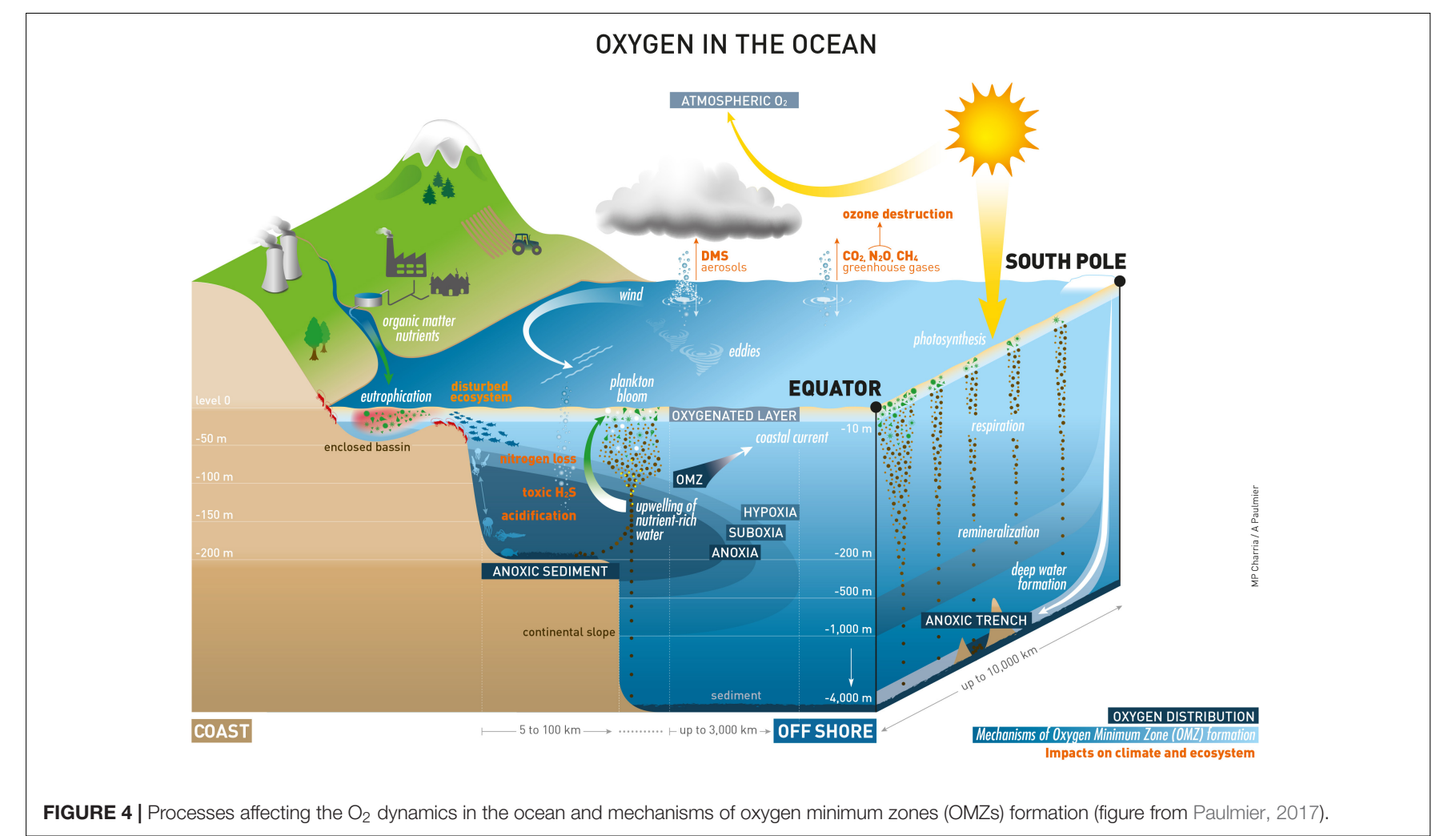

$\mathrm{O}_{2}$ data and derived products (e.g., indicators, maps) can be used by international policy makers (see Table $\mathbf{1}$ for a definition of acronyms) and the science that supports policy in the context of climate change (UNFCCC, IPCC), water quality and pollution (e.g., IMO, GESAMP), biodiversity (e.g., CBD, IPBES); international legally binding instruments UNCLOSBBNJ, seabed mining (e.g., LTC-ISA), fisheries (FAO, RFMOs) and the UN General Assembly. Marine spatial planning and significant, special, vulnerable and protected area designations can benefit from $\mathrm{O}_{2}$ predictions (e.g., Ecologically or Biologically Significant Marine Areas, Vulnerable Marine Ecosystems). $\mathrm{GO}_{2}$ DAT can promote achievement of Sustainable Development Goal (SDG) 14 on the oceans, and specifically SDG14.1 on pollution, SDG14.5 on conserving $10 \%$ of the ocean, SDG 14.7 on Small Island Developing States (SIDS) sustainable use of marine resources, including through sustainable management of fisheries, aquaculture and tourism, and SDG 14.a on scientific knowledge, research capacity and marine technology.

Following the call for international programs contributing to the success of the UN Ocean Science Decade (IOC, 2019), $\mathrm{GO}_{2} \mathrm{NE}$ in collaboration with partners submitted the "Global Ocean Oxygen Decade" (GOOD) program which has been endorsed. The activities and actions planned will raise global awareness about ocean deoxygenation, provide knowledge for action and develop hypoxia mitigation and adaptation measures through local, regional and global efforts, including intensified monitoring, transdisciplinary research, bi-directional knowledge transfer among stakeholders and scientists, innovative outreach and ocean education and literacy. The high-level objective of GOOD is to provide data, knowledge and best practices to enable society, stakeholders, and scientists to codesign and develop measures that can mitigate the drivers and impacts of ocean deoxygenation and provide appropriate adaptation measures where mitigation is not possible. GOOD will be implemented through several projects carried out by different consortia in different regions of the world ocean. The development of $\mathrm{GO}_{2} \mathrm{DAT}$ is proposed as one of the outcomes of the GOOD program.

$\mathrm{GO}_{2}$ DAT will be a key element, a tool to support assessments and decision-making leading to mitigation strategies for climate change and its impacts, maintaining ocean health and biodiversity preservation, and sustainable fisheries management (Garçon et al., 2019; Laffoley and Baxter, 2019; Limburg et al., 2020). Declining $\mathrm{O}_{2}$ is a stressor that covaries with warming and ocean acidification (Zhai et al., 2009; Gobler and Baumann, 2016; Breitburg et al., 2018) and now there is opportunity to ready the scientific and management communities for the next set of analyses and applications. When combined with socioeconomic data such as those reported in Dyck and Sumaila (2010), Swartz et al. (2013), Pauly and Zeller (2016), and Sumaila et al. (2019), $\mathrm{GO}_{2}$ DAT will support the decision-making processes associated with the emerging blue economy.

Below, we illustrate the many uses of $\mathrm{O}_{2}$ data in coastal sciences and oceanography using selected examples which relate to the societal outcomes stated as part of the UN Ocean Decade. Our review is not comprehensive but rather serves to show the diverse uses of $\mathrm{O}_{2}$ in analyses and modeling and how $\mathrm{GO}_{2} \mathrm{DAT}$ would provide data to many applications. 
TABLE 1 | Examples of stakeholders, international conventions, directives and programs that would benefit from $\mathrm{GO}_{2}$ DAT.

\begin{tabular}{ll}
\hline International bodies & \\
\hline CBD & Convention on Biological Diversity \\
EEA & European Environmental Agency \\
FAO & Food and Agriculture Organization of the United Nations \\
GOOS & Global Ocean Observing System \\
GESAMP & Group of Experts on the Scientific Aspects of Marine \\
IMO & Environmental Protection \\
IOC-UNESCO & International Maritime Organization \\
IOCCP & Intergovernmental Oceanographic Commission of UNESCO \\
IPBES & Intergovernmental Science-Policy Platform on Biodiversity \\
and Ecosystem Services \\
IPCC & Intergovernmental Panel on Climate Change \\
TTC-ISA & $\begin{array}{l}\text { The Legal and Technical Commission of the International } \\
\text { Seabed Authority } \\
\text { RFMO }\end{array}$ \\
Regional Fisheries Management Organizations and advisory \\
bodies \\
World Meteorological Organization
\end{tabular}

International conventions, directives

\begin{tabular}{ll}
\hline EU MSFD & EUropean Marine Strategy Framework Directive \\
UNCLOS-BBNJ & $\begin{array}{l}\text { United Nations Convention on the Law of the Sea for } \\
\text { marine Biodiversity of areas Beyond National Jurisdiction }\end{array}$ \\
UNFCCC & United Nations Framework Convention on Climate change
\end{tabular}

International programs, projects, networks and initiatives

\begin{tabular}{ll}
\hline CMEMS & Copernicus Marine Environment and Monitoring Service \\
DOSI & Deep-Ocean Stewardship Initiative \\
EMODnet & European Marine Observation and Data Network \\
GLODAP & Global Ocean Data Analysis Project \\
GOOD & Global Ocean Oxygen Decade \\
IMBeR & Integrated Marine Biosphere Research \\
IODE & International Oceanographic Data and Information \\
SOLAS & Exchange program \\
UN Decade & Surface Ocean Lower Atmosphere Study \\
& UN Decade of Ocean Science for Sustainable Development
\end{tabular}

\section{A Clean Ocean}

Increasingly, $\mathrm{O}_{2}$ factors into management-related analyses of ecological responses to nutrient inputs into coastal zones (Rabalais et al., 2007a; Kemp et al., 2009), ensuring sustainable fisheries (Breitburg et al., 2009; Dulvy et al., 2011; Eero et al., 2015; Rabalais, 2015), ocean management under climate change (Queirós et al., 2016; Lu et al., 2018; Levin et al., 2020), and as indicators of the progress of large-scale restoration efforts (e.g., Rabalais et al., 2010; Andersen et al., 2011; Zhang et al., 2018). Tomasetti and Gobler (2020) argue that environmental regulations and water quality standards have not kept pace with the rising importance and increasing scientific understanding of coastal hypoxia and acidification. Although some coastal zones are well characterized, many are not; for example, it has been found that corals in the tropics may be at risk from both warming, eutrophication and hypoxia (Altieri et al., 2017; Hughes et al., 2020).

\section{A Healthy and Resilient Ocean}

The $\mathrm{O}_{2}$ content is an indicator of ocean health. The development and extension of low $\mathrm{O}_{2}$ areas degrade the living conditions and vertically contract the metabolically viable habitat for a large number of pelagic, mesopelagic, and benthic organisms. At 100\% saturation, the amount of $\mathrm{O}_{2}$ available in one liter of water is $\sim 35$ times less than that in an equivalent volume of air. The effects on individuals exposed to low $\mathrm{O}_{2}$ can cascade and result in altered foodweb structure, including the diversion of organic matter flow to low $\mathrm{O}_{2}$ tolerant species like microbes (Breitburg et al., 2018). $\mathrm{O}_{2}$ data are important for assessing the habitat quality of many organisms within the coastal-shelf-open ocean environments. Examples include field-based determination of effects of $\mathrm{O}_{2}$ on zooplankton (Wishner et al., 2018; Roman et al., 2019), benthos (Levin, 2003; Rabalais et al., 2007b; Levin et al., 2009; Yasuhara et al., 2012, 2017; Gammal et al., 2017), fish and shellfish (Keister et al., 2000; Breitburg, 2002; Pollock et al., 2007; Thomas and Rahman, 2010; Keller et al., 2017; Limburg and Casini, 2019; Roman et al., 2019), deep-sea coral along seamounts (e.g., Anderson et al., 2016), and fish habitat (e.g., Stramma et al., 2012; Sánchez-Velasco et al., 2019; Gallo et al., 2020). The effects of low $\mathrm{O}_{2}$ on the physiological conditions of organisms have been investigated in many laboratory and field studies (e.g., Vaquer-Sunyer and Duarte, 2008; Wu, 2009; Neilan and Rose, 2014; Limburg and Casini, 2018, 2019) and are summarized by the metabolic index (ability to meet temperature-dependent $\mathrm{O}_{2}$ demands) and related indices $\left(\mathrm{P}_{\text {crit }}\right)$ for species in a variety of systems (Chu and Gale, 2017; Deutsch et al., 2020; Howard et al., 2020; Seibel et al., 2021). The tight link between thermal tolerance (TT) and $\mathrm{O}_{2}$ and capacity limitation (OCL) is proposed to govern body size, species biogeographical range distributions and their response to climate change (Pörtner, 2021).

\section{A Productive Ocean}

Evidence is growing that $\mathrm{O}_{2}$ is an important driver of fish population and food web dynamics (Noone et al., 2013; de Mutsert et al., 2017; Townhill et al., 2017; Cheung, 2018; Rose et al., 2018) and its relationship with fishing activities (vessels and fishers) has been documented for multiple fisheries (Druon et al., 2017; Keller et al., 2017; Purcell et al., 2017). Understanding $\mathrm{O}_{2}$ conditions in the current and future climate has important consequences for management decisions in fisheries and other sectors. For example, Asch et al. (2018) used a habitat-based approach and showed that maximum catch potential under climate change (2100 under business-as-usual RCP 8.5 scenario), which included a decrease in $\mathrm{O}_{2}$ concentrations, would be reduced by more than $50 \%$ in some areas for the Pacific Island countries and territories. Rose et al. (2019) recently reviewed, using case studies, how low $\mathrm{O}_{2}$ in coastal systems and OMZs can affect the modeling analyses used to inform fisheries management decisions; situations arise that result in decisions (management advice) that likely underestimate the risk of overfishing.

Beyond fisheries, climate-sensitive industries such as aquaculture and tourism may rely on $\mathrm{O}_{2}$ data for a historical perspective, for spatial planning, and potentially for the provision of an early warning. Management of living resources and tourism can benefit from improved hypoxia modeling, understanding 
changes in habitat quality, links to HABs, and resilience. The same is true for environmental management of ocean industries extracting non-living resources such as minerals or oil (Levin et al., 2020).

\section{A Predicted Ocean}

A challenge going forward is the use of $\mathrm{O}_{2}$ data to understand and mitigate climate risks. This will involve cross-system comparisons and extensive development and testing of biogeochemical models. Presently, $\mathrm{O}_{2}$ data are used to provide inventories, budgets, and spatio-temporal trends analyses (Fennel and Testa, 2019; Mavropoulou et al., 2020) on regional (Long et al., 2016; Coppola et al., 2017; Levin, 2018; Sasano et al., 2018; Savchuk, 2018) and global scales (Beaty et al., 2017; Schmidtko et al., 2017; Claustre et al., 2020).

$\mathrm{O}_{2}$ data are frequently used to calibrate, validate, initialize and force regional (Montes et al., 2014; Vergara et al., 2016; Duteil et al., 2018) and earth system (global) models (Ridgwell et al., 2007; Andrews et al., 2017; Kriest et al., 2017; Oschlies et al., 2018). $\mathrm{O}_{2}$, along with other water quality variables, has been incorporated into data assimilation (Dickey, 2003; Brasseur et al., 2009) to improve the forecasting skill of biogeochemical, water quality, and nutrient-phytoplankton-zooplankton models (Pastres et al., 2003; Gharamti et al., 2017). Further analyses and model development to project future ocean $\mathrm{O}_{2}$ content and distribution in the open and coastal ocean will be greatly enhanced by the development of $\mathrm{GO}_{2} \mathrm{DAT}$ that will offer a high-quality reference dataset for constraining formulation, parameterization, assimilation and validation of models.

\section{A Safe Ocean}

$\mathrm{GO}_{2} \mathrm{DAT}$ will offer the information to support a better understanding and forecasting of hypoxic and anoxic events, which in the extreme cases are hazards to human health. Deoxygenation can lead to the production of $\mathrm{H}_{2} \mathrm{~S}$, a toxic gas that can eventually escape to the atmosphere, and consumption of spoiled seafood killed by low-oxygen events can lead to illness in people dependent on these resources for health and livelihoods.

\section{An Accessible Ocean}

With some exceptions such as the World Ocean Database (WOD, Boyer et al., 2018), GLODAP (Global Ocean Data Analysis Project, Key et al., 2004; Olsen et al., 2016, 2020), the Copernicus Marine Environment and Monitoring Service (CMEMS) and the European Marine Observation and Data Network (EMODnet) Chemistry (Vinci et al., 2017; Martín Míguez et al., 2019), a large portion of observational $\mathrm{O}_{2}$ data are not openly accessible, nor are they usable online without restrictions and with welldocumented uncertainty estimates. For this reason, most analyses of $\mathrm{O}_{2}$ data use only a subset of all that are available and the quality and quantity of the data vary across analyses. Each system has multiple case studies that use different, often independent $\mathrm{O}_{2}$ datasets, making cross-systems analyses a challenge. In some cases, published information (rather than the underlying data) has been used to characterize $\mathrm{O}_{2}$ conditions in coastal and ocean areas (Diaz and Rosenberg, 2008; Gilbert et al., 2010; Levin, 2018). Additionally, to improve the overall quality of individual datasets, researchers often perform empirical adjustments (e.g., data bias adjustments) and specific quality control procedures that are often not described in detail. Transparency of quality control protocols and resulting adjustments is paramount in order to achieve reproducibility of data analyses (e.g., trend estimate) and reusability for data synthesis. It is difficult to replicate independently the findings of most studies that assess the trend of ocean $\mathrm{O}_{2}$ content based on observations. The $\mathrm{GO}_{2} \mathrm{DAT}$ will offer a single unified database to enable more rigorous and comparative analyses, and better integration of results across studies within a system and across systems.

\section{An Inspiring and Engaging Ocean}

$\mathrm{GO}_{2}$ DAT can also support educational activities from K-12 through to underpinning Ph.D. theses, provide a resource for journalists and other communication media, facilitate capacity building and provide a foundation for technology transfer. $\mathrm{GO}_{2}$ DAT will contribute to the building of a digital twin of the ocean for $\mathrm{O}_{2}$ making available to a wide variety of stakeholders a quality control information on ocean $\mathrm{O}_{2}$ in the three space directions and in time.

\section{Quality Requirements of $\mathrm{O}_{2}$ Data to Assess Mean State, Weather and Climate Variability}

The required accuracy (i.e., the difference between the measurement and a true value, the Certified Reference Material, CRMs, which is not directly defined for $\mathrm{O}_{2}$ but indirectly through e.g., Winkler, atmospheric $\mathrm{pO}_{2}$ ) and precision (i.e., the repeatability between measurements of a same sample) of the $\mathrm{O}_{2}$ measurements differ depending on the scientific questions to be answered, and the signal amplitude to be detected which varies from a few tenths up to a few $\mu \mathrm{mol} \mathrm{kg}-1$ for the climate and weather changes, respectively (Table 2). Quantifying global ocean deoxygenation trend (i.e., $0.075 \mu \mathrm{mol} \mathrm{kg}{ }^{-1} \mathrm{yr}^{-1}$ or $\sim 4.5 \mu \mathrm{mol}$ $\mathrm{kg}^{-1}$ over the last 60 years) imposes stringent requirements on the quality of the data, while for estimating the typical $\mathrm{O}_{2}$ levels in a region or the occurrence of hypoxia, even far less accurate data can be of scientific value (e.g., accuracy better than $\left.5 \mu \mathrm{mol} \mathrm{kg}^{-1}\right)$.

The quantification of the Net Community Production (i.e., NCP, the net difference between community photosynthesis and respiration) from the high frequency variation of $\mathrm{O}_{2}$ is very sensitive to the presence of bias and noise in the data. A $0.5 \%$ $\left(\approx 1 \mu \mathrm{mol} \mathrm{kg}{ }^{-1}\right)$ error in $\mathrm{O}_{2}$ measurements significantly degrades the quality of the retrieved NCP (Emerson et al., 2008; Soetaert and Grégoire, 2011). In OMZs, because, nanomolar levels $\mathrm{O}_{2}$ inhibit denitrification and anaerobic ammonium oxidation, studies of these processes require sensors with detection limits of a few nanomoles (Tiano et al., 2014).

For ecological analyses, the required data quality depends on the specific organisms, biological processes, and questions (hypotheses) being addressed. Common topics include detecting, and if possible, quantifying, the $\mathrm{O}_{2}$ effects on individual organisms in terms of: (1) presence, absence or abundance, (2) energetics-related physiology, and (3) behavior and vital process 
TABLE 2 | Examples of scientific topics, characteristics of the signal, recommended quality, applications.

\begin{tabular}{|c|c|c|c|}
\hline Scientific topics & Signal characteristics to capture & $\begin{array}{l}\text { Recommended quality of } \mathrm{O}_{2} \\
\text { measurement }\end{array}$ & Applications \\
\hline \multicolumn{4}{|c|}{ Mean state determination } \\
\hline $\begin{array}{l}\text { Order of magnitude of the } \\
\mathrm{O}_{2} \text { content } \\
\text { Gridded fields }\end{array}$ & $227.4 \pm 1.1$ petamoles $\left(10^{15} \mathrm{~mol}\right)^{(1)}$ & Accuracy better than $5 \mu \mathrm{mol} \mathrm{kg}-1$ & $\begin{array}{l}\text { Model initialization, } \\
\text { validation }\end{array}$ \\
\hline Coastal hypoxic area & & Accuracy better than $2.5 \mu \mathrm{mol} \mathrm{kg}-1(2)$ & $\begin{array}{l}\text { Ocean health, } \\
\text { environmental Management }\end{array}$ \\
\hline $\begin{array}{l}\text { OMZs } \\
\left(\mathrm{O}_{2}<45 \mu \mathrm{mol} \mathrm{kg}{ }^{-1}\right) \\
\text { Extension, Oxycline }\end{array}$ & $\begin{array}{l}\text { High vertical gradient, up to } 20 \mu \mathrm{mol} \\
\qquad \mathrm{kg}^{-1} \mathrm{~m}^{-1(3)}\end{array}$ & $\begin{array}{c}\text { High ratio of the sampling frequency over } \\
\text { the response time (a few sec) and/or low } \\
\text { vertical sampling velocity }{ }^{(4)}\end{array}$ & Ocean health \\
\hline $\begin{array}{l}\text { AMZs } \\
\left(\mathrm{O}_{2}<\text { a few } \mathrm{nmol} \mathrm{kg}^{-1}\right) \\
\text { Extension }\end{array}$ & Detection of zero value & Zero detection a few nmol kg-1(3) & $\begin{array}{c}\text { Global denitrification, model } \\
\text { parameterization in anoxic } \\
\text { conditions }\end{array}$ \\
\hline \multicolumn{4}{|c|}{ Climate variability } \\
\hline $\begin{array}{l}\text { Global ocean } \\
\text { deoxygenation trend }\end{array}$ & $\begin{array}{c}\text { Global decrease: } 4.38 \pm 1.98 \mu \mathrm{mol} \mathrm{kg}{ }^{-1} \\
\text { since } 1960^{(1)}\end{array}$ & Accuracy better than $0.5 \mu \mathrm{mol} \mathrm{kg} \mathrm{kg}^{-1}$ & $\begin{array}{l}\text { Climate application } \\
\text { Carbon budget }\end{array}$ \\
\hline \multicolumn{4}{|c|}{ Weather variability } \\
\hline Air-Sea seasonal fluxes & 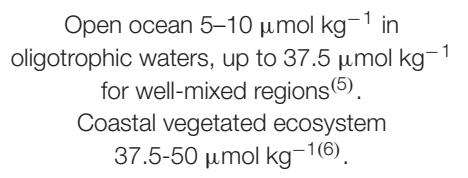 & $\begin{array}{l}\text { Accuracy: } \sim 1-5 \mu \mathrm{mol} \mathrm{kg}-1 \\
\text { Precision: } \sim 1-5 \mu \mathrm{mol} \mathrm{kg}\end{array}$ & \\
\hline \multicolumn{4}{|c|}{ Processes estimation } \\
\hline $\begin{array}{l}\text { Net Community } \\
\text { Production }\end{array}$ & $\begin{array}{c}\text { Open ocean: from } 1 \text { to } 6 \mathrm{molO}_{2} \\
\qquad \mathrm{~m}^{-2} \mathrm{yr}^{-1(5)} \\
\text { Coastal vegetated ecosystem: } 23.2 \pm 8.2 \\
\mathrm{molO}_{2} \mathrm{~m}^{-2} \mathrm{yr}^{-1(6)}\end{array}$ & $\begin{array}{l}\text { Very sensitive to the presence of noise (e.g., } \\
\text { an error of } 0.5 \% \text { degrades the estimation of } \\
\text { the rate) }{ }^{(7,8)} \text {. Smoothing is recommended. }\end{array}$ & $\begin{array}{c}\text { Understanding ocean } \\
\text { physical and } \\
\text { biogeochemical functioning }\end{array}$ \\
\hline Ventilation/convection & $\begin{array}{c}>20 \mathrm{~mol} \mathrm{~m}^{-2} \mathrm{yr}^{-1} \text { (during the months of } \\
\text { convection) }(9,10)\end{array}$ & $\begin{array}{l}\text { Deep waters: } 1-2 \mu \mathrm{mol} \mathrm{kg} \\
\text { Intermediate waters: few } \mu \mathrm{mol} \mathrm{kg}^{-1}\end{array}$ & \\
\hline
\end{tabular}

Recommended quality of $\mathrm{O}_{2}$ measurement is done through either referring to existing studies or considering that the measurement's accuracy should be better than $1 \%$ of the expected signal. (1) Schmidtko et al., 2017; (2) 1\% of saturation; (3) Tiano et al., 2014; (4) Bittig et al., 2014; (5) Emerson et al., 2008; (6) Champenois and Borges, 2019; (7) Emerson et al., 2008; (8) Soetaert and Grégoire, 2011; (9) Körtzinger et al., 2004; (10) Coppola et al., 2017.

rates of growth, mortality, and reproduction (Batiuk et al., 2009). Analyses are also performed to quantify $\mathrm{O}_{2}$ effects on groups of individuals, such as spatial distributions, and on scaled-up responses, such as population-level (reduced annual abundance), community (e.g., diversity), and food web (e.g., changes in predator-prey interactions) ( $\mathrm{Wu}, 2002)$. In some cases, very high precision and accuracy will be needed because responses are ultra-sensitive to small changes in $\mathrm{O}_{2}$ concentrations (Wishner et al., 2018), while in other situations precision and accuracy can be relatively low because the taxa or responses of interest show low sensitivity to variation or the $\mathrm{O}_{2}$ concentrations themselves vary greatly across the comparisons.

\section{METHODOLOGY FOR $\mathrm{O}_{2}$ OBSERVATION}

\section{Methods for Measuring $\mathrm{O}_{2}$}

There are three major methods used for determining the amount of $\mathrm{O}_{2}$ in seawater. These are (a) the iodometric titration (the so-called Winkler titration); (b) electrochemical approaches (e.g., potentiometry, amperometry); and (c) optical (fluorescence quenching) sensors method. Each method has its specific merits, applications and quality.

\section{lodometric Methods: Winkler Titration}

Winkler titration (Winkler, 1888) is a reference method used for 140 years to measure $\mathrm{O}_{2}$. Winkler $\mathrm{O}_{2}$ determination during oceanographic cruises requires a discrete sample commonly collected from a Niskin bottle into a glass bottle (Winkler bottle). The Winkler chemical titration is based on the oxidation of $\mathrm{Mn}$-(II) by $\mathrm{O}_{2}$ in alkaline conditions (Equations 1 and 2) and the reaction of the precipitated Mn-(III) with iodide in acidic conditions to form iodine and tri-iodine in a second step (Equation 3). The lumped amount of iodine and tri-iodine is quantified by a titration with thiosulfate (Equation 4; Carpenter, 1965; Langdon, 2010) or spectrophotometrically (Labasque et al., 2004) and from that the concentration of $\mathrm{O}_{2}$ is determined. The Winkler $\mathrm{O}_{2}$ measurement is a commonly used reference to 
calibrate the data provided by $\mathrm{O}_{2}$ sensors.

$$
\begin{gathered}
\mathrm{Mn}^{2+}+2 \mathrm{OH}^{-} \rightarrow \mathrm{Mn}(\mathrm{OH})_{2} \quad \text { (white) } \\
2 \mathrm{Mn}(\mathrm{OH})_{2}+1 / 2 \mathrm{O}_{2}+\mathrm{H}_{2} \mathrm{O} \rightarrow 2 \mathrm{Mn}(\mathrm{OH})_{3} \quad \text { (brown) } \\
2 \mathrm{Mn}(\mathrm{OH})_{3}+2 \mathrm{I}^{-}+6 \mathrm{H}^{+} \rightarrow 2 \mathrm{Mn}^{2+}+6 \mathrm{H}_{2} \mathrm{O}+\mathrm{I}_{2} \\
2 \mathrm{~S}_{2} \mathrm{O}_{3}^{2-}+\mathrm{I}_{2} \rightarrow \mathrm{S}_{4} \mathrm{O}_{6}^{2-}+2 \mathrm{I}^{-}
\end{gathered}
$$

\section{Sensors}

The electrochemical and optical methods for measuring $\mathrm{O}_{2}$ are simple, fast and automated. They are now widely used on platforms such as $\mathrm{CTD}-\mathrm{O}_{2}$ rosette samplers, autonomous platforms (e.g., floats, gliders), drifting buoys and fixed-point moorings. Their use on autonomous platforms offers continuous monitoring of $\mathrm{O}_{2}$ in space and time throughout the ocean. The number of sensor-based $\mathrm{O}_{2}$ measurements in the water column collected in the past decade alone is now comparable to the Winkler $\mathrm{O}_{2}$ data collected since 1900 (Figure 5).

\section{Electrochemical Sensors}

Electrochemical detection is the most widely used method, within which the polarographic $\mathrm{O}_{2}$ sensor is the most common application (see the review by Wei et al., 2019). The working principle of polarographic sensors is based on the measurement of a current that is proportional to the rate of $\mathrm{O}_{2}$ diffusing through a permeable membrane and being reduced on a metal surface. In Clark-type $\mathrm{O}_{2}$ sensors (Clark et al., 1953), the $\mathrm{O}_{2}$ diffuses through the membrane and dissolves in the electrolyte before reacting with the cathode. The amount of $\mathrm{O}_{2}$ that diffuses through the membrane depends on the external $\mathrm{O}_{2}$ partial pressure $\left(\mathrm{pO}_{2}\right)$ (Glud et al., 2000). At the cathode, $\mathrm{O}_{2}$ is reduced and gives an electric signal that depends on the amount of $\mathrm{O}_{2}$. This implies that the sensor signal is dependent on the transport of the analyte from the surrounding medium, the socalled stirring sensitivity (Glud et al., 2000). A robust conversion of the electric signal into a $\mathrm{pO}_{2}$ requires a steady flux of $\mathrm{O}_{2}$ into the sensor tip. If there is no steady-state $\mathrm{O}_{2}$ diffusion across the membrane and cathode, the conversion is not robust. There is thus a trade-off between the sensor's stirring sensitivity and its response time: sensors with a high stirring sensitivity have short response time but the $\mathrm{O}_{2}$ flux is much more variable. Low stirring sensitivity microsensors can be constructed while macro-sensors are more affected by this effect.

The modifications of Clark-type $\mathrm{O}_{2}$ microsensors led to the development of the STOX (Switchable Trace amount OXygen) sensor, based on Clark-type microsensors, where $\mathrm{O}_{2}$ can be determined at low (nM) concentrations (Revsbech et al., 2009). The small dimensions of the tip in $\mathrm{O}_{2}$ microsensors make them able to achieve response times of $0.1 \mathrm{~s}$ and are thus recommended for high-resolution measurements. However, $\mathrm{O}_{2}$ microsensors are more affected by aging and sensitive to drifts than macrosensors due to their reduced quantity of electrolytes and the smaller size of their cathodes.

\section{Optical Sensors}

Optical $\mathrm{O}_{2}$ sensors (optodes) have become attractive in the past four decades because there is no $\mathrm{O}_{2}$ consumed during the measurement (i.e., no stirring sensitivity as with polarographic sensors), they offer good precision and accuracy and they can measure $\mathrm{O}_{2}$ in both gas and liquid phase. Bittig et al. (2018, 2019) provide a thorough review of the most widely used optodes. Optical $\mathrm{O}_{2}$ sensors used in oceanography are mostly

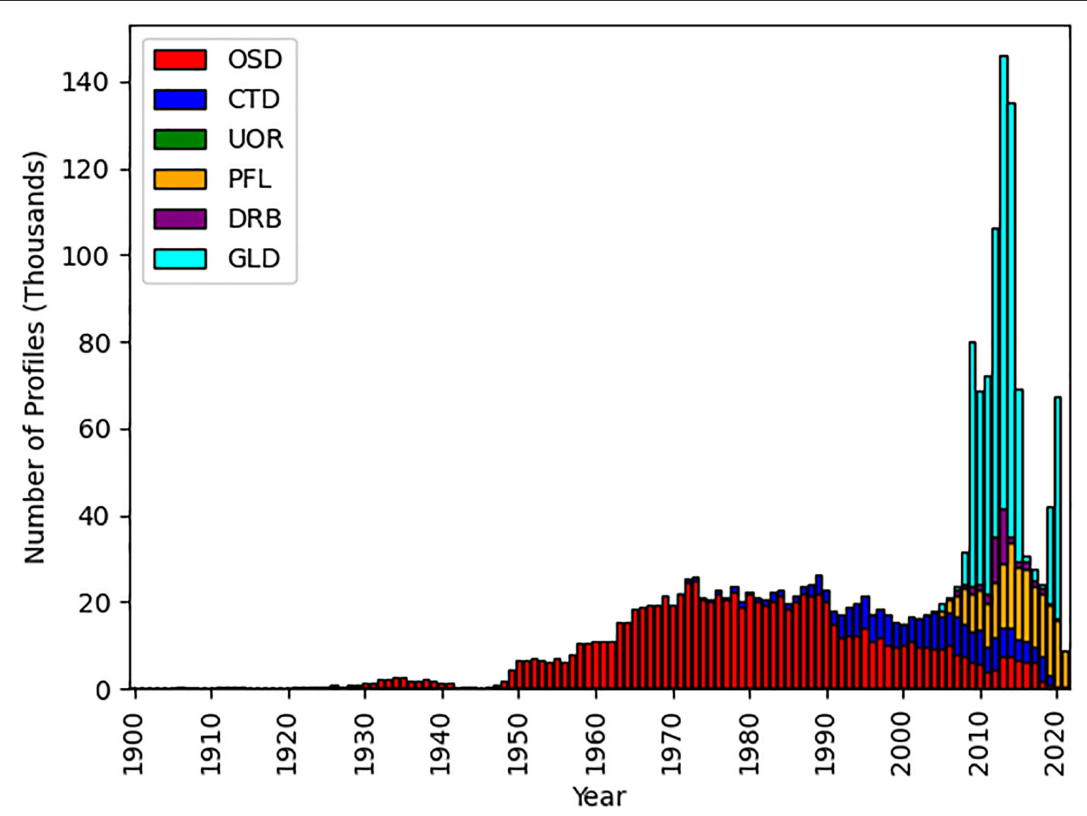

FIGURE 5 | Number of dissolved $\mathrm{O}_{2}$ profiles available in the WOD 2018 (WOD18, Boyer et al., 2018) by observing system/instrument. OSD: chemical Winkler data from shipboard bottle Ocean Station Data; CTD, sensor data from Conductivity-Temperature-Depth-Oxygen ( 200 000 profiles); PFL, Profiling Float data ( 160 000 profiles); DBD, Drifting Buoy Data ( 40 000 profiles); GLD, GLider Data ( 450 000 profiles); UOR, Undulating Oceanographic Recorder ( 360 profiles). 
based on the principle of luminescence quenching (Lakowicz, 2006). A luminescent substance is embedded in a sensing foil or coating and placed on an optical window. The sensing foil of the optode is permeable only to gases, i.e., the sensors respond to the gases' partial pressure, in this case $\mathrm{pO}_{2}$. By modification of the luminescent substance, oxygen optodes can be used to measure trace amounts of oxygen down to a detection limit of $0.5 \mathrm{nM}$ (Lehner et al., 2015), though only available so far for laboratory measurements.

\section{Platforms}

We provide an overview of the Eulerian and Lagrangian platforms from which $\mathrm{O}_{2}$ is measured using the Winkler titration method or optical and electrochemical sensors. Table 3 provides a synthesis, for each $\mathrm{O}_{2}$ observing platform, of information on the existence of best practices documents, a DAC that centralizes data processing, community-agreed calibration, correction (secondary QC) and QF as well as level of accessibility, in particular, in Real Time (RT) and Delayed Mode (DM) mode. This across platforms analysis allows to understand how the different platforms are currently organized in terms of calibration, QC and QF and can be coordinated toward the building of $\mathrm{GO}_{2}$ DAT.

\section{Ship-Based CTD-O 2 Observations}

Over the past decades, there have been significant advancements in $\mathrm{O}_{2}$ sensor instrumentation mounted on CTD rosette samplers (e.g., Wang et al., 2019) and probes. Historically, polarographic sensors were used on ship-based CTDs while now optical sensors are also used. The polarographic sensors used on CTD casts are mostly based on the Clark-type polarographic membranecovered electrodes. In order to avoid the stirring effect (Gust et al., 1987) without compromising the time response of the sensors in rosette samplers, an external water pump supplying a constant water flow to the sensor is used in the standard CTD configurations. In areas with sharp $\mathrm{O}_{2}$ gradients such as in OMZs and low $\mathrm{O}_{2}$ coastal waters the cast speed should be adjusted to adequately sample the oxycline.

Irrespective of present-day $\mathrm{O}_{2}$ sensor type, calibration at sea or in delayed mode of $\mathrm{O}_{2}$ sensors is often performed using simultaneous water sampling at one or preferably more selected depths (e.g., at all the Niskin sampling depths) together with routine $\mathrm{O}_{2}$ analysis using Winkler titrations (Langdon, 2010; Uchida et al., 2010). This calibration is particularly important in oceanic regions with large spatial $\mathrm{O}_{2}$ concentration gradients. International research programs such as the World Ocean Circulation Experiment (WOCE), Climate and Ocean:

TABLE 3 | Characteristics of the last generation of ocean $\mathrm{O}_{2}$ observing systems: (1) Bittig and Körtzinger, 2015; (2) Thierry et al., 2018; (3) Thierry and Bittig, 2018; (4) Bittig et al., 2019; (5) BGC-Argo data are freely available from the Global Data Assembly Centres (GDACs: ftp://ftp.ifremer.fr/ifremer/argo/ and ftp://usgodae.org/pub/outgoing/argo/); (6) Testor et al., 2019; (7) oceangliders (https://www.oceangliders.org/); (8) Uchida et al., 2010; (9) WOCE and GO-SHIP protocols; (10) WOCE and GO-SHIP data are freely available on CLIVAR and Carbon Hydrographic Data Office; (11) Coppola et al., 2016; (12) Best Practices EMSO/OceanSites (OBPS); (13) National Data Buoy Center (NDBC) in the United States and Coriolis at IFREMER; (14) in delayed mode (see GO-SHIP method); (15) under development; (16) based on Winkler or 100\%-0\% calibration of sensors; (17) no DAC but Stratmann et al., 2019.

\begin{tabular}{|c|c|c|c|c|c|c|c|c|c|}
\hline $\begin{array}{l}\text { Observing } \\
\text { platform }\end{array}$ & Methods & $\begin{array}{c}\text { Spatial and } \\
\text { temporal scales } \\
\text { resolved }\end{array}$ & $\begin{array}{l}\text { Spatial and } \\
\text { temporal } \\
\text { coverage }\end{array}$ & $\begin{array}{l}\text { Community- } \\
\text { agreed } \\
\text { calibration and } \\
\text { best practices }\end{array}$ & $\begin{array}{l}\text { Community- } \\
\text { agreed QF }\end{array}$ & $\begin{array}{c}\text { Secondary } \\
\text { community- } \\
\text { agreed correction }\end{array}$ & GDAC & (N)RT/DM & FAIR \\
\hline Profiling floats & Sensors & $\begin{array}{c}\text { Horizontal: } \\
10-10^{2} \mathrm{~km} \\
\text { Vertical: } 10^{-3} \mathrm{~km} \\
5-10 \text { days }\end{array}$ & $\begin{array}{c}10^{2}-10^{3} \mathrm{~km} \\
3-5 \text { years }\end{array}$ & $\begin{array}{c}\text { With the } \\
\text { atmosphere }\end{array}$ & Yes $(2,3)$ & $\begin{array}{c}\text { Yes } \\
\text { In situ Drift (4) }\end{array}$ & Yes (5) & $\begin{array}{l}\text { NRT } \\
\text { and } \\
\text { DM }\end{array}$ & Yes \\
\hline Gliders & Sensors & $\begin{array}{l}\text { Horizontal: } 10^{-1} \text { - } \\
\qquad 1 \mathrm{~km} \\
\text { Vertical: } 10^{-3} \mathrm{~km} \\
\text { Hourly-daily }\end{array}$ & $\begin{array}{c}1-10^{2} \mathrm{~km} \\
\text { Several } \\
\text { days-weeks }\end{array}$ & In progress ${ }^{(6)}$ & No & No & Yes $^{(7)}$ & $\begin{array}{l}\text { NRT } \\
\text { and } \\
\text { DM }\end{array}$ & Yes \\
\hline $\begin{array}{l}\text { Ship-based Repeat } \\
\text { Hydrography }\end{array}$ & $\begin{array}{c}\text { Winkler } \\
+ \\
\text { Sensors }\end{array}$ & $\begin{array}{l}\text { Horizontal: } 10 \mathrm{~km} \\
\text { Vertical: } 10^{-3} \mathrm{~km} \\
\text { Decadal }\end{array}$ & $\begin{array}{l}10^{2}-10^{3} \mathrm{~km} \\
\text { Multi-decadal }\end{array}$ & $\begin{array}{l}\text { At sea or in delayed } \\
\text { mode using Winkler }\end{array}$ & Yes ${ }^{(8)}$ & Yes ${ }^{(9)}$ & Yes $^{(10)}$ & $\mathrm{DM}$ & Yes \\
\hline $\begin{array}{l}\text { Moored fixed point } \\
\text { observatories }\end{array}$ & $\begin{array}{l}\text { Mainly } \\
\text { optical } \\
\text { sensors }\end{array}$ & Hourly & Multi-year & Yes ${ }^{(11)}$ & Yes ${ }^{(12)}$ & No & Yes (13) & $\begin{array}{l}\text { NRT \& } \\
\text { DM }\end{array}$ & No \\
\hline $\begin{array}{l}\text { Ship-based } \\
\text { Fixed-point } \\
\text { Observatories }\end{array}$ & $\begin{array}{c}\text { Winkler } \\
+ \\
\text { Sensors }\end{array}$ & Monthly & Multi-year & $\mathrm{No}{ }^{(14)}$ & $Y_{e s}^{(8)}$ & Yes & Yes (10) & $\mathrm{DM}$ & Yes \\
\hline $\begin{array}{l}\text { Ship-based } \\
\text { underway } \\
\text { observations }\end{array}$ & $\begin{array}{l}\text { Optical } \\
\text { sensors }\end{array}$ & $\begin{array}{l}\text { Sub-weekly to } \\
\text { monthly }\end{array}$ & $10-10^{2} \mathrm{~km}$ & $\mathrm{No}{ }^{(15)}$ & No & No & No & $\mathrm{DM}$ & No \\
\hline Coastal/benthic & $\begin{array}{c}\text { Winkler } \\
+ \\
\text { Sensors }\end{array}$ & $\begin{array}{c}\text { Vertical: } 10^{-5}- \\
10^{-4} \mathrm{~km} \\
\text { Temporal:punctual }\end{array}$ & $10-10^{2} \mathrm{~km}$ & Yes ${ }^{(16)}$ & No & No & No ${ }^{(17)}$ & $\mathrm{DM}$ & No \\
\hline
\end{tabular}

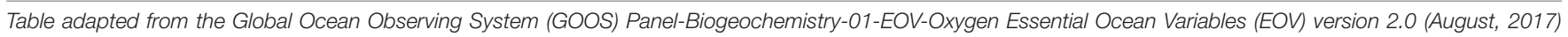
see here $h$ ttps://www.jcomm.info/index.php?option=com_oe\&task=viewDoclistRecord\&doclist/D=168. 
Variability, Predictability and Change (CLIVAR) and Global Ocean Ship-based Hydrographic Investigations Program (GOSHIP) adopt the precision of the "best-laboratory" $\mathrm{O}_{2}$ data. For example, WOCE and GO-SHIP adopted an $\mathrm{O}_{2}$ target precision of $0.08 \%(\sim \pm 0.2 \mu \mathrm{mol} \mathrm{kg}-1)$ of the highest concentration found in the ocean (Joyce, 1991; Hood et al., 2010).

\section{Biogeochemical Argo}

$\mathrm{O}_{2}$ was the first BGC variable to be measured by Argo (Körtzinger et al., 2004; Gruber et al., 2010) and continues to be the most common BGC variable measured. Figure 6 illustrates how Argo floats can be used to investigate the mesoscale $\mathrm{O}_{2}$ dynamics at the oxic-anoxic transitional layer in the Black Sea where the $\mathrm{O}_{2}$ level varies from saturation to zero.

Since 2002, BGC Argo floats have been equipped with different categories of $\mathrm{O}_{2}$ sensors (electrochemical, optical, multipoint-calibrated, air-calibrated). Table A1 in Appendix summarizes information on the types of sensors used, known issues, adjustments performed and data streams. BGC-Argo has two data streams: "RT" and "DM." The RT stream, targeted at operational users, is subject to automated, RT QC (e.g., automated search for outliers) and may receive an automated, initial adjustment ("A" data). The DM stream, targeted at science users, provides the best quality data.

Some floats include regular in-air measurements as recommended by the SCOR WG 142 (Bittig et al., 2015). This provides an accurate (i.e., 1\%), easily accessible reference for correction (Bittig and Körtzinger, 2015; Johnson et al., 2015; Bushinsky et al., 2016) of the drift between manufacturer calibration and deployment (Johnson et al., 2017; Bittig et al., 2018). For older floats where in-air measurements were not performed, such data can be mimicked by using the WOA surface $\mathrm{O}_{2}$ saturation field and converting $\mathrm{O}_{2}$ saturation to surface partial pressure $\left(\mathrm{pO}_{2}\right)$ using the float's temperature and salinity (Thierry and Bittig, 2018).

When available, a laboratory calibration using standard $\mathrm{O}_{2}$ water (Winkler) before the launching of the float and corrections based on frequent ship observations after the float launching can be used to check the accuracy of measurements. If multiple check and correction methods are available before and after launching Argo $\mathrm{O}_{2}$ floats, the integrated calibration procedure will be useful to assess and improve accuracies for the $\mathrm{O}_{2}$ and the long-term drift of $\mathrm{O}_{2}$ values.

\section{Gliders}

Underwater gliders may be thought of as profiling floats that are able to control their horizontal position (Rudnick, 2016a). This control over position makes gliders especially useful for regional oceanography, complementing the global footprint of Argo. The same suite of sensors as in floats is used, including Aanderaa $\mathrm{O}_{2}$ optodes (Nicholson et al., 2008; Adams et al., 2016), and Sea-Bird SBE 43 (Ohman et al., 2013) and 63 (Takeshita et al., 2021). Gliders are used to investigate the (sub)mesoscale $\mathrm{O}_{2}$ variability (Figure 7).

Because gliders are deployed and recovered, there is opportunity for pre- and post-mission laboratory calibrations and drift correction. In some applications of Sea-Bird instruments, the sensor is plumbed in line with the CTD, taking advantage of a constant flow and the presence of tributyltin antifouling measures. The requirement for plumbing in this case and the need to minimize drag on gliders make it challenging to measure in air for in situ calibration. However, Nicholson and Feen (2017) used a mount forward of a glider's tail fin to achieve this calibration at sea using an Aanderaa optode.

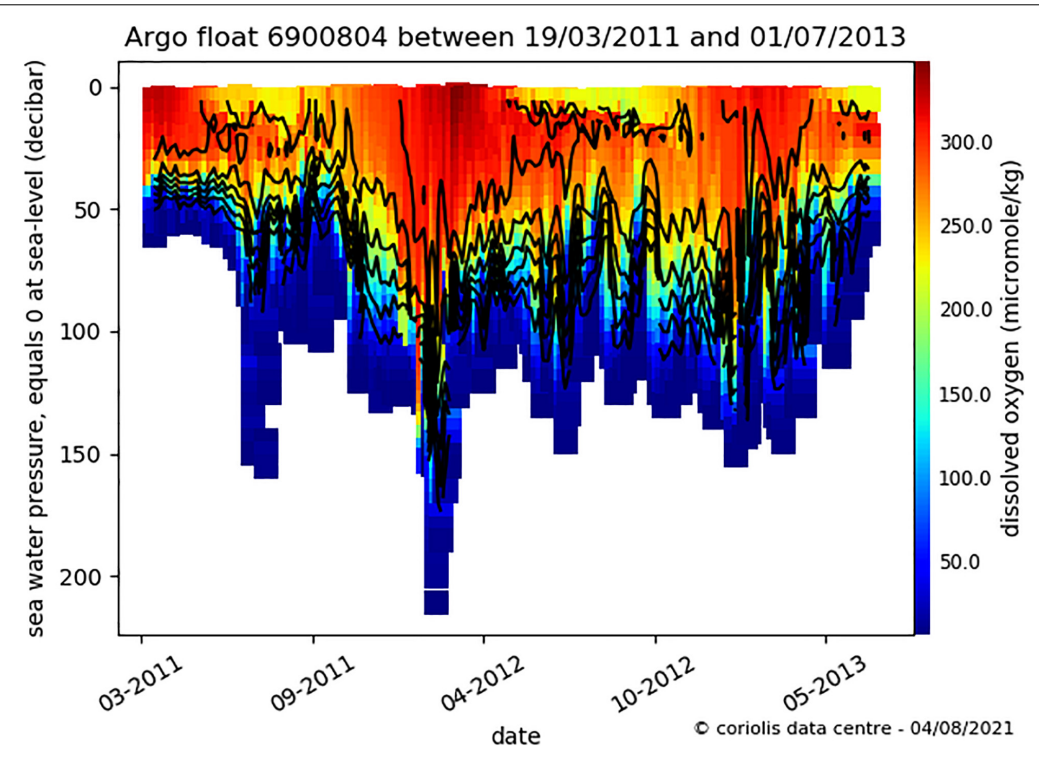

FIGURE 6 | Temporal evolution of the vertical profile of $\mathrm{O}_{2}\left(\mu \mathrm{mol} \mathrm{kg}{ }^{-1}\right)$ in the Black Sea measured by an Argo float (WMO 6900804) deployed in the western basin and moving along the coast following the main Rim Current. The plot illustrates the variability along the trajectory of the $\mathrm{O}_{2}$ vertical profile according to the local hydrodynamics and season. It illustrates the presence of a subsurface $\mathrm{O}_{2}$ maximum associated to enhanced photosynthetic activity at depth when the thermocline is established from the end of spring to fall. The depth of $\mathrm{O}_{2}$ disappearance varies from $\sim 65 \mathrm{~m}$ to more than $200 \mathrm{~m}$. 

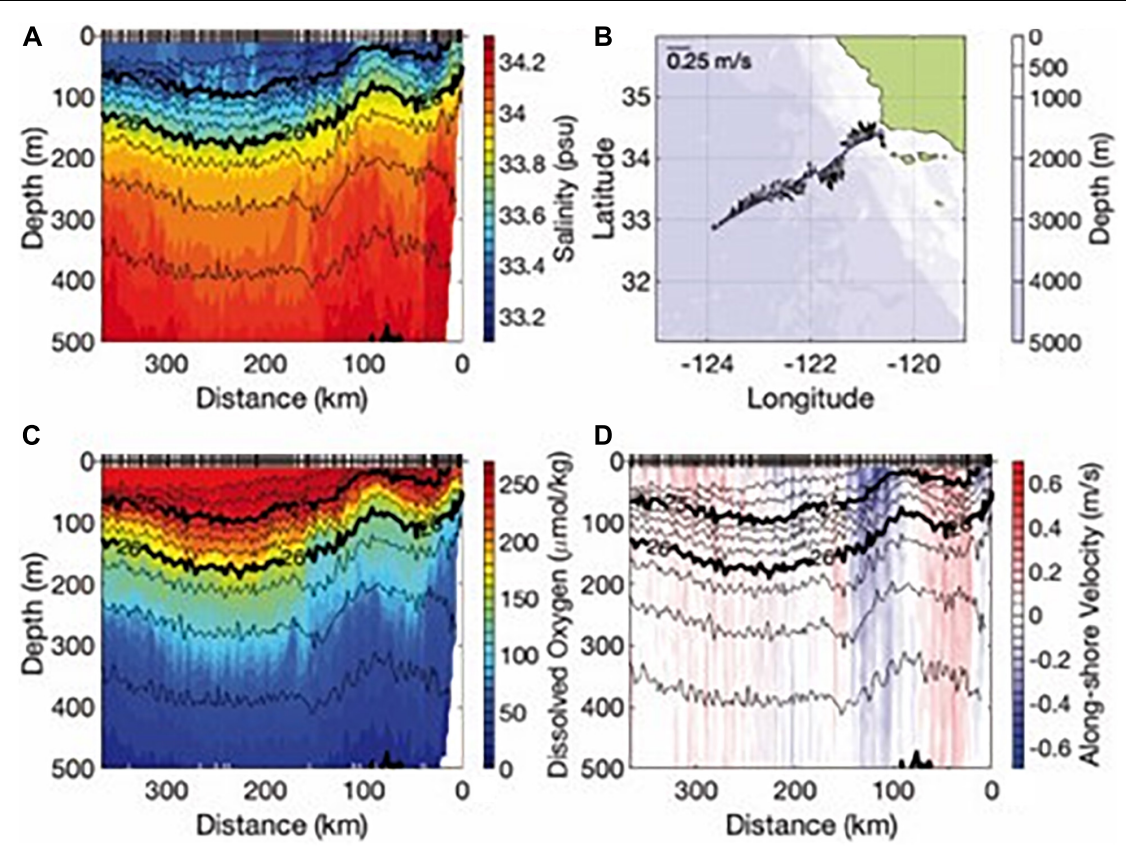

FIGURE 7 | Data from the California Underwater Glider Network (Rudnick, 2016b; Rudnick et al., 2017). Shown are (B) the track and 500-m depth average velocity, and sections of (A) salinity, (C) dissolved $\mathrm{O}_{2}$, and (D) alongshore velocity. Nearshore upwelling brings dense low $\mathrm{O}_{2}$ water to the surface. Further offshore a strong cyclonic feature has upward doming isopycnals with associated high salinity and low $\mathrm{O}_{2}$. The separation between glider profiles is $3 \mathrm{~km}$ allowing resolution of these structures with sizes of tens of kilometers.

The OceanGliders program (Testor et al., 2019) provides an international umbrella in GOOS for ocean observations using underwater gliders. In common with many regional observing assets, the support for glider programs usually comes from the countries where the observations are undertaken. For this reason, the international glider data system is not as advanced as other more mature programs like Argo. Data management is accomplished through regional DAC, with established centers in the United States, Australia, and Europe. An ongoing initiative is to coalesce around a single international underwater glider data format. This format, which will be compliant with Climate Forecasting conventions, is likely to be adopted within the next 2 years.

\section{Moorings}

Although any type of $\mathrm{O}_{2}$ sensor can be used on fixed-point mooring systems, optical sensors are more common due to their long-term stability compared to electrochemical sensors. In general, the response time of optical sensors is slower than that of electrochemical sensors; however, the effect of slow response time is reduced on fixed-point mooring systems as the surrounding environment $\left(\mathrm{O}_{2}\right.$ concentration, temperature and pressure) does not change rapidly. But, if $\mathrm{O}_{2}$ sensors with slow response times are used on moored profilers, data quality may be reduced particularly in environments with strong vertical gradients.

Drift in $\mathrm{O}_{2}$ measurements over time is the main issue for long-term deployments (e.g., 1-year). The drift is principally due to: (1) degradation, (2) marine biofouling, and (3) timedependent pressure hysteresis of the sensing element (only on very deep moorings $>1000 \mathrm{~m}$ ). In particular, biofouling may rapidly degrade the quality of $\mathrm{O}_{2}$ and CTD data collected at shallow depths $(<200 \mathrm{~m})$.

Due to the efforts of the FIXed-point Open Ocean Observatories $\left(\mathrm{FIXO}^{3}\right)$ and European Multidisciplinary Seafloor and Water-Column Observatory (EMSO) European Research Infrastructure Consortium (ERIC) communities some recommendations have been proposed as best practices for $\mathrm{O}_{2}$ sensors installed on fixed moorings (Coppola et al., 2016). The recommendations include conducting an intercomparison at sea with Winkler data after mooring line recovery. This intercomparison allows $\mathrm{O}_{2}$ data from the mooring to be adjusted using slope and offset coefficients.

\section{Benthic Platforms}

Numerous benthic $\mathrm{O}_{2}$ measurements have been performed over the last 40 years. They were generally based on single sampling or deployments in the water column and sediment conducted during cruises (Tengberg et al., 1995). Benthic observation platforms were originally based on landers which carry instrumentation for measuring exchange fluxes between the sediment and the water column by benthic chambers or $\mathrm{O}_{2}$ distribution in sediment porewaters using micro-electrodes. The basic principle of these benthic chambers is the enclosure of a known surface area of sediment and its incubation over a short time to estimate exchange fluxes (Jahnke and Christiansen, 1989; Tengberg et al., 1995; Berelson et al., 2019). $\mathrm{O}_{2}$ concentration measurements in the benthic chambers are nowadays mostly based on optode measurements in the chamber (see Hall et al., 
2017; Staudinger et al., 2018). These exchange fluxes offer a unique method to describe the metabolic activity in sediments.

Observation of $\mathrm{O}_{2}$ in $\mathrm{BBL}$ and sediments was achieved by measuring $\mathrm{O}_{2}$ distribution across the water-sediment interface using in situ microsensors (Tengberg et al., 1995; Wenzhöfer and Glud, 2002; Glud, 2008; Cathalot et al., 2010). The microsensors measured $\mathrm{O}_{2}$ concentration in the $\mathrm{BBL}$ as a forcing variable or external control, but very few measurement campaigns were dedicated to the measurement of $\mathrm{O}_{2}$ in the BBL except specific instruments such as the benthic boundary sampler (Holtappels et al., 2011). Recently, nanolanders for in situ monitoring of $\mathrm{O}_{2}$ in the $\mathrm{BBL}$ and benthic fauna behavior in $\mathrm{O}_{2}$-limited zones (Gallo et al., 2020) were developed. Among other things, these new types of observation allow a better understanding of temporal $\mathrm{O}_{2}$ dynamics in hypoxic bottom waters and its impact on benthic fauna.

In addition, a new observation system has been developed during the last decade based on eddy covariance techniques (Berg and Hüttel, 2008; Reimers et al., 2012). In this technique, joint high frequency measurement of $\mathrm{O}_{2}(>10 \mathrm{~Hz})$ and of vertical currents at a given point in $\mathrm{BBL}$ by an acoustic doppler velocimeter (ADV) enables continuous estimates of the $\mathrm{O}_{2}$ exchange flux and $\mathrm{O}_{2}$ dynamics within the BBL. The technique is also applicable in habitats with hard and complex substrate in coastal or deep-ocean settings (Berg et al., 2009; Rovelli et al., 2015; Attard et al., 2019; Polsenaere et al., 2021).

More recently, mobile and fixed platforms were developed in order to capture temporal variations linked to intense events (deep mixing by convection, storms and floods in the coastal ocean). Single-point benthic observatories measure $\mathrm{O}_{2}$ concentration and various other environmental characteristics in the BBL (e.g., S, T, turbidity) in the deep-sea (EMSO, NEPTUNE) or the coastal sea (Pairaud et al., 2016). At these coastal or deep-sea observatories, time series of sediment $\mathrm{O}_{2}$ distributions based on micro-electrode profiles are acquired by benthic stations in the coastal ocean (Toussaint et al., 2014; Rigaud et al., 2018). Furthermore, mobile platforms called crawlers or rovers (Wenzhöfer et al., 2016; Smith et al., 2017; Lemburg et al., 2018) were recently developed and deployed to explore the spatial heterogeneity inherent in the benthic realm and to study its temporal variation. This enables investigations of the spatiotemporal $\mathrm{O}_{2}$ dynamics in the $\mathrm{BBL}$ and porewaters for one year (or more) (Purser et al., 2013).

CTDs with $\mathrm{O}_{2}$ sensors are routinely mounted on remotely operated vehicles (ROVs) and human occupied vehicles (HOVs) conducting benthic research. Single dives typically provide vertical profiles made during descent and ascent and extended measurements within $2 \mathrm{~m}$ of the sea floor during bottom operations. The data may be accessed through operating agencies (e.g., $\mathrm{NOAA}^{4}$ ) or through PIs, but are not always accessible or in databases.

The availability in databases of $\mathrm{O}_{2}$ concentrations in the $\mathrm{BBL}$ and in sediments is limited and not optimally organized. Pioneering papers (CARS, 2009; Jahnke, 1996) proposed a synthesis of the limited dataset of benthic $\mathrm{O}_{2}$ demand collected

${ }^{4}$ https://www.ncei.noaa.gov/maps/oer-digital-atlas/mapsOE.htm at that time which contains indications of $\mathrm{O}_{2}$ concentration in bottom waters. Some regional syntheses were conducted using basin scale compilations of $\mathrm{O}_{2}$ demands (e.g., South Atlantic; Wenzhöfer and Glud, 2002). More recently, a compilation based on 230 papers containing a collection of total and diffusive $\mathrm{O}_{2}$ uptakes was achieved and made publicly available (Stratmann et al., 2019) from published and unpublished data (Pangaea data publisher ${ }^{5}$ ). None of these data collections, however, comprises an exhaustive compilation of $\mathrm{O}_{2}$ in the $\mathrm{BBL}$ and in the sediments. This work remains to be completed.

Concerning common (or best) practices, most calibrations ultimately rely on sensor readings in 100 and $0 \% \mathrm{O}_{2}$ solutions prior to deployment most often combined with Winkler $\mathrm{O}_{2}$ titration on recovered water samples, some long-term moorings rely on measurements of $\mathrm{O}_{2}$ concentration using calibrated optodes throughout the deployment, but no consensus on best practices has been established for the bottom part of the ocean including sediments.

At a first stage, $\mathrm{GO}_{2} \mathrm{DAT}$ will incorporate $\mathrm{O}_{2}$ concentration data from the water column including the BBL. Accurate $\mathrm{O}_{2}$ data in the BBL are crucial for the mapping of bottom water hypoxia. CTDs usually stop $\sim 2 \mathrm{~m}$ before the bottom and do not sample the BBL. Benthic $\mathrm{O}_{2}$ fluxes and oxygen concentrations in sediment porewaters will be integrated at a later stage.

\section{Underway Systems}

Underway systems are typically ship-based, but can also include instrumented marine mammals. The potential for collecting high temporal resolution data from such platforms is high, but currently there is no real community for underway $\mathrm{O}_{2}$ measurements (on any platform) and no consensus as to which sensors should be used and what quality control measures should be taken. Ships Of OPportunity (SOOPs) of the European Integrated Carbon Observation System (ICOS) ERIC, which measure surface $p \mathrm{CO}_{2}$ and contribute to the Surface Ocean $\mathrm{CO}_{2}$ Observing NETwork (SOCONET, Wanninkhof et al., 2019), are required to perform concurrent surface $\mathrm{O}_{2}$ measurements for scientific use to be labeled as "Class 1" station (Steinhoff et al., 2019), which currently 11 out of 12 ICOS-Ocean SOOP lines have. They typically use $\mathrm{O}_{2}$ optodes in a flow through system. However, data processing and quality control is not yet standardized by SOOPs. To this end, Becker et al. (2021) present a setup that allows regular in-air measurements in such underway installations on SOOPs, thus allowing continuous drift correction and drastically improving data accuracy. From a preliminary assessment with only a few transects, they estimate an accuracy around 3\% with an uncertainty (i.e., the standard deviation of the measured $\mathrm{O}_{2}$ concentration compared to a standard reference value) of $0.26 \%$. Bailleul et al. (2015) added an optode sensor 4330F to Argos CTD-SRDL (i.e., Depth-Satellite Relayed Data Loggers) tags deployed on female elephant seals in the Southern Ocean as a way to both increase the $\mathrm{O}_{2}$ database in the Southern Ocean and to investigate the relationship between air-breathing marine predators and other components of marine ecosystems. $\mathrm{O}_{2}$ pop-up satellite archival tags (DO-PATs) have been deployed

\footnotetext{
${ }^{5}$ https://www.pangaea.de
} 
on bluntnose six gill sharks to understand their vertical and horizontal distributions (Coffey and Holland, 2015). A MEOP (Marine Mammals exploring the ocean pole to pole) data base ${ }^{6}$ exists but presently only includes pressure, temperature and salinity profiles.

\section{Quality and Calibration of $\mathrm{O}_{2}$ Data Data Quality of Winkler $\mathrm{O}_{2}$ Measurements}

Winkler $\mathrm{O}_{2}$ measurements are the reference for the major range of $\mathrm{O}_{2}$ concentrations in the oxygenated ocean. Historical (pre1970) Winkler $\mathrm{O}_{2}$ measurements have an overall precision of about $\pm 1 \mu \mathrm{mol} \mathrm{kg}{ }^{-1}$. In recent years, the use of potentiometric, amperometric, spectro-photometric and photometric $\mathrm{O}_{2}$ end-point detection methods have improved the quality of the titrations because of greater automation. Winkler $\mathrm{O}_{2}$ measurements have an estimated accuracy of $0.1 \%$ (Carpenter, 1965); equivalent to approximately $\pm 0.25 \mu \mathrm{mol} \mathrm{kg}^{-1}$ and a precision of $0.15 \mu \mathrm{mol} \mathrm{kg}^{-1}$ (Saunders, 1986; Langdon, 2010).

However, some compounds commonly present in seawater can modify the Winkler-estimated $\mathrm{O}_{2}$ concentration. In fully oxic conditions, the most relevant interference is iodate that increases the measured concentration by $1.5 \mu$ moles of $\mathrm{O}_{2}$ per $\mu \mathrm{mol}$ of iodate. The concentration of iodate in the oceans is relatively stable with values of $0.35-0.45 \mu \mathrm{mol} \mathrm{kg}^{-1}$ in the surface and deep waters, respectively, and lower values in coastal areas (Wong and Cheng, 1998; Chance et al., 2014). Considering these typical iodate concentrations, Winkler measurements overestimate the real $\mathrm{O}_{2}$ concentration by $0.53-0.68 \mu \mathrm{mol} \mathrm{O} \mathrm{kg}^{-1}$, which could be a significant error in OMZs, if one wants to estimate the air-sea $\mathrm{O}_{2}$ fluxes (Wong and $\mathrm{Li}, 2009$ ) or determine NCP from $\mathrm{O}_{2}$ trends (Yang et al., 2017). In addition, samples can be contaminated by exposure to the atmosphere during sample handling and from polymers, present even in the widely used Niskin bottle (Broenkow and Cline, 1969; Garcia-Robledo et al., 2021). Therefore, the quality of Winkler measurement degrades and overestimations of the in situ $\mathrm{O}_{2}$ concentrations might be produced which can be of significance in OMZ (see Box 1). For the building of $\mathrm{GO}_{2} \mathrm{DAT}$, full information on the data collection protocol is required (e.g., type of bottles, atmospheric contamination). This is particularly critical in OMZs where details on the level of $\mathrm{NO}_{2}$ that can potentially interfere with the measurement of $\mathrm{O}_{2}$ is also needed.

\section{Data Quality of Sensor $\mathrm{O}_{2}$ Measurements}

Although $\mathrm{O}_{2}$ sensor technology has advanced further compared to some other biogeochemical sensors, the quality of sensorbased in situ $\mathrm{O}_{2}$ measurements is still heterogeneous and differs, depending mainly on the calibration type, calculation method (see Box 2 for an example), and possibility of frequent recalibration. Proper use, calibration, response time and drift remain challenges.

The uncertainty (i.e., the standard deviation of the measured $\mathrm{O}_{2}$ concentration compared to a standard reference value) on $\mathrm{O}_{2}$ sensor-based data differs depending mainly on the calibration type, calculation method and possibility of frequent recalibration

${ }^{6} \mathrm{http}: / /$ www.meop.net/database/ through comparison with Winkler measurements or in-air calibration (e.g., BGC Argo). Table 4 shows that the uncertainty associated to the last generation of optical sensors that uses a community-adopted calibration and calculation method has been reduced by a factor of $\sim 2-3$ compared to the previous generation.

$\mathrm{O}_{2}$ sensors are generally affected by three main types of drift: (1) an $\mathrm{O}_{2}$ sensitivity drift when not deployed and stored in air (i.e., the "storage" drift), (2) an "in situ" drift when submerged in the water and (3) a drift in the pressure correction visible on deep moorings $(>1000 \mathrm{~m})$. The storage regime drift is the most problematic with a loss of $\mathrm{O}_{2}$ sensitivity that can reach $\sim 5 \% \mathrm{yr}^{-1}$ and requires a re-calibration of the sensor before its deployment (see Box 2). The in situ drift amounts $\sim 0.5 \%$ $\mathrm{yr}^{-1}$ and requires frequent recalibrations and adjustments. For instance, best practices for electrochemical sensors (e.g., SBE43) recommend calibration of the sensor daily with Winkler $\mathrm{O}_{2}$ data acquired from surface to deep waters (Coppola et al., 2016). A least-square method (Uchida et al., 2010) is then used to adjust the coefficients of the empirical equation relating $\mathrm{O}_{2}$ voltage and temperature to $\mathrm{O}_{2}$ concentrations. These frequent recalibrations are particularly critical for autonomous platforms with long time series and/or without recovery like Argo floats. In that case, climatological surface $\mathrm{O}_{2}$ data can be employed for crude correction (Takeshita et al., 2013), and the advent of optodes with in-air measurements provides a robust approach to address in situ drift correction, offering a routine calibration of the sensors (Bittig and Körtzinger, 2015). In addition, oxygen optodes can show a time-dependent lag in response to a change in $\mathrm{O}_{2}$, which affects data accuracy when sensors experience $\mathrm{O}_{2}$ gradients, e.g., on profiling platforms. Methods to characterize the response time and to correct for the sensor lag have been described in the literature (Bittig et al., 2014; Bittig and Körtzinger, 2017; Gordon et al., 2020). The time response of the sensors is a function of the membrane thickness, temperature, and flow. For instance, for the most common $\mathrm{O}_{2}$ sensor used in CTDs, the SeaBird SBE-43, it may vary from a few to several tens of second. The effect of time-dependent pressure hysteresis is serious for $\mathrm{O}_{2}$ sensors deployed at deeper depths as long-term change in the $\mathrm{O}_{2}$ concentration in the deep ocean might be smaller than the magnitude of the pressure hysteresis (e.g., Uchida et al., 2010). The Scientific Committee on Oceanic Research (SCOR) 142 Working Group on "Quality Control Procedures for $\mathrm{O}_{2}$ and Other Biogeochemical Sensors on Floats and Gliders" produced well-documented guidelines for the calibration of $\mathrm{O}_{2}$ optodes (e.g., Bittig et al., 2018) that serve notably for the calibration of BGC Argo (e.g., Thierry and Bittig, 2018).

The quality flagging of $\mathrm{O}_{2}$ data collected by sensors requires the full specification of the sensors, calibration method and equation as well as information on potential drift corrections by the data owner. This will be recommended for the building of $\mathrm{GO}_{2}$ DAT (see section "Roadmap to GO2DAT").

\section{Adequation of $\mathrm{O}_{2}$ Measurements to Assess Mean State, Weather and Climate Variability}

The uncertainty associated with the last generation of $\mathrm{O}_{2}$ sensors that uses the best calibration and calculation methods amounts, in the best case at $\sim 2 \mu \mathrm{mol} \mathrm{kg}-1$ (Table 4) which is adequate 
BOX 1 | Challenges of measuring low $\mathrm{O}_{2}$ values.

Anoxic samples collected in the core of the OMZs and subpycnocline waters of some coastal systems have the maximum concentration difference with the atmosphere or with $\mathrm{O}_{2}$ permeable materials such as many polymers commonly used in scientific equipment (e.g., silicone, PVC, rubber, nylon). The contact of the sample with these compounds results in the increase of the $\mathrm{O}_{2}$ concentration from the initially anoxic sample to values up to $1 \mu$ mol $\mathrm{kg}^{-1}$ just by the Niskin collection (Garcia-Robledo et al., 2021). In addition, samples are exposed to the atmosphere during the filling process and the waiting time until reagents are added and the bottle is finally closed, allowing certain equilibration with the atmosphere. As a consequence, in under-saturated waters, atmospheric $\mathrm{O}_{2}$ dissolves in the sample and increases the measured concentration up to a few $\mu \mathrm{mol} \mathrm{kg}^{-1}$.
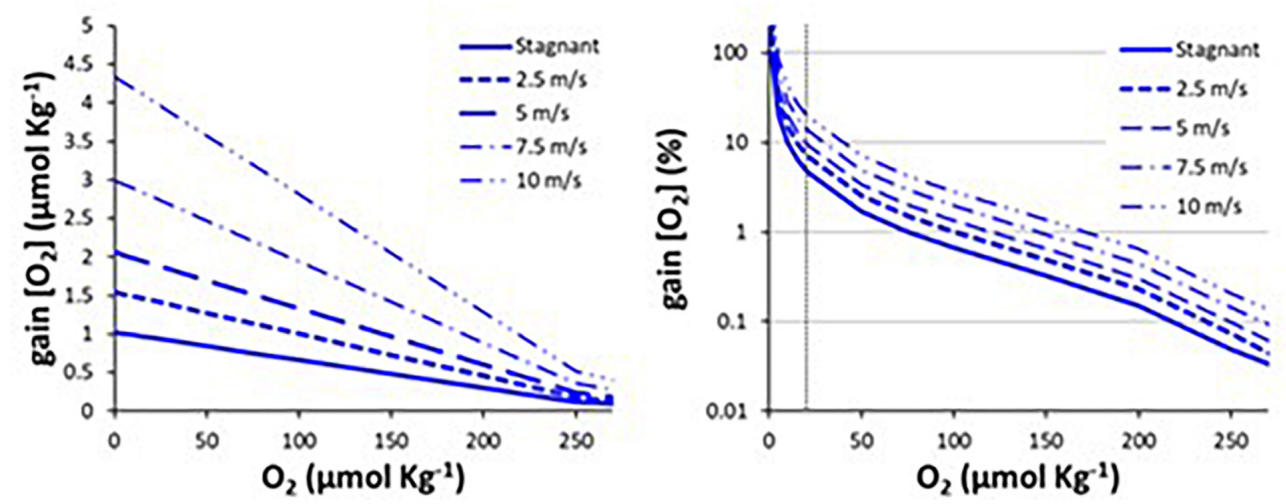

The above figure shows the estimation of the $\mathrm{O}_{2}$ contamination from the atmosphere calculated as a function of the initial sample concentration ( $x$-axis) and wind speed on deck (or sailing speed if there is no wind, in $\mathrm{m} / \mathrm{s}$ ), considering an oceanic sample at $10^{\circ} \mathrm{C}$ being collected on a $160 \mathrm{ml}$ bottle with an opening diameter of $2.4 \mathrm{~cm}$. The extra $\mathrm{O}_{2}$ dissolved in the sample is also used to calculate the gain in percentage of the initial $\mathrm{O}_{2}$ in the sample (right panel). A dotted line at $20 \mu \mathrm{mol}$ $\mathrm{kg}^{-1}$ is drawn to illustrate the $\mathrm{O}_{2}$ range in the OMZs. Note the logarithmic scale in the right panel. The contamination of $\mathrm{O}_{2}$ introduced only by the atmosphere could be as high as ca. $4.5 \mu \mathrm{mol} \mathrm{kg}^{-1}$.

Some compounds interfere with the Winkler titration. At low $\mathrm{O}_{2}$ concentrations, these interferences gain relevance due to the lower $\mathrm{O}_{2}$ measured and the increase in some of these compounds. lodate is consumed in anoxic environments, but at low $\mathrm{O}_{2}$ conditions such as the oxyclines of OMZs, it can increase the measured concentrations by $0.5-0.6 \mu \mathrm{mol} \mathrm{kg}{ }^{-1}$. Below the oxycline, nitrite usually accumulates in truly anoxic conditions such as the anoxic core of the Pacific OMZs. However, nitrite also interferes with Winkler titration, increasing the apparent $\mathrm{O}_{2}$ concentration by $0.5 \mu$ moles per $\mu$ mole of nitrite. Considering that nitrite concentrations up to $10 \mu \mathrm{mol} \mathrm{kg}{ }^{-1}$ can be measured in the Pacific OMZs, the deviation from anoxic values can be as high as $5 \mu$ mol $\mathrm{kg}^{-1}$ excluding other sources of error. If the contamination with atmospheric $\mathrm{O}_{2}$ is taken into account, a variable apparent $\mathrm{O}_{2}$ concentration of ca. $10 \mu \mathrm{mol} \mathrm{kg}^{-1}$ could be measured in samples collected in anoxic environments. Although extreme precautions can be taken to avoid atmospheric $\mathrm{O}_{2}$ contamination (Broenkow and Cline, 1969 ), other chemical compounds must be also quantified to correct the final $\mathrm{O}_{2}$ concentration estimated by Winkler titration. Due to the complexity of such corrections and the likely lack of complementary data from historical databases, Winkler determinations should not be used to correct in situ sensors in waters with $\left[\mathrm{O}_{2}\right]<15-20 \mu \mathrm{mol} \mathrm{kg}^{-1}$ (estimated error $\sim 10 \%$ ). In such cases a zero-calibration is recommended.

to answer questions on the mean state and weather variability but is still too large to resolve climate variability (Table 2). On the other hand, Winkler $\mathrm{O}_{2}$ data have the level of accuracy and precision needed to assess the long-term climate deoxygenation signal. Yet, these data do not have the quality, spatial and temporal coverage needed to infer the long-term trend in OMZs spatial extension and to concurrently correct sensor data in these regions. A posteriori correction or calibration of historical $\mathrm{O}_{2}$ data requires information on the sampling (e.g., contamination, concentrations of other compounds, calibration procedures, sampling protocol) that is very often not available. The rapid evolution over the last decades of sensor technology and calibration methods makes the application of a correction scheme derived from current instruments to past measurements difficult.

\section{Second Order Adjustment of $\mathrm{O}_{2}$ Data}

A posteriori correction can also be performed to increase the internal consistency of diverse datasets collected over several decades by different methodologies and laboratories. This secondary correction will not improve the accuracy of the data but rather is expected to increase the internal consistency of the datasets (e.g., Key et al., 2004) for e.g., the building of data synthesis products. In the deep ocean $(\sim 2000 \mathrm{~m})$, a common procedure consists of correcting sensors' offsets by comparing their measured values with those collected by Winkler (e.g., Winkler-based climatology, data taken years apart), assuming that the level of $\mathrm{O}_{2}$ remains unchanged in that part of the ocean. For instance, GLODAP (Key et al., 2004; Olsen et al., 2016) uses a crossover analysis to determine cruise-by-cruise offsets for discrete bottle data (Winkler) collected since 1972. The comparison is made irrespective of the year and season of data collection. Identified offsets larger than $1 \%$ are then adjusted after expert evaluation of all available information, including known climate trends in $\mathrm{O}_{2}$ and water mass structure (Tanhua et al., 2010; Lauvset and Tanhua, 2015; Olsen et al., 2020). Significant $\mathrm{O}_{2}$ and temperature warming trends have been detected even below 2000 m depth (e.g., Desbruyères et al., 2016; Schmidtko et al., 2017). For instance, Desbruyères et al. (2016) reported long-term (1991-2010) global warming trends at all pressure levels below $2000 \mathrm{~m}$ with the strongest warming rates in the abyssal layer $(4000-6000 \mathrm{~m})$. Even if the changes in $\mathrm{O}_{2}$ associated with this warming is likely less than $1 \%$, it requires differentiating sensor drift from climate variability. 
BOX $2 \mid \mathrm{O}_{2}$ response drift in optical and electrochemical sensors.

$\mathrm{An}_{2}$ sensitivity drift has been reported frequently between calibration by the manufacturer and deployment in the field (i.e., the "storage" drift, order - $5 \%$ yr ${ }^{-1}$, Bittig et al., 2018). This leads to a significant deviation of the stability properties compared to those found during the factory/laboratory calibrations (e.g., Bittig et al., 2012; Takeshita et al., 2013). Bittig and Körtzinger (2015) describe the nature of the storage drift as systematic, linear with $\mathrm{O}_{2}$ level and towards underestimation of actual $\mathrm{O}_{2}$.

A

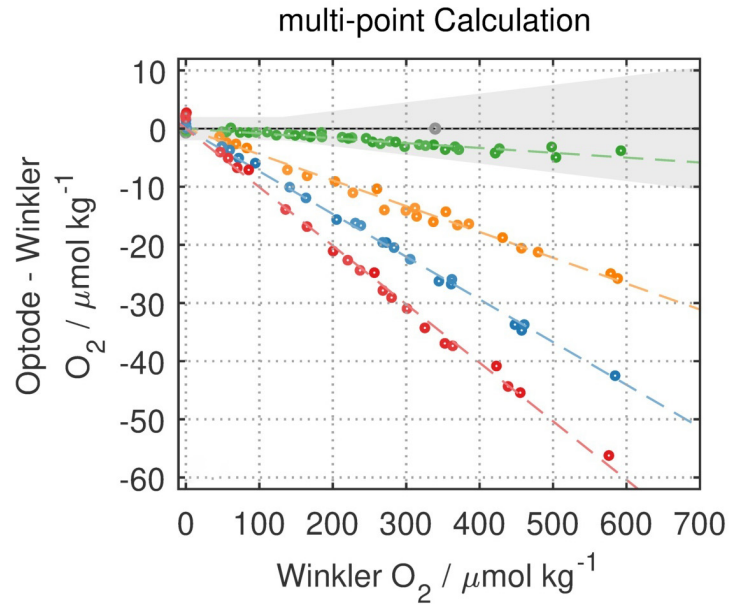

C

$\mathrm{O}_{2}$ Sensitivity Drift with batch Calculation

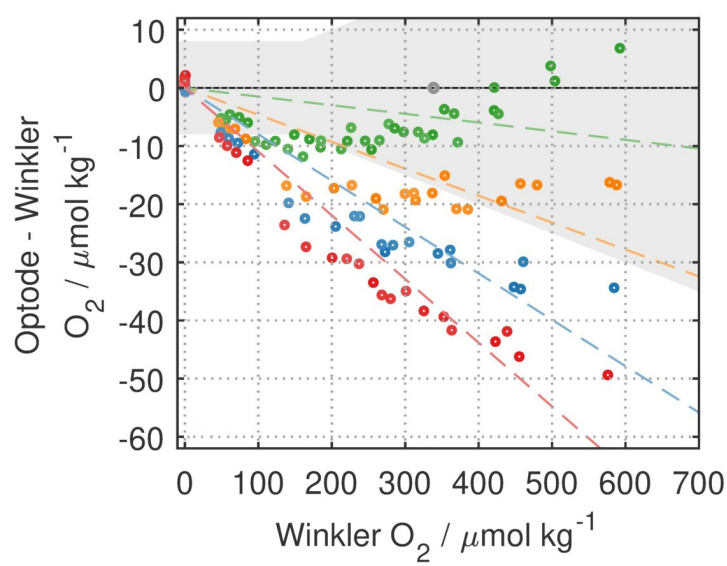

B

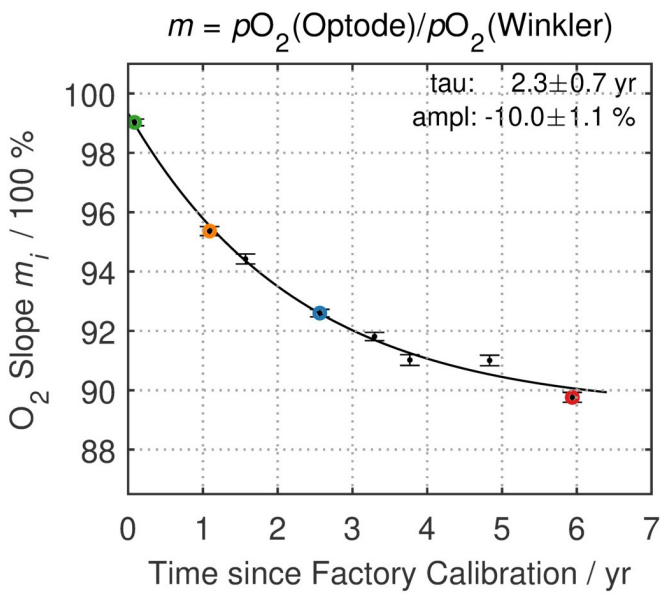

D

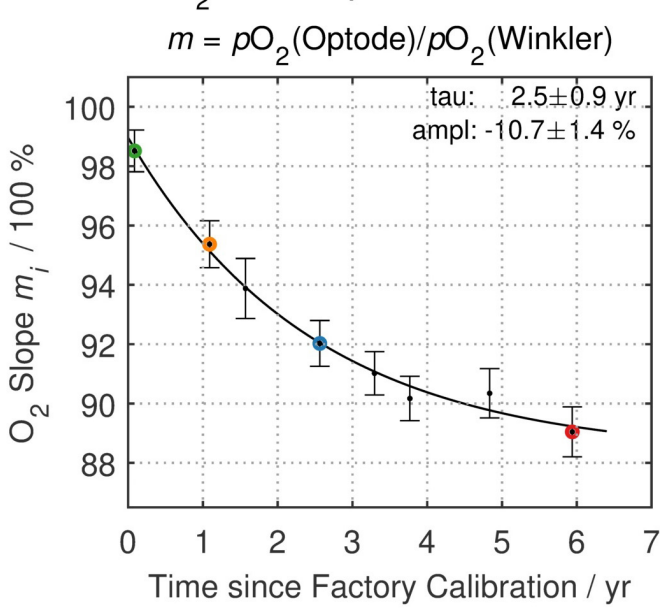

The above figure shows the characterization of the $\mathrm{O}_{2}$ sensitivity storage drift using as an example a subset of calibration data from an optode (Aanderaa optode model 3835) with factory two-point/batch calibration (in November 2010), multi-point calibrated directly afterward (December 2010) and, thereafter, multi-point recalibrated in approximately yearly intervals. All data courtesy of Craig Neill (CSIRO Oceans \& Atmosphere, Hobart). (A) Difference between optode data and Winkler reference data using the multi-point calculation, with the factory two-point data (gray circles) as initial state. Dashed lines are the slope regression forced through the origin and the different colors correspond to different time since factory calibration shown in panel (B). Only a subset of recalibrations (colored circles) is shown for clarity. (B) Temporal evolution of the $\mathrm{O}_{2}$ slope [i.e., $\mathrm{pO}_{2}\left(\right.$ Optode)/pO $\mathrm{O}_{2}$ (Winkler)] with colors corresponding to calibrations shown in panel (A). (C) Same data as in (A) but treated with the batch-foil/2-point adjustment calibration calculation. The linear $\mathrm{O}_{2}$ sensitivity drift appears non-linear with the batch-foil calculation. A slope $\mathrm{O}_{2}$ regression (dashed lines) still shows a drift towards lower $\mathrm{O}_{2}$, however, slopes are dependent on at which $\mathrm{O}_{2}$ levels reference data are available. (D) Same as (B) but for batch-foil calculation. The above figure illustrates the potentially biasing effect of calibration method on the appearance of storage drift. (A) Shows that in the case of the multi-point calibration the $\mathrm{O}_{2}$ sensitive bias can be modelled (through regression) at each calibration time (i.e., from 0 to 7 years since factory calibration) as a linear function of the $\mathrm{O}_{2}$ going through the origin with a negative slope. In the case of using the same, multi-point data but with the batch foil calibration approach with a two-point correction (e.g., 0 and $100 \% \mathrm{O}_{2}$ saturation), the $\mathrm{O}_{2}$ sensitivity drift appears non-linear but still a regression line indicates a drift towards lower $\mathrm{O}_{2}$ (C). However, slopes are dependent on which $\mathrm{O}_{2}$ levels reference data are available. This is where a large portion of the added uncertainty on batch-foil calibrated optodes originates (Table 4).

Bittig et al. (2018) propose a parameterization of the drift as a slope effect (i.e., the loss of $\mathrm{O}_{2}$ sensitivity defined as $p \mathrm{O}_{2}(\mathrm{optode}) / \mathrm{pO} \mathrm{O}_{2}(\mathrm{Winkler}$ ) resulting from reduced $\mathrm{O}_{2}$ sensitivity with a small positive offset coming from a reduced luminophore lifetime. (B) Shows that the storage drift rate (i.e., the slope effect) decreases with age of the sensor, being strongest in new optodes, of the order of $5 \% \mathrm{yr}^{-1}$, and decreasing in more mature optodes. Therefore, in-situ calibration before or during deployment is crucial and can be done either using Winkler- $\mathrm{O}_{2}$ determination on a cast taken at the same time and place of the sensor's deployment or, in the case of Argo floats equipped with optode in-air measurements, using near surface and in-air measurements (Bittig and Körtzinger, 2015; Johnson et al., 2015). 
TABLE 4 | Calibration type and calculation method for sensors and platforms.

\begin{tabular}{|c|c|c|c|}
\hline $\begin{array}{l}\text { Calibration type and calculation } \\
\text { method }\end{array}$ & Examples for sensors & Examples for platforms & Uncertainty \\
\hline $\begin{array}{l}\text { Electrochemical sensors with } \\
\text { 2-point calibration }\end{array}$ & SBE43 & $\begin{array}{c}\text { Shipboard CTD, 1st category of sensors } \\
\text { used on Argo Floats, Moorings, Benthic } \\
\text { Observations, Gliders }\end{array}$ & 2-10 $\mu \mathrm{mol} \mathrm{kg-1}$ \\
\hline $\begin{array}{l}\text { Batch-foil calibration; polynomial } \\
\text { with 2-point adjustment }\end{array}$ & $\begin{array}{c}\text { Aanderaa 3830/3835, all Aanderaa } \\
\text { 4330/4831 produced until 2013, some } \\
\text { Aanderaa 4330/4831 produced } 2013-2018\end{array}$ & $\begin{array}{c}\text { Moorings, Benthic Observations, Gliders, } \\
\text { 2nd category of sensors used on Argo } \\
\text { Floats. }\end{array}$ & $6-25 \mu \mathrm{mol} \mathrm{kg}-$ \\
\hline $\begin{array}{l}\text { Multi-point calibration; SVU/Uchida } \\
\text { et al., 2010-like equation }\end{array}$ & $\begin{array}{c}\text { Aaanderaa 4330/4831 since 2018, SBE63, } \\
\text { RINKO ARO-FT }\end{array}$ & $\begin{array}{c}\text { Moorings, Benthic Observations, Gliders, } \\
\text { 3rd category of sensors used on Argo } \\
\text { Floats. }\end{array}$ & $2-10 \mu \mathrm{mol} \mathrm{kg}{ }^{-1}$ \\
\hline
\end{tabular}

Measurement uncertainty is defined here as the standard deviation of the measured $\mathrm{O}_{2}$ concentration compared to a standard reference value (mostly Winkler).

Shallower coastal regions are subject to higher variability than deep, open-ocean regions, which further complicates the application of adjustments. Deep reference values cannot be used for data calibration in the shallower coastal areas, and thus, targeted data calibration approaches and QC procedures are needed there.

\section{Mapping $\mathrm{O}_{2}$ : Technical Challenges}

Some of the most common objective mapping procedures used in ocean sciences are the Barnes scheme (Barnes, 1964) which is used to create WOA18 and GLODAPv1.1, and variational inverse analysis (such as DIVA - data interpolating variational analysis; Troupin et al., 2012; Barth et al., 2014), which is used to create GLODAPv2. There are many objective mapping methods, and each has advantages and disadvantages depending on the data product requirements, the availability of high-quality data, behavior of the mapping method around topographic features (e.g., islands, trenches, seamounts), the ability to take ocean currents into account, and other factors. Mapping is commonly done on depth/pressure surfaces, but mapping on isopycnal (density) surfaces is also useful where possible. There are several technical challenges for creating mapped $\mathrm{O}_{2}$ data products, including the need to merge several highly diverse data sources with different sampling frequencies in time and space. Additionally, there are issues specifically related to ocean biogeochemical variables and, in particular, $\mathrm{O}_{2}$, such as the heterogeneous data distribution in time and space, data quality, and the existence of Anoxic Marine Zones (AMZs) (i.e., $\mathrm{O}_{2}=0 \mu \mathrm{mol} \mathrm{kg} \mathrm{kg}^{-1}$ ) and OMZs, which present several challenges including the scarcity of data, high gradients and ultra-low $\mathrm{O}_{2}$ values (e.g., Bianchi et al., 2012). The global coastal ocean presents another challenge given its relatively higher variability when compared to the open ocean. It is therefore likely that mapped data products for the global open and coastal ocean will have to sometimes rely on auxiliary data (such as temperature and salinity) and machine learning methods (such as neural networks, e.g., Krasnopolsky et al., 2016; Barth et al., 2020).

Existing and commonly used mapped data products include GLODAPv1.1 (Key et al., 2004), GLODAPv2 (Lauvset et al., 2016), WOA18 (Garcia et al., 2019), CSIRO Atlas of Regional
Seas (CARS, 2009), and Global Nutrients Dataset 2013 (GND13; Aoyama, 2020). All these data products are examples of global three-dimensional (longitude, latitude, and depth) fields of $\mathrm{O}_{2}$ and other variables, with varying temporal resolution (monthly to annual averages), created using various forms of objective mapping procedures. In addition, there exist several regional mapped data products such as EMODNet Chemistry.

\section{ROADMAP TO $\mathrm{GO}_{2} \mathrm{DAT}$}

The WOD (Garcia et al., 2005, 2019), CMEMS (Le Traon et al., 2019), GLODAP (Key et al., 2004; Olsen et al., 2016, 2020), and EMODnet (Giorgetti et al., 2018) are excellent foundations to support the development of $\mathrm{GO}_{2} \mathrm{DAT}$. Data collected by Argo, gliders and moorings have their own GDACs, which offers a certain level of consistency in terms of metadata specifications, QC, QF, computation models of sensors response (i.e., from raw data to $\mathrm{O}_{2}$ value), calibration and adjustment procedures. Best practice documents are available for sensor calibration (e.g., see Table 4) and the data are delivered according to the FAIR principles in RT and DM streams. However, these different databases and GDACs have their specific standards and, inside a given platform, these standards may differ across regional DACs. A $\mathrm{GO}_{2}$ DAT steering committee will be established and will work with existing GDACs and the IOC UNESCO International Oceanographic Data and Information Exchange program (IODE) towards the definition of common best practices and an alignment between GDACs of metadata structure, QC and QF procedures as concerns $\mathrm{O}_{2}$. These community agreed best practices will be communicated to data providers and repositories via the OceanTeacher network. $\mathrm{GO}_{2} \mathrm{DAT}$ will have its own $\mathrm{O}_{2}$ GDAC (i.e., $\mathrm{GO}_{2}$ DAT-GDAC), approved by IODE and complying with the terms of references of a, IODE-approved GDAC (see https://www.iode.org/index.php?option=com_content\&view= article\&id=372\&Itemid=100088). For instance, $\mathrm{GO}_{2} \mathrm{DAT}$ GDAC will receive and assemble marine $\mathrm{O}_{2}$ data and metadata from the data streams described in section "GO2DAT data flow," check their consistency, identify duplicates, make sure that the data are quality controlled according to the $\mathrm{GO}_{2}$ DAT-GDAC standards and methods, provide feedbacks 
to the source of data regarding quality issues, make data accessible and metadata available through the $\mathrm{GO}_{2} \mathrm{DAT}$ data portal and to IODE.

\section{$\mathrm{GO}_{2}$ DAT Data Flow}

In order to enable a sustainable data submission system that will integrate and make use of existing infrastructures, it is crucial to align it with overarching data flow and the structural elements of IODE. IODE will offer a seamless connection with its structural elements such as National Oceanographic Data Centres (NODCs), Associated Data Units (ADUs), and GDACS.

The proposed data submission will be two-fold: a centralized data submission to existing GDACs and a bottom-up data flow via NODCs (Figure 8). For platforms that already have their own GDAC (see Table 3), the submission process will remain unchanged (i.e., data will be submitted to the corresponding GDAC, e.g., Argo, gliders, moorings). Otherwise, submission to NODCs will be encouraged. Data providers will nevertheless still have the possibility to directly submit their data to regional hubs (e.g., EMODnet, CMEMS-TAC) and, in that case, data will be instantly exchanged with NODCs where PIDs will be assigned, and data get archived.

At the end, all data will be delivered and archived in the $\mathrm{GO}_{2}$ DAT GDAC. The adjustments performed on each data set at each level should be traceable and well documented. During the whole process, best practices and OceanTeacher will guide data providers in the submission process.

Acknowledgment of data providers will be provided through the assignment of a PID (e.g., DOI) where appropriate credit is given not only to the data provider but also to the project, funding agency and hosting agencies/institutes. The data usage license should be free and open but requires citation (e.g., Creative Commons BY). Data providers, NODCs, and Associated Data Units (ADUs) should be informed of download statistics.

Annual release of the $\mathrm{GO}_{2}$ DAT data will be publicized and interconnection with international initiatives (e.g., CMEMS, SeaDataNet, GLODAP, WOD) and other related GDACs will be recommended. Data will be received and made available through the World Data Service for Oceanography of the World Data System.

Table 5 summarizes the fundamental principles of $\mathrm{GO}_{2} \mathrm{DAT}$.

\section{Definition of Community-Approved $\mathrm{GO}_{2}$ DAT Standards \\ Metadata Specifications}

Understanding $\mathrm{O}_{2}$ variability and change requires information on the environmental conditions associated with each measurement. For instance, temperature and salinity are essential variables to estimate the density and $\mathrm{O}_{2}$ solubility of a water parcel allowing differentiation of physical and biogeochemical contributions to the $\mathrm{O}_{2}$ dynamics and trends. Temperature and salinity are also needed to convert observed $\mathrm{O}_{2}$ concentration into partial pressure $\left(\mathrm{pO}_{2}\right)$, a meaningful quantity when assessing the impact on marine life (e.g., Seibel and Deutsch, 2020). We recommend that raw $\mathrm{O}_{2}$ data be provided with information on temperature, salinity and pressure. Data will be delivered on a per mass basis in order to avoid the temperature and pressure effect on the volume. A clear and comprehensive definition of metadata specifications needs to be agreed upon by the scientific community. It will be recommended that NODCs, regional

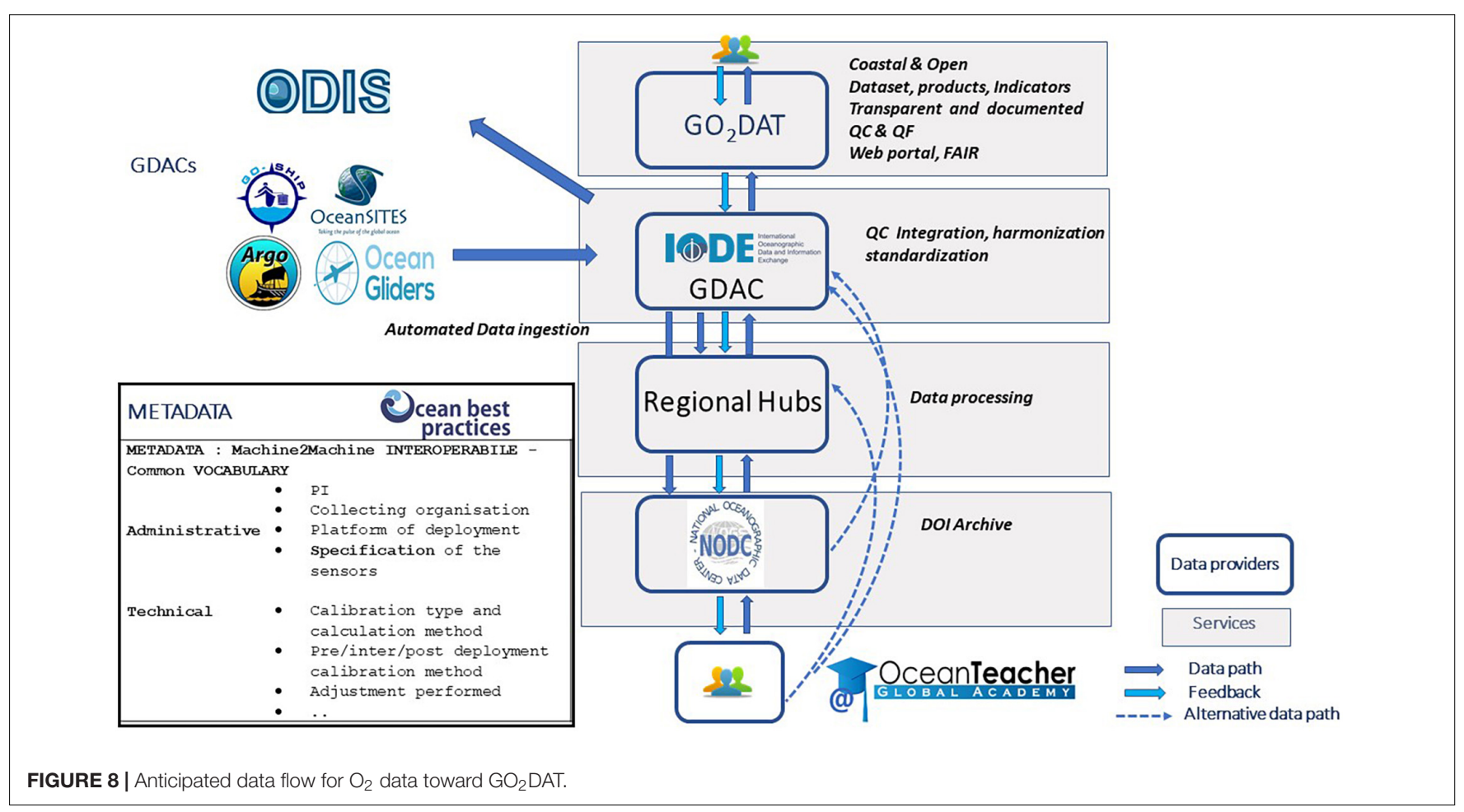


TABLE 5 | $\mathrm{GO}_{2}$ DAT principles.

\begin{tabular}{|c|c|}
\hline Attribute for raw data & Requirements \\
\hline Access & $\begin{array}{l}\text { Open-access without data use restrictions } \\
\text { under Creative Commons. }\end{array}$ \\
\hline Cost to use data and products & Free \\
\hline Data and product attribution & PID, DOI \\
\hline Archival of primary reference & $\begin{array}{l}\text { All data must be available at an international } \\
\text { long-term archive with long term funding (e.g., } \\
\text { World Data Service for Oceanography) }\end{array}$ \\
\hline Sustainability & $\begin{array}{l}\text { Long-term to ensure reproducibility of the } \\
\text { products }\end{array}$ \\
\hline Data versioning & Metadata best practices \\
\hline Reference QC and QF & Community consensus \\
\hline Database structure & $\begin{array}{l}\text { Common digital format (e.g., netCDF, ASCII), } \\
\text { units, and searchable/download online. }\end{array}$ \\
\hline Data products & $\begin{array}{l}\text { Available online without restriction in common } \\
\text { format (e.g., netCDF) }\end{array}$ \\
\hline Variables & EOV, (ECV, EBV) \\
\hline Reference & Depth (pressure), density \\
\hline Other... & \\
\hline
\end{tabular}

hubs, GDACs map their existing standards to the agreed $\mathrm{GO}_{2} \mathrm{DAT}$ standard.

\section{A Fully Documented and Transparent Quality Flagging System}

$\mathrm{GO}_{2}$ DAT will ensure that data in each flagging level are assigned an uncertainty, and that sufficient metadata to interpret this uncertainty are included. This will facilitate understanding of data uncertainty by the users allowing them to decide whether these data fit their specific requirements. Data correction factors and flagging should be fully traceable, consistent and based on a community agreement between groups of experts defined for the different sensors and platforms. Fully documented, transparent flagging procedure will allow any user to understand the details of a particular QF assigned to a data value and to have sufficient information to assess the suitability of the data for a particular purpose (e.g., mean state, variability, climate trend assessment). The questions listed in Table 2 can serve as a base to define the QF system. In the coastal ocean, the quality of data may vary greatly from very accurate data taken according to the best protocols to low quality data taken with hand-held, air-calibrated meters (e.g., $\mathrm{YSI} \mathrm{O}_{2}$ meter). Even if of lower quality, such datasets should not be rejected from $\mathrm{GO}_{2}$ DAT, but should be appropriately flagged. Some important applications of $\mathrm{O}_{2}$ data in coastal systems (e.g., protection of fisheries species) do not require the accuracy and precision required in open-ocean climate studies.

\section{Integrating Coastal Ocean Data in $\mathrm{GO}_{2}$ DAT}

Whereas open data sharing is generally accepted for openocean monitoring, this concept needs further support in coastal communities and, particularly, from NODCs and national and local organizations funding the monitoring programs. The compilation of data for the coastal ocean will be facilitated by the establishment of regional hubs adhering to the $\mathrm{GO}_{2}$ DAT- best practices. The connection of these regional hubs and $\mathrm{GO}_{2} \mathrm{DAT}$ will be realized through international and regional initiatives. For instance, the Chesapeake Bay Program ${ }^{7}$ and, the Baltic Environmental Database ${ }^{8}$ have been instrumental in data sharing, thereby supporting studies of hypoxia at a larger scale (e.g., Hagy et al., 2004; Conley et al., 2009; Carstensen et al., 2014). In the Pacific region, connection with WESPAC-O ${ }_{2} \mathrm{NE}$ (WEStern PACific-Oxygen Network) will promote the sharing of data in a region where the risks of eutrophication and hypoxia are likely to continue to intensify due to the projected increase of discharges of inorganic nitrogen and phosphorus over the next decades (Seitzinger et al., 2010). In the North Pacific, $\mathrm{GO}_{2} \mathrm{DAT}$ will benefit from the efforts led by the North Pacific Marine Science Organization (PICES) that is planning to construct a list of coastal $\mathrm{O}_{2}$ monitoring stations among their member countries. In the Eastern Pacific, existing initiatives like the California Cooperative Oceanic Fisheries Investigation (CalCOFI) and the Tongo Bay (off Chile) observing system ${ }^{9}$ will provide open access, longterm $\mathrm{O}_{2}$ data that have stimulated numerous mechanistic studies of regional $\mathrm{O}_{2}$ trends (e.g., Evans et al., 2020). The building of the research infrastructure JERICO-RI for the observation of the coastal ocean at the EU level will probably provide a regular flow of coastal $\mathrm{O}_{2}$ data to $\mathrm{GO}_{2} \mathrm{DAT}$.

Despite the existing services to facilitate and streamline the ingestion of data by providers not yet connected to marine data management infrastructures, the success of such services depends on the willingness of data holders to share their data. The existence of $\mathrm{GO}_{2} \mathrm{DAT}$, with rules on publication and attribution of data, may encourage individual researchers as well as government agencies responsible for data collection in coastal systems to participate and increase access to their data.

\section{$\mathrm{GO}_{2}$ DAT Products}

$\mathrm{GO}_{2} \mathrm{DAT}$ gridded data products (hereafter referred to as "mapped data") will be two- or three-dimensional fields of $\mathrm{O}_{2}$ concentration, $\mathrm{pO}_{2}$ and degree of saturation for the coastal and global ocean in support of scientific and management purposes. Each $\mathrm{GO}_{2}$ DAT product will be provided with a documented QF and with information about the quality, source and treatment of the data used for their production.

We anticipate providing several choices of mapped $\mathrm{O}_{2}$ products at different spatial and temporal scales to give users the choice to select the most appropriate for their application. In addition, we will strive to provide information about which methods are appropriate and relevant for the user application. The building of $\mathrm{GO}_{2}$ DAT mapped $\mathrm{O}_{2}$ products will progress in different iterative steps, as illustrated in Figure 9. At the first level, $\mathrm{GO}_{2}$ DAT mapped products will integrate $\mathrm{O}_{2}$ Winkler observation from the different databases (e.g., WOD, EMODnet, CMEMS) using the consistent community-agreed QC procedure. The second level of mapped $\mathrm{O}_{2}$ products will include the CTD$\mathrm{O}_{2}$ sensor data, after an appropriate QC procedure. The third and fourth levels entail inclusion of $\mathrm{O}_{2}$ data from Argo-floats

\footnotetext{
${ }^{7}$ https://www.chesapeakebay.net/

${ }^{8}$ http://nest.su.se/bed/

${ }^{9}$ http://www.cdom.cl/equipamiento.php
} 


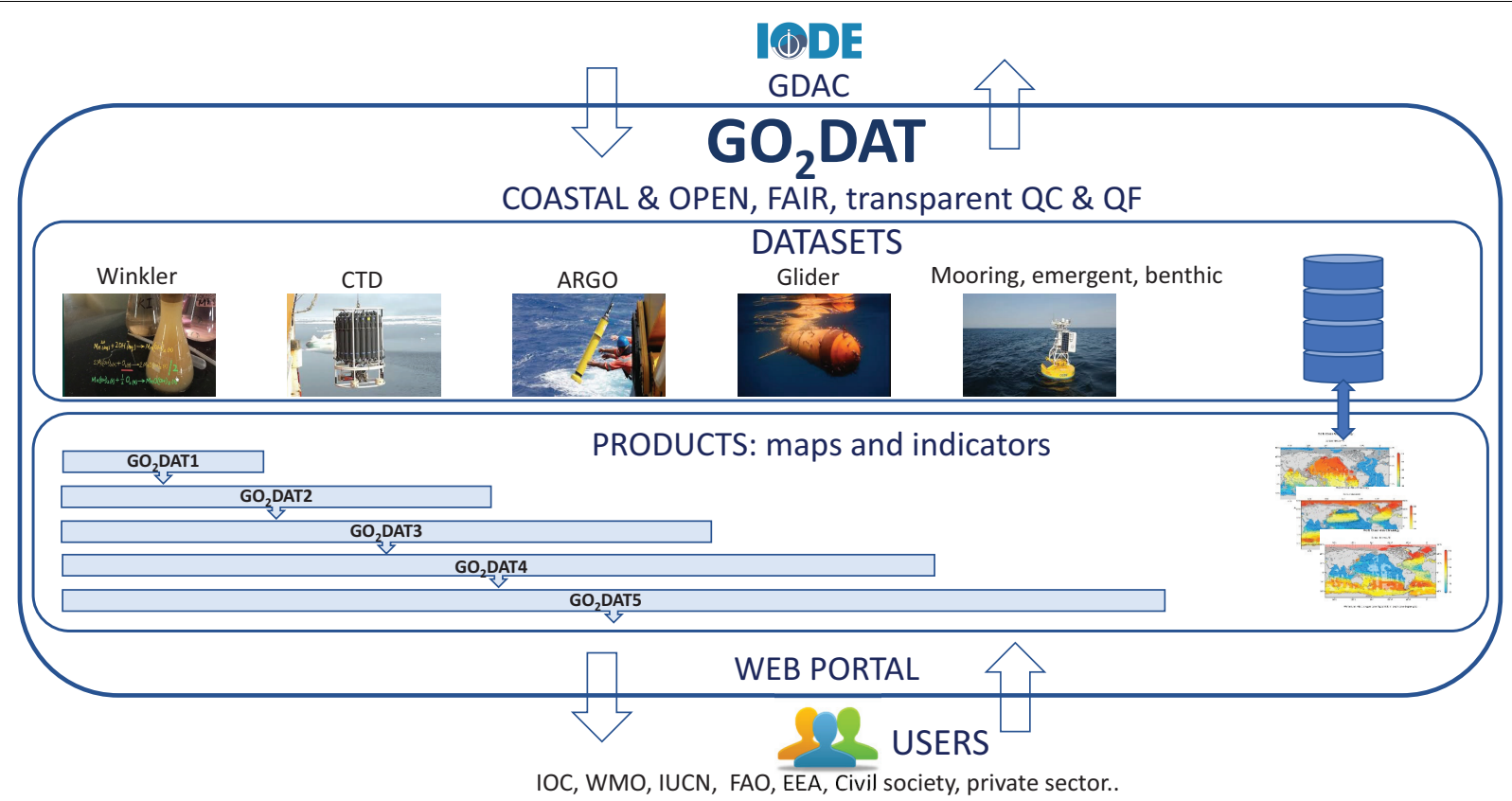

IPCC, IPBES, UN-Decade, UNFCCC, SOLAS, GOOS, IMBER, EU Green Deal, CBD, ..

FIGURE 9 | $\mathrm{GO}_{2}$ DAT Framework illustrating the different levels of gridded products that are expected.

and gliders, respectively. The fifth and final level is inclusion of data from moorings and underway systems, as well as BBL data and other emergent data platforms. $\mathrm{GO}_{2} \mathrm{DAT}$ will thus make the development of a range of data synthesis products at different depth and density levels possible.

Users will be able to download separate synthesis products for each level, or, when completed, a combined product with all levels included. It is envisioned that the synthesis product will be scalable to accommodate new observing systems and to facilitate continuous updates as new data become available. This is an important and required characteristic to enable frequent updates of products and to serve a wide range of users. $\mathrm{GO}_{2} \mathrm{DAT}$ will collaborate closely with the CMEMS in situ Thematic Centre, NOAA NCEI and EMODnet Chemistry to avoid duplication of efforts.

While $\mathrm{GO}_{2}$ DAT will focus on providing mapped data products, it will also aid the users wanting to use $\mathrm{GO}_{2} \mathrm{DAT}$ datasets for building their own mapped products and develop user-specific tools.

An interactive web-platform where $\mathrm{GO}_{2} \mathrm{DAT}$ data and products can be visualized will enhance interactions with the users and general public. This $\mathrm{GO}_{2} \mathrm{DAT}$ web interface will be optimized in order to obtain feedback on the interface, datasets and products.

\section{$\mathrm{GO}_{2}$ DAT Human Resources}

The development of $\mathrm{GO}_{2} \mathrm{DAT}$ will require human resources and engagement from the community including scientists, data managers, data providers and data users. The following tasks have been identified for the building of $\mathrm{GO}_{2}$ DAT to which human resources need to be dedicated.
Definition and documentation in the Ocean Best Practices System of community-agreed $\mathrm{GO}_{2}$ DAT standards for metadata specification, sensors calibration, data quality check and flagging.

Mapping existing data standards (e.g., in NODCs, GDACs) to that agreed in $\mathrm{GO}_{2}$ DAT.

Integration (preferably interoperable) in $\mathrm{GO}_{2} \mathrm{DAT}$ GDAC of existing datasets, search for duplicates, application of the agreed $\mathrm{GO}_{2}$ DAT standards.

Building regular updates (e.g., yearly) and analysis of the $\mathrm{GO}_{2}$ DAT mapped products and indicators.

Building of the web interface and interactions with the users.

\section{CONCLUSION}

Since the community white paper by Gruber et al. (2010) that called for the addition of $\mathrm{O}_{2}$ sensors on Argo floats and more generally on autonomous platforms, the number of $\mathrm{O}_{2}$ sensors has dramatically increased offering unprecedented capabilities to monitor $\mathrm{O}_{2}$ state and variability in the open, regional and coastal ocean. As the number of profiles increased, the quality of the sensor measurements has also improved. The uncertainty associated to the last generation of sensors has been reduced by a factor of $\sim 3$ when the best calibration and calculation method are used. This offers new opportunities to combine sensors and Winkler data in consistent data-synthesis products. These products will be used to understand the $\mathrm{O}_{2}$ dynamics and the deoxygenation process in the open and global coastal ocean in response to climate change. 
The building of $\mathrm{GO}_{2} \mathrm{DAT}$ is a timely initiative that can build on WOD, EMODnet, CMEMS, GLODAP. The integration of sensors and Winkler data from eulerian and lagrangian platforms from the different databases would offer data-synthesis products at an increased resolution. For the coastal ocean, the necessity to support the decisionmaking process aiming at preserving ocean health requires a coordination of NODCs, (inter)national and local organizations via the establishment of regional hubs. $\mathrm{GO}_{2} \mathrm{DAT}$ will offer the opportunity to build an $\mathrm{O}_{2}$ gridded product for the global coastal ocean with regular updates to monitor the multiannual evolution of coastal hypoxia in a warming climate.

The building of $\mathrm{GO}_{2} \mathrm{DAT}$ would allow to fully harness the potential of the boost in $\mathrm{O}_{2}$ profiles that is expected to quadruple in the frame of the future GOOS strategy. The alignment of well-documented and consistent QC and QF procedures proposed in $\mathrm{GO}_{2} \mathrm{DAT}$ will allow the user to make an informed choice on which data that are fit for purpose. $\mathrm{GO}_{2}$ DAT will facilitate the dissemination of information on ocean deoxygenation and its impact for marine life to a wide community of stakeholders (e.g., policymakers, industries, see Table 1) and contribute to the education of the young generation and general public.

The development of $\mathrm{GO}_{2}$ DAT requires human resources and engagement from the scientific community, data providers, data managers and end-users. Engagement around $\mathrm{GO}_{2} \mathrm{DAT}$ will be promoted by the UN Decade GOOD program.

\section{AUTHOR CONTRIBUTIONS}

MG, VG, HG, DB, KI, AO, and MT organized the workshops. MG, VG, and $\mathrm{HG}$ designed and wrote the manuscript with contributions from all co-authors. All the authors discussed and reviewed the manuscript.

\section{REFERENCES}

Adams, K. A., Barth, J. A., and Shearman, R. K. (2016). Intraseasonal cross-shelf variability of hypoxia along the newport, oregon, hydrographic line. J. Phys. Oceanogr. 46, 2219-2238. doi: 10.1175/JPO-D-15-0119.1

Altieri, A. H., Harrison, S. B., Seemann, J., Collin, R., Diaz, R. J., and Knowlton, N. (2017). Tropical dead zones and mass mortalities on coral reefs. Proc. Natl. Acad. Sci. 114, 3660-3665. doi: 10.1073/pnas.1621517114

Andersen, J. H., Axe, P., Backer, H., Carstensen, J., Claussen, U., Fleming-Lehtinen, V., et al. (2011). Getting the measure of eutrophication in the Baltic Sea: towards improved assessment principles and methods. Biogeochemistry 106, 137-156. doi: 10.1007/s10533-010-9508-4

Anderson, O. F., Guinotte, J. M., Rowden, A. A., Clark, M. R., Mormede, S., Davies A. J., et al. (2016). Field validation of habitat suitability models for vulnerable marine ecosystems in the South Pacific Ocean: implications for the use of broadscale models in fisheries management. Ocean Coast. Manag. 120, 110-126. doi: 10.1016/j.ocecoaman.2015.11.025

Andrews, O., Buitenhuis, E., Le Quéré, C., and Suntharalingam, P. (2017). Biogeochemical modelling of dissolved oxygen in a changing ocean. Philos. Trans. Royal Soc. A 375:20160328. doi: 10.1098/rsta.2016.0328

\section{FUNDING}

All authors would like to thank IOC-UNESCO, International Ocean Carbon Coordination Project (IOCCP), NOAA, and the German SFB754. MG is funded by the Fonds National de la Recherche Scientifique (FRS-FNRS) and received fundings from the FNRS BENTHOX program grant T.1009.15, the Copernicus Marine Service (CMEMS), and the European Union's Horizon 2020 BRIDGE-BS project under grant agreement No. 101000240. MG, VG, KI, and BDew are supported by the Project CE2COAST funded by ANR (FR), BELSPO (BE), FCT (PT), IZM (LV), MI (IE), MIUR (IT), Rannis (IS), and RCN (NO) through the 2019 "Joint Transnational Call on Next Generation Climate Science in Europe for Oceans" initiated by JPI Climate and JPI Oceans. MT, KC, and VG acknowledge support from the United States National Science Foundation grant OCE-1840868 to the Scientific Committee on Oceanic Research (SCOR, United States). BoD also acknowledges support from ANID grants R20F0008-CEAZA and 1190276. This research (through VG, AP and BoD) received fundings from the European Union's Horizon 2020 Research and Innovation Programme under grant agreement No. 869300 (FutureMARES). CB, AP, VG, LC, BrD, VR, VT, and CS acknowledge support of the French CES ODATIS Oxygen through INSU funding. SKL acknowledges support from the Research Council of Norway (Grant No. 269753). This manuscript is a contribution to the UN Decade Global Ocean Oxygen (GOOD) Program.

\section{ACKNOWLEDGMENTS}

This manuscript has been produced as an outcome of a 2-day workshop organized in Sopot in November 2019 by the IOC-UNESCO Global Ocean Oxygen Network $\left(\mathrm{GO}_{2} \mathrm{NE}\right)$ and sponsored by IOC-UNESCO, the International Ocean Carbon Coordination Project (IOCCP), U.S. NOAA and German SFB754 and of a 2-day virtual workshop in November 2020.

Aoyama, M. (2020). Global certified-reference-material- or reference-materialscaled nutrient gridded dataset GND13. Earth Syst. Sci. Data 12, 487-449. doi: 10.5194/essd-12-487-2020

Asch, R. G., Cheung, W. W., and Reygondeau, G. (2018). Future marine ecosystem drivers, biodiversity, and fisheries maximum catch potential in Pacific Island countries and territories under climate change. Mar. Pol. 88, 285-294. doi: 10.1016/j.marpol.2017.08.015

Attard, K. M., Rodil, I. F., Glud, R., Berg, P., Norkko, J., and Norkko, A. (2019). Seasonal ecosystem metabolism across shallow benthic habitats measured by aquatic eddy covariance. Limnol. Oceanogr. Lett. 4, 79-86. doi: 10.1002/lol2. 10107

Bailleul, F., Vacquie-Garcia, J., and Guinet, C. (2015). Dissolved oxygen sensor in animal-borne instruments: An innovation for monitoring the health of oceans and investigating the functioning of marine ecosystems. PLoS One 10:e0132681. doi: 10.1371/journal.pone.0132681

Barnes, S. L. (1964). A technique for maximizing details in numerical weather map analysis. J. App. Meteor. 3, 396-409. doi: 10.1175/1520-0450(1964)003<0396: ATFMDI $>2.0 . \mathrm{CO} ; 2$

Barth, A., Alvera-Azcárate, A., Licer, M., and Beckers, J.-M. (2020). DINCAE 1.0: a convolutional neural network with error estimates to reconstruct sea 
surface temperature satellite observations. Geosci. Model. Dev. 13, 1609-1622. doi: 10.5194/gmd-13-1609-2020

Barth, A., Beckers, J.-M., Troupin, C., Alvera-Azcárate, A., and Vandenbulcke, L. (2014). Divand-1.0: n-dimensional variational data analysis for ocean observations. Geosci. Mod. Dev. 7, 225-241. doi: 10.5194/gmd-7-225-2014

Batiuk, R. A., Breitburg, D. L., Diaz, R. J., Cronin, T. M., Secor, D. H., and Thursby, G. (2009). Derivation of habitat-specific dissolved oxygen criteria for Chesapeake Bay and its tidal tributaries. J. Exper. Mar. Biol. Ecol. 381, S204-S215. doi: 10.1016/j.jembe.2009.07.023

Beaty, T., Heinze, C., Hughlett, T., and Winguth, A. M. (2017). Response of export production and dissolved oxygen concentrations in oxygen minimum zones to $\mathrm{pCO} 2$ and temperature stabilization scenarios in the biogeochemical model HAMOCC 2.0. Biogeosciences 14, 781-797. doi: 10.5194/bg-14-781-2017

Becker, M., Olsen, A., and Reverdin, G. (2021). In-air one-point calibration of oxygen optodes in underway systems. Limnol. Oceanogr. Methods 19, 293-302. doi: $10.1002 / \operatorname{lom} 3.10423$

Berelson, W., McManus, J., Severmann, S., and Rollin, N. (2019). Benthic fluxes from hypoxia-influenced Gulf of Mexico sediments: Impact on bottom water acidification. Mar. Chem. 209, 94-106. doi: 10.1016/j.marchem.2019.01.004

Berg, P., and Hüttel, M. (2008). Monitoring the seafloor using the noninvasive Eddy Correlation technique: Integrated benthic exchange dynamics. Oceanography 21, 164-167. doi: 10.5670/oceanog.2008.13

Berg, P., Glud, R. N., Hume, A., Stahl, H., Oguri, K., Meyer, V., et al. (2009). Eddy correlation measurements of oxygen uptake in deep ocean sediments. Limnol. Oceanogr. 7, 576-584. doi: 10.4319/lom.2009.7.576

Bianchi, D., Dunne, J. P., Sarmiento, J. L., and Galbraith, E. D. (2012). Databased estimates of suboxia, denitrification, and $\mathrm{N} 2 \mathrm{O}$ production in the ocean and their sensitivities to dissolved O2. Glob. Biogeochem. Cycles 26:2009. doi: 10.1029/2011GB004209

Bittig, H. C., and Körtzinger, A. (2015). Tackling oxygen optode drift: Near-surface and in-air oxygen optode measurements on a float provide an accurate in situ reference. J. Atmos. Ocean. Technol. 32, 1536-1543. doi: 10.1175/JTECH-D14-00162.1

Bittig, H. C., and Körtzinger, A. (2017). Technical note: Update on response times, in-air measurements, and in situ drift for oxygen optodes on profiling platforms. Ocean Sci. 13, 1-11. doi: 10.5194/os-13-1-2017

Bittig, H. C., Körtzinger, A., Neill, C., van Ooijen, E., Plant, J. N., Hahn, J., et al. (2018). Oxygen optode sensors: principle, characterization, calibration, and application in the ocean. Front. Mar. Sci. 4:429. doi: 10.3389/fmars.2017. 00429

Bittig, H., Fiedler, B., Scholz, R., Krahmann, G., and Körtzinger, A. (2014). Time response of oxygen optodes on profiling platforms and its dependence on flow speed and temperature. Limnol. Oceanogr. Methods 12, 617-636. doi: 10.4319/ lom.2014.12.617

Bittig, H., Fiedler, B., Steinhoff, T., and Körtzonger, A. (2012). A novel electrochemical calibration setup for oxygen sensors and its use for the stability assessment of Aanderaa optodes. Limnol. Oceanogr. Methods 10, 921-933. doi: 10.4319/lom.2012.10.921

Bittig, H., Körtzinger, A., Johnson, K., Claustre, H., Emerson, S., Fennel, K., et al. (2015). SCOR WG 142: Quality Control Procedures for Oxygen and Other Biogeochemical Sensors on Floats and Gliders. Recommendation for Oxygen Measurements From Argo Floats, Implementation of In-Air-Measurement Routine to Assure Highest Long-Term Accuracy. Plouzane, France: IFREMER.

Bittig, H., Maurer, T., Plant, J., Schmechtig, C., Wong, A., Claustre, H., et al. (2019). A BGC-argo guide: planning, deployment, data handling and usage. Front. Mar. Sci. 6:502. doi: 10.3389/fmars.2019.00502

Boyer, T. P., Baranova, O. K., Coleman, C., Garcia, H. E., Grodsky, A., Locarnini, R. A., et al. (2018). "World ocean database 2018," in NOAA Atlas NESDIS, ed. A. V. Mishonov (Silver Spring, MD: NOAA), 87.

Bopp, L., Resplandy, L., Orr, J. C., Doney, S. C., Dunne, J. P., Gehlen, M., et al. (2013). Multiple stressors of ocean ecosystems in the 21st century: projections with CMIP5 models. Biogeosciences 10, 6225-6245.

Brasseur, P., Gruber, N., Barciela, R., Brander, K., Doron, M., Elmoussaoui, A., et al. (2009). Integrating biogeochemistry and ecology into ocean data assimilation systems. Oceanography 22, 206-215. doi: 10.5670/oceanog.2009.80

Breitburg, D. (2002). Effects of hypoxia, and the balance between hypoxia and enrichment, on coastal fishes and fisheries. Estuaries 25, 767-781. doi: 10.1007/ BF02804904
Breitburg, D. L., Craig, J. K., Fulford, R. S., Rose, K. A., Boynton, W. R., Brady, D. C., et al. (2009). Nutrient enrichment and fisheries exploitation: interactive effects on estuarine living resources and their management. Hydrobiologia 629, 31-47. doi: 10.1007/s10750-009-9762-4

Breitburg, D., Levin, L. A., Oschlies, A., Grégoire, M., Chavez, F. P., Conley, D. J., et al. (2018). Declining oxygen in the global ocean and coastal waters. Science 359:6371. doi: 10.1126/science.aam 7240

Broenkow, W. W., and Cline, J. D. (1969). Colorimetric determination of dissolved oxygen at low concentrations. Limnol. Oceanogr. 4, 450-454. doi: 10.4319/lo. 1969.14.3.0450

Bushinsky, S., Emerson, S., Riser, S., and Swift, D. (2016). Accurate oxygen measurements on modified Argo floats using in situ air calibrations. Limnol. Oceanogr. Methods 14, 491-505. doi: 10.1002/lom3.10107

Cai, W.-J., and Sayles, F. (1996). Oxygen penetration depths and fluxes in marine sediments. Mar. Chem. 52, 123-131.

Carpenter, J. H. (1965). The accuracy of the winkler method for dissolved oxygen analysis. Limnol. Oceanogr. 10, 135-140. doi: 10.4319/lo.1965.10.1.0135

CARS (2009). CSIRO Atlas of Regional Seas - World Monthly. Battery Point, TAS: Integrated Marine Observing System.

Carstensen, J., and Conley, D. J. (2019). Baltic Sea hypoxia takes many shapes and sizes. Bul. Limnol. Oceanogr. 28, 125-129. doi: 10.1002/lob.10350

Carstensen, J., Andersen, J. H., Gustafsson, B. G., and Conley, D. J. (2014). Deoxygenation of the Baltic Sea during the last century. Proc. Natl. Acad. Sci. 111, 5628-5633. doi: 10.1073/pnas.1323156111

Cathalot, C., Rabouille, C., Pastor, L., Deflandre, B., Viollier, E., Buscail, R., et al. (2010). Temporal variability of carbon recycling in coastal sediments influenced by rivers: assessing the impact of flood inputs in the Rhone River prodelta. Biogeosciences 7, 1187-1205. doi: 10.5194/bg-7-1187-2010

Champenois, W., and Borges, A. (2019). Inter-annual variations over a decade of primary production of the seagrass Posidonia oceanica. Limnol. Oceanogr. 64, 32-45. doi: 10.1002/lno.11017

Chance, R., Baker, A. R., Carpenter, L., and Jickells, T. (2014). The distribution of iodide at the sea surface. Environ. Sci. Process Impacts 16, 1841-1859. doi: 10.1039/C4EM00139G

Cheung, W. W. L. (2018). The future of fishes and fisheries in the changing oceans. J. Fish Biol. 92, 790-803. doi: 10.1111/jfb.13558

Chu, J. W., and Gale, K. S. (2017). Ecophysiological limits to aerobic metabolism in hypoxia determine epibenthic distributions and energy sequestration in the northeast Pacific Ocean. Limnol. Oceanogr. 62, 59-74. doi: 10.1002/lno.10370

Clark, L. C. Jr., Wolf, R., Granger, D., and Taylor, Z. (1953). Continuous recording of blood oxygen tensions by polarography. J. Appl. Physiol. 6, 189-193. doi: 10.1152/jappl.1953.6.3.189

Claustre, H., Johnson, K. S., and Takeshita, Y. (2020). Observing the global ocean with biogeochemical-Argo. Annu. Rev. Mar. Sci. 12, 23-48. doi: 10.1146/ annurev-marine-010419-010956

Coffey, D. M., and Holland, K. N. (2015). First autonomous recording of in situ dissolved oxygen from free-ranging fish. Anim. Biotelem. 3, 47. doi: 10.1186/ s40317-015-0088-x

Conley, D. J., Carstensen, J., Vaquer-Sunyer, R., and Duarte, C. M. (2009). Ecosystem thresholds with hypoxia. Hydrobiologica 629, 21-29. doi: 10.1007/ s10750-009-9764-2

Coppola, L., Ntoumas, M., Bozzano, R., Bensi, M., Hartman, S. E., Charcos Llorens, M., et al. (2016). Handbook of Best Practices for Open Ocean Fixed Observatories. Report of the FixO3 Project. Brussels, Belgium: European Commission, 127.

Coppola, L., Prieur, L., Taupier-Letage, I., Estournel, C., Testor, P., Lefevre, D., et al. (2017). Observation of oxygen ventilation into deep waters through targeted deployment of multiple Argo-O2 floats in the north- western Mediterranean Sea in 2013. J. Geophys. Res. Oceans 122, 6325-6341. 2016JC012594 doi: 10. 1002/2016JC012594

de Mutsert, K., Steenbeek, J., Cowan, J. H., and Christensen, V. (2017). "Using ecosystem modeling to determine hypoxia effects on fish and fisheries," in Modeling Coastal Hypoxia, eds J. Dubravko, K. Rose, R. Hetland, and K. Fennel (Cham: Springer), 377-400. doi: 10.1007/978-3-319-54571-4_14

Desbruyères, D. G., Purkey, S. G., McDonagh, E. L., Johnson, G. C., and King, B. A. (2016). Deep and abyssal ocean warming from 35 years of repeat hydrography. Geo. Phys. Res. Lett. 43, 10356-10365. doi: 10.1002/2016GL070413

Deutsch, C., Penn, J. L., and Seibel, B. (2020). Metabolic trait diversity shapes marine biogeography. Nature 585, 557-562. doi: 10.1038/s41586-020-2721-y 
Diaz, R. J., and Rosenberg, R. (2008). Spreading dead zones and consequences for marine ecosystems. Science 321, 926-929. doi: 10.1126/science.1156401

Dickey, T. D. (2003). Emerging ocean observations for interdisciplinary data assimilation systems. J. Mar. Syst. 40, 5-48. doi: 10.1016/S0924-7963(03)0 $0011-3$

Druon, J. N., Chassot, E., Murua, H., and Lopez, J. (2017). Skipjack tuna availability for purse seine fisheries is driven by suitable feeding habitat dynamics in the Atlantic and Indian Oceans. Front. Mar. Sci. 4:315. doi: 10.3389/fmars.2017. 00315

Dulvy, N., Reynolds, J. D., Pilling, G. M., Pinnegar, J. K., Scutt Phillips, J., Allison, E. H., et al. (2011). Fisheries management and governance challenges in a climate change, in The Economics of Adapting Fisheries to Climate Change. Paris: OECD Publishing, 31-88. doi: 10.1787/9789264090415-4-en

Duteil, O., Oschlies, A., and Böning, C. W. (2018). Pacific Decadal Oscillation and recent oxygen decline in the eastern tropical Pacific Ocean. Biogeosciences 15, 7111-7126. doi: 10.5194/bg-15-7111-2018

Dyck, A. J., and Sumaila, U. R. (2010). Economic impact of ocean fish populations in the global fishery. J. Bioecon. 12, 227-243. doi: 10.1007/s10818-010-9088-3

Eero, M., Hjelm, J., Behrens, J., Buchmann, K., Cardinale, M., Casini, M., et al. (2015). Eastern Baltic cod in distress: biological changes and challenges for stock assessment. ICES J. Mar. Sci. 72, 2180-2186. doi: 10.1093/icesjms/fsv109

Emerson, S., Quay, P., Karl, D. M., Winn, C., and Tupas, L. M. (1997). Experimental determination of the organic carbon flux from open-ocean surface waters. Nature 389, 951-954. doi: 10.1038/40111

Emerson, S., Stump, C., and Nicholson, D. (2008). Net biological oxygen production in the ocean: Remote in situ measurements of $\mathrm{O} 2$ and $\mathrm{N} 2$ in surface waters. Glob. Biogeochem. Cycles 22:GB3023. doi: 10.1029/2007GB003095

Evans, N., Schroeder, I. D., Pozo Buil, M., Jacox, M. G., and Bograd, S. J. (2020). Drivers of subsurface deoxygenation in the southern California Current System. Geophys. Res. Lett. 46:e2020GL089274. doi: 10.1029/2020GL089274

Fennel, K., and Testa, J. M. (2019). Biogeochemical controls on coastal hypoxia. Annu. Rev. Mar. Sci. 11, 105-130. doi: 10.1146/annurev-marine-010318095138

Gallo, N., Wei, C.-L., Levin, L., Kuhnz, L., and Barry, J. (2020). Dissolved oxygen and temperature best predict deep-sea fish community structure in the Gulf of California with implications for climate change. Mar. Ecol. Prog. Ser. 637, 159-180. doi: 10.3354/meps 13240

Gammal, J., Norkko, J., Pilditch, C. A., and Norkko, A. (2017). Coastal hypoxia and the importance of benthic macrofauna communities for ecosystem functioning. Estuaries Coasts 40, 457-468. doi: 10.1007/s12237-016-0152-7

Garcia, H. E., Boyer, T. P., Levitus, S., Locarnini, R. A., and Antonov, J. (2005). On the variability of dissolved oxygen and apparent oxygen utilization content for the upper world ocean: 1955 to 1998. Geophys. Res. Lett. 32:L09604. doi: 10.1029/2004GL022286

Garcia, H. E., Locarnini, R. A., Boyer, T. P., Antonov, J. I., Baranova, O. K., Zweng, M. M., et al. (2013). "World ocean atlas 2013, volume 3: dissolved oxygen, apparent oxygen utilization, and oxygen saturation," in NOAA Atlas NESDIS, Vol. 75, eds S. Levitus and A. Mishonov (Silver Spring, MD: NOAA).

Garcia, H. E., Weathers, K., Paver, C. R., Smolyar, I., Boyer, T., Locarnini, R., et al. (2019). "World Ocean Atlas 2018, Volume 3: Dissolved Oxygen, Apparent Oxygen Utilization, and Oxygen Saturation," in NOAA Atlas NESDIS, Vol. 83, ed. A. Mishonov (Silver Spring, MD: NOAA).

Garcia-Robledo, E., Paulmier, A., Borisov, S. M., and Revsbech, N. P. (2021). Sampling in low oxygen aquatic environments: The deviation from anoxic conditions. Limnol. Oceanogr. Methods 2021:10457. doi: 10.1002/lom3. 10457

Garçon, V. C., Karstensen, J., Palacz, A., Telszewski, M., Aparco Lara, T., Breitburg, D., et al. (2019). Multidisciplinary observing in the World Ocean's oxygen minimum zone regions: from climate to fish-the VOICE initiative. Front. Mar. Sci. 6:722. doi: 10.3389/fmars.2019.00722

Gharamti, M. E., Tjiputra, J., Bethke, I., Samuelsen, A., Skjelvan, I., Bentsen, M., et al. (2017). Ensemble data assimilation for ocean biogeochemical state and parameter estimation at different sites. Ocean Model. 112, 65-89. doi: 10.1016/ j.ocemod.2017.02.006

Gilbert, D., Rabalais, N. N., Diaz, R. J., and Zhang, J. (2010). Evidence for greater oxygen decline rates in the coastal ocean than in the open ocean. Biogeosciences 7:2283. doi: $10.5194 /$ bg-7-2283-2010
Giorgetti, A. E., Partescano, E., Barth, A., Buga, L., Gatti, J., Giorgi, G., et al. (2018). EMODnet chemistry spatial data infrastructure for marine observations and related information. Ocean Coast. Manag. 166, 9-17. doi: 10.1016/j.ocecoaman. 2018.03.016

Glud, R. N. (2008). Oxygen dynamics of marine sediments. Mar. Biol. Res. 4, 243-289. doi: $10.1080 / 17451000801888726$

Glud, R. N., Gundersen, J. K., Ramsing, N. B., Buffle, J., and Horvai, G. (2000). Electrochemical and optical oxygen microsensors for in situ measurements: In situ monitoring of aquatic systems: Chemical analysis and speciation. Chichester, UK: John Wiley and Sons, 20-73.

Gobler, C. J., and Baumann, H. (2016). Hypoxia and acidification in ocean ecosystems: coupled dynamics and effects on marine life. Biol. Lett. 12:20150976. doi: 10.1098/rsbl.2015.0976

Gordon, C., Fennel, K., Richards, C., Shay, L. K., and Brewster, J. K. (2020). Can ocean community production and respiration be determined by measuring high-frequency oxygen profiles from autonomous floats? Biogeosciences 17, 4119-4134. doi: 10.5194/bg-17-4119-2020

Gruber, N., Doney, S. C., Emerson, S. R., Gilbert, D., Kobayashi, T., Körtzinger, A., et al. (2010). "Adding oxygen to argo: Developing a global in situ observatory for ocean deoxygenation and biogeochemistry," in Proceedings of Ocean Obs '09: Sustained Ocean Observations and Information for Society, eds J. Hall, D. E. Harrison, and D. Stammer (New Zealand: ESA Publication), 12. doi: 10.5270/ OceanObs09.cwp.39

Gust, G., Booij, K., Helder, W., and Sundby, B. (1987). On the velocity sensitivity (stirring effect) of polarographic oxygen microelectrodes. Neth. J. Sea Res. 21, 255-263. doi: 10.1016/0077-7579(87)90001-9

Hagy, J., Boynton, W., Keefe, C., and Wood, K. (2004). Hypoxia in Chesapeake Bay, 1950-2001: Long-term change in relation to Nutrient loading and river flow. Estuaries 27, 634-658. doi: 10.1007/BF02907650

Hall, P. O. J., Almroth-Rosell, E., Bonaglia, S., Dale, A. W., Hylen, A., Kononets, M., et al. (2017). Influence of natural oxygenation of baltic proper deep water on benthic recycling and removal of phosphorus, nitrogen, silicon and carbon. Front. Mar. Sci. 4:27. doi: 10.3389/fmars.2017.00027

Helly, J., and Levin, L. A. (2004). Global distribution of naturally occurring marine hypoxia on continental margins. Deep Sea Res. 51, 1159-1168. doi: 10.1016/j. dsr.2004.03.009

Holtappels, M., Kuypers, M. M. M., Schlüter, M., and Brüchert, V. (2011). Measurement and interpretation of solute concentration gradients in the benthic boundary layer. Limnol. Oceanogr. Meth. 9, 1-13. doi: 10.4319/lom. 2011.9.1

Hood, E. M., Sabine, C. L., and Sloyan, B. M. (eds) (2010). The GO-SHIP Repeat Hydrography Manual: A Collection of Expert Reports and Guidelines, Version 1. (IOCCP Report 14), (ICPO Publication Series 134). Available online at: http: //www.go-ship.org/HydroMan.html. doi: 10.25607/OBP- 1341

Howard, E. M., Penn, J. L., Frenzel, H., Seibel, B. A., Bianchi, D., Renault, L., et al. (2020). Climate-driven aerobic habitat loss in the California Current System. Sci. Adv. 6:eaay3188. doi: 10.1126/sciadv.aay3188

Hughes, D. J., Alderdice, R., Cooney, C., Kühl, M., Pernice, M., Voolstra, C. R., et al. (2020). Coral reef survival under accelerating ocean deoxygenation. Nat. Climate Change 10, 296-307. doi: 10.1038/s41558-020-0737-9

IOC (2019). The Science We Need for the Ocean We Want: The United Nations Decade of Ocean Science for Sustainable Development (2021-2030). Paris: IOC, 24.

Jahnke, R. A. (1996). The global ocean flux of particulate organic carbon: Areal distribution and magnitude. Glob. Biogeochem. Cycles 10, 71-88. doi: 10.1029/ 95GB03525

Jahnke, R. A., and Christiansen, M. B. (1989). A free vehicle benthic chamber instrument for sea floor studies. Deep-sea Res. 32, 885-897. doi: 10.1016/01980149(89)90011-3

Johnson, K. S., and Claustre, H. (2016). Bringing Biogeochemistry Into the Argo age. Washington, DC: EOS, 97. doi: 10.1029/2016EO062427

Johnson, K. S., Plant, J. N., Riser, S. C., and Gilbert, D. (2015). Air oxygen calibration of oxygen optodes on a profiling float array. J. Atmos. Ocean. Technol. 32, 2160-2172. doi: 10.1175/JTECH-D-15-0101.1

Johnson, K. S., Plant, J., Coletti, L., Jannasch, H., Sakamoto, C., Riser, S., et al. (2017). Biogeochemical sensor performance in the SOCCOM profiling float array. J. Geophys. Res. Oceans 122, 6416-6436. doi: 10.1002/2017JC012838 
Joyce, T. M. (1991). Introduction to the Collection of Expert Reports Compiled for the WHP Programme. WHP Operations and Methods-July 1991. Southampton: WOCE Hydrographic Programme Office, 4.

Keeling, R. F., and Manning, A. C. (2014). Studies of Recent Changes in Atmospheric O2 Content. Treatise on Geochemistry, Second Edn, Vol. 5. Amsterdam: Elsevier, 385-404. doi: 10.1016/B978-0-08-095975-7.00420-4

Keeling, R., Körtzinger, A., and Gruber, N. (2010). Ocean deoxygenation in a warming world. Annu. Rev. Mar. Sci. 2, 199-229. doi: 10.1146/annurev.marine. 010908.163855

Keister, J. E., Houde, E. D., and Breitburg, D. L. (2000). Effects of bottom-layer hypoxia on abundances and depth distributions of organisms in Patuxent River, Chesapeake Bay. Mar. Ecol. Prog. Ser. 205, 43-59. doi: 10.3354/meps20 5043

Keller, A. A., Ciannelli, L., Wakefield, W. W., Simon, V., Barth, J. A., and Pierce, S. D. (2017). Species-specific responses of demersal fishes to near-bottom oxygen levels within the California Current large marine ecosystem. Mar. Ecol. Prog. Ser. 568, 151-173. doi: 10.3354/meps12066

Kemp, W. M., Testa, J. M., Conley, D. J., Gilbert, D., and Hagy, J. D. (2009). Coastal hypoxia responses to remediation. Biogeosciences 6, 2985-3008. doi: 10.5194/bg-6-2985-2009

Key, R. M., Kozyr, A., Sabine, C. L., Lee, K., Wanninkhof, R., Bullister, J. L., et al. (2004). A global ocean carbon climatology: Results from Global Data Analysis Project (GLODAP). Glob. Biogeochem. Cycles 18, 1-23. doi: 10.1029/ 2004GB002247

Körtzinger, A., Schimanski, J., Send, U., and Wallace, D. (2004). The ocean takes a deep breath. Science 306:1337. doi: 10.1126/science.1102557

Krasnopolsky, V., Nadiga, S., Mehra, A., Bayler, E., and Behringer, D. (2016). Neural networks technique for filling gaps in satellite measurements: application to ocean color observations. Comput. Intel. Neurosci. 2016:6156513. doi: $10.1155 / 2016 / 6156513$

Kriest, I., Sauerland, V., Khatiwala, S., Srivastav, A., and Oschlies, A. (2017). Calibrating a global three-dimensional biogeochemical ocean model (MOPS1.0). Geosci. Model Dev. 10, 127-154. doi: 10.5194/gmd-10-127-2017

Labasque, T., Chaumery, C., Aminot, A., and Kergoat, G. (2004). Spectrophotometric winkler determination of dissolved oxygen: Reexamination of critical factors and reliability. Mar. Chem. 88, 53-60. doi: 10.1016/j.marchem.2004.03.004

Laffoley, D., and Baxter, J. M. (2019). Ocean Deoxygenation: Everyone's Problem Causes, Impacts, Consequences and Solutions. Gland, Switzerland: IUCN, 580. doi: 10.2305/IUCN.CH.2019.13.en

Lakowicz, J. (2006). Principles of Fluorescence Spectroscopy, 3rd Edn. Amsterdam: Elsevier, 954. doi: 10.1007/978-0-387-46312-4

Langdon, C. (2010). "Determination of dissolved oxygen in seaweater by Winkler titration using Amperometric Technique," in The GO-SHIP Repeat Hydrography Manual: A Collection of Expert Reports and Guidelines. Version 1 (IOCCP Report Number 14; ICPO Publication Series Number 134), eds E. M. Hood, C. L. Sabine and B. M. Sloyan (Lyon: ICPO), 18. doi: 10.25607/OBP- 1350

Lauvset, S. K., and Tanhua, T. (2015). A toolbox for secondary quality control on ocean chemistry and hydrographic data. Limnol. Oceanogr. Meth. 13, 601-608. doi: 10.1002/lom3.10050

Lauvset, S. K., Key, R. M., Olsen, A., van Heuven, S., Velo, A., Lin, X., et al. (2016). A new global interior ocean mapped climatology: the $1^{\circ} \mathrm{x} 1^{\circ}$ GLODAP version 2. Earth Syst. Sci. Data 8, 325-340. doi: 10.5194/essd-8-325-2016

Le Traon, P. Y., Reppucci, A., Fanjul, E. A., Aouf, L., Behrens, A., Belmonte, M., et al. (2019). From observation to information and users: The copernicus marine service perspective. Front. Mar. Sci. 6:234. doi: 10.3389/fmars.2019. 00234

Lehner, P., Larndorfer, C., Garcia-Robledo, E., Larsen, M., Borisov, S. M., Revsbech, N. P., et al. (2015). Lumos - a sensitive and reliable optode system for measuring dissolved oxygen in the nanomolar range. PLoS One 10:e0128125. doi: 10.1371/ journal.pone.0128125

Lemburg, J., Wenzhöfer, F., Hofbauer, M., Färber, P., and Meyer, V. (2018). "Benthic crawler NOMAD," in Proceedings of the 2018 OCEANS - MTS/IEEE Kobe Techno-Oceans (OTO), Kobe, 1-7. doi: 10.1109/OCEANSKOBE.2018. 8559446

Levin, L. A. (2003). Oxygen minimum zone benthos: Adaptation and community response to hypoxia. Oceanogr. Mar. Biol. 41, 1-45.
Levin, L. A. (2018). Manifestation, drivers, and emergence of open ocean deoxygenation. Annu. Rev. Mar. Sci. 10, 229-260. doi: 10.1146/annurevmarine-121916-063359

Levin, L. A., Ekau, W., Gooday, A. J., Jorissen, F., Middelburg, J. J., Naqvi, S. W. A., et al. (2009). Effects of natural and human-induced hypoxia on coastal benthos. Biogeosciences 6, 2063-2098. doi: 10.5194/bg-6-20632009

Levin, L. A., Wei, C. L., Dunn, D. C., Amon, D., Ashford, O., Cheung, W., et al. (2020). Climate change considerations are fundamental to management of deep-sea resource extraction. Glob. Change Biol. 26, 4664-4678. doi: 10.1111/ gcb. 15223

Li, P., and Tanhua, T. (2020). Recent changes in deep ventilation of the mediterranean sea; evidence from long-term transient tracer observations. Front. Mar. Sci. 7:594. doi: 10.3389/fmars.2020.00594

Limburg, K. E., and Casini, M. (2018). Effect of marine hypoxia on Baltic Sea cod Gadus morhua: evidence from otolith chemical proxies. Front. Mar. Sci. 5:482. doi: $10.3389 /$ fmars.2018.00482

Limburg, K. E., and Casini, M. (2019). Otolith chemistry indicates recent worsened Baltic cod condition is linked to hypoxia exposure. Biol. Lett. 15:20190352. doi: 10.1098/rsbl.2019.0352

Limburg, K. E., Breitburg, D., Swaney, D., and Jacinto, G. (2020). Ocean deoxygenation: a primer. One Earth 2, 24-29. doi: 10.1016/j.oneear.2020.01.001

Long, M. C., Deutsch, C., and Ito, T. (2016). Finding forced trends in oceanic oxygen. Glob. Biogeochem. Cycles 30, 381-397. doi: 10.1002/2015GB00 5310

Lu, Y., Yuan, J., Lu, X., Su, C., Zhang, Y., Wang, C., et al. (2018). Major threats of pollution and climate change to global coastal ecosystems and enhanced management for sustainability. Environ. Pollut. 239, 670-680. doi: 10.1016/j. envpol.2018.04.016

Martín Míguez, B., Novellino, A., Vinci, M., Claus, S., van Calewaert, J.-B., Vallius, H., et al. (2019). The European Marine Observation and Data Network (EMODnet): visions and roles of the gateway to marine data in Europe. Front. Mar. Sci. 6:313. doi: 10.3389/fmars.2019.00313

Mavropoulou, A. M., Vervatis, V., and Sofianos, S. (2020). Dissolved oxygen variability in the Mediterranean Sea. J. Mar. Syst. 2020:103348. doi: 10.1016/ j.jmarsys.2020.103348

Montes, I., Dewitte, B., Gutknecht, E., Paulmier, A., Dadou, I., Oschlies, A., et al. (2014). High-resolution modeling of the eastern Tropical Pacific oxygen minimum zone: Sensitivity to the tropical oceanic circulation. J. Geophys. Res. Oceans 119, 5515-5532. doi: 10.1002/2014JC009858

Neilan, R. M., and Rose, K. (2014). Simulating the effects of fluctuating dissolved oxygen on growth, reproduction, and survival of fish and shrimp. J. Theor. Bio. 343, 54-68. doi: 10.1016/j.jtbi.2013.11.004

Nicholson, D. P., and Feen, M. L. (2017). Air calibration of an oxygen optode on an underwater glider. Limnol. Oceanogr. Meth. 15, 495-502. doi: 10.1002/lom3. 10177

Nicholson, D., Emerson, S., and Eriksen, C. C. (2008). Net community production in the deep euphotic zone of the subtropical North Pacific gyre from glider surveys. Limnol. Oceanogr. 53, 2226-2236. doi: 10.4319/lo.2008.53.5_part_2. 2226

Noone, K. J., Sumaila, U. R., and Diaz, R. J. (2013). Managing Ocean Environments in a Changing Climate: Sustainability and Economic Perspectives. London, UK: Elsevier, 359.

Ohman, M. D., Rudnick, D. L., Chekalyuk, A., Davis, R. E., Feely, R. A., Kahru, M., et al. (2013). Autonomous ocean measurements in the California current ecosystem. Oceanography 26, 18-25. doi: 10.5670/oceanog.2013.41

Olsen, A., Key, R. M., van Heuven, S., Lauvset, S. K., Velo, A., Lin, X., et al. (2016). The Global Ocean Data Analysis Project version 2 (GLODAPv2) - an internally consistent data product for the world ocean. Earth Syst. Sci. Data 8, 297-323. doi: 10.5194/essd-8-297-2016

Olsen, A., Lange, N., Key, R. M., Tanhua, T., Bittig, H., and Kozyr, A. (2020). GLODAPv2.2020 - the second update of GLODAPv2. Earth Syst. Sci. Data 2020:165. doi: 10.5194/essd-2020-165

Oschlies, A. (2018). "Reconciling systematic differences between observed and simulated ocean deoxygenation," in Proceedings of the 4th International Symposium on the Effects of Climate Change on the World's Oceans 4 (ECCWO) Meeting, Washington, DC. 
Oschlies, A., Brandt, P., Stramma, L., and Schmidtko, S. (2018). Drivers and mechanisms of ocean deoxygenation. Nat. Geosci. 11, 467-473. doi: 10.1038/ s41561-018-0152-2

Pairaud, I., Repecaud, M., Ravel, C., Fuchs, R., Arnaud, M., Champelovier, A., et al. (2016). "MesuRho. Plateforme instrumentée de suivi des paramètres environnementaux à l'embouchure du Rhône," in Mesures à haute résolution dans l'environnement marin côtier, eds F. G. Schmitt and A. Lefebvre (Paris: CNRS), 73-87.

Pastres, R., Ciavatta, S., and Solidoro, C. (2003). The Extended Kalman Filter (EKF) as a tool for the assimilation of high frequency water quality data. Ecol. Model. 170, 227-235. doi: 10.1016/S0304-3800(03)00230-8

Paulmier, A. (2017). "Oxygen and the ocean," in The Ocean revealed, eds A. Euzen, F. Gaill, D. Lacroix, and P. Cury (Paris: CNRS), 48-49.

Paulmier, A., and Ruiz-Pino, D. (2009). Oxygen minimum zones (OMZs) in the modern ocean. Prog. Oceanogr. 80, 113-128. doi: 10.1016/j.pocean.2008.08.001

Pauly, D., and Zeller, D. (2016). Catch reconstructions reveal that global marine fisheries catches are higher than reported and declining. Nat. Commun. 7, 1-9. doi: $10.1038 /$ ncomms 10244

Pitcher, G. C., Aguirre, A., Breitburg, D., Cardich, J., Carstensen, J., Conley, D. J., et al. (2021). System controls of coastal and open ocean oxygen depletion. Prog. Oceanogr. 197:102613. doi: 10.1016/j.pocean.2021.102613

Pollock, M. S., Clarke, L. M. J., and Dubé, M. G. (2007). The effects of hypoxia on fishes: from ecological relevance to physiological effects. Environ. Rev. 5, 1-14. doi: 10.1139/a06-006

Polsenaere, P., Deflandre, B., Thouzeau, G., Rigaud, S., Cox, T., Amice, E., et al. (2021). Comparison of benthic oxygen exchange measured by aquatic Eddy Covariance and Benthic Chambers in two contrasting coastal biotopes (Bay of Brest, France). Regional Stud. Mar. Sci. 43:101668. doi: 10.1016/j.rsma.2021. 101668

Pörtner, H. O. (2021). Climate impacts on organisms, ecosystems and human societies:integrating OCLTT into a wider context. J. Exper. Biol. 224:jeb238360. doi: $10.1242 /$ jeb. 238360

Purcell, K. M., Craig, J. K., Nance, J. M., Smith, M. D., and Bennear, L. S. (2017). Fleet behavior is responsive to a large-scale environmental disturbance: Hypoxia effects on the spatial dynamics of the northern Gulf of Mexico shrimp fishery. PloS One 12:e183032. doi: 10.1371/journal.pone.0183032

Purser, A., Thomsen, L., Barnes, C., Best, M., Chapman, R., Hofbauer, M., et al. (2013). Temporal and spatial benthic data collection via an internet operated deep sea crawler. Meth. Oceanogr. 5, 1-18. doi: 10.1016/j.mio.2013. 07.001

Queirós, A. M., Huebert, K. B., Keyl, F., Fernandes, J. A., Stolte, W., Maar, M., et al. (2016). Solutions for ecosystem-level protection of ocean systems under climate change. Glob. Change Biol. 22, 3927-3936. doi: 10.1111/gcb.13423

Rabalais, N. N. (2015). Human impacts on fisheries across the land-sea interface. Proc. Natl. Acad. Sci. 112, 7892-7893. doi: 10.1073/pnas.1508766112

Rabalais, N. N., Diaz, R. J., Levin, L. A., Turner, R. E., Gilbert, D., and Zhang, J. (2010). Dynamics and distribution of natural and human-caused hypoxia. Biogeosciences 7:585. doi: 10.5194/bg-7-585-2010

Rabalais, N. N., Turner, R. E., and Wiseman, W. J. (2002). Gulf of Mexico hypoxia, a.k.a. "the dead zone". Annu. Rev. Ecol. Syst. 33, 235-263. doi: 10.1146/annurev. ecolsys.33.010802.150513

Rabalais, N. N., Turner, R. E., Gupta, B. S., Boesch, D. F., Chapman, P., and Murrell, M. C. (2007a). Hypoxia in the northern Gulf of Mexico: Does the science support the plan to reduce, mitigate, and control hypoxia? Estuaries Coasts 30, 753-772. doi: 10.1007/BF02841332

Rabalais, N. N., Turner, R. E., Sen Gupta, B. K., Platon, E., and Parsons, M. L. (2007b). Sediments tell the history of eutrophication and hypoxia in the northern Gulf of Mexico. Ecol. Appl. 17, S129-S143. doi: 10.1890/060644.1

Racapé, V., Thierry, V., Mercier, H., and Cabanes, C. (2019). ISOW spreading and mixing as revealed by deep-argo floats launched in the charlie gibbs fracture zone. J. Geophys. Res. 124, 6787-6808. doi: 10.1029/2019JC015040

Reimers, C. E., Özkan-Haller, H. T., Berg, P., Devol, A., McCann-Grosvenor, K., and Sanders, R. D. (2012). Benthic oxygen consumption rates during hypoxic conditions on the Oregon continental shelf: Evaluation of the eddy correlation method. J. Geophys. Res. 117:C02021. doi: 10.1029/2011JC007564

Resplandy, L., Keeling, M., Eddebbar, Y., Brooks, M. K., Wang, R., Bopp, L., et al. (2018). Quantification of ocean heat uptake from changes in atmospheric
$\mathrm{O}_{2}$ and $\mathrm{CO}_{2}$ composition. Nature 563, 105-108. doi: 10.1038/s41586-0180651-8

Revsbech, N. P., Larsen, L. H., Gundersen, J. K., Dalsgaard, T., Ulloa, O., Thamdrup, B., et al. (2009). Determination of ultra-low oxygen concentrations in oxygen minimum zones by the stox sensor. Limnol. Oceanogr. Meth. 7, 371-381. doi: 10.4319/lom.2009.7.371

Ridgwell, A., Hargreaves, J. C., Edwards, N. R., Annan, J. D., Lenton, T. M., Marsh, R., et al. (2007). Marine geochemical data assimilation in an efficient earth system model of global biogeochemical cycling. Biogeosciences 4, 87-104. doi: 10.5194/bg-4-87-2007

Rigaud, S., Deflandre, B., Maire, O., Bernard, G., Duchêne, J. C., Poirier, D., et al (2018). Transient biogeochemistry in intertidal sediments: New insights from tidal pools in Zostera noltei meadows of Arcachon Bay (France). Mar. Chem. 200, 1-13. doi: 10.1016/j.marchem.2018.02.002

Roemmich, D., Alford, M. H., Claustre, H., Johnson, K., King, B., Moum, J., et al. (2019). On the future of Argo: An enhanced global array of physical and biogeochemical sensing floats. Front. Mar. Sci. 6:439. . doi: 10.3389/fmars.2019. 00439

Roman, M. R., Brandt, S. B., Houde, E. D., and Pierson, J. J. (2019). Interactive effects of hypoxia and temperature on coastal pelagic zooplankton and fish. Front. Mar. Sci. 6:139. doi: 10.3389/fmars.2019.00139

Rose, K. A., Creekmore, S., Thomas, P., Craig, J. K., Rahman, M. S., and Neilan, R. M. (2018). Modeling the population effects of hypoxia on Atlantic croaker (Micropogonias undulatus) in the northwestern Gulf of Mexico: part 1-model description and idealized hypoxia. Estuaries Coasts 41, 233-254. doi: 10.1007/ s12237-017-0266-6

Rose, K. A., Gutierrez Aguilar, D., Breitburg, D., Conley, D., Craig, J. K. Froehlich, H. E., et al. (2019). "Impacts of ocean deoxygenation on fisheries," in Ocean Deoxygenation: Everyone's Problem - Causes, impacts, consequences and solutions, eds D. Laffoley and J. M. Baxter (Gland, Switzerland: International Union for Conservation of Nature and Natural Resources (IUCN)), 519-544.

Rovelli, L., Attard, K. M., Bryant, L. D., Flögel, S., Stahl, H., Roberts, J. M., et al. (2015). Benthic O2 uptake of two cold-water coral communities estimated with the non-invasive eddy-correlation technique. Mar. Ecol. Prog. Ser. 525, 97-104. doi: $10.3354 /$ meps 11211

Rudnick, D. L. (2016b). Instrument Development Group, Scripps Institution of Oceanography. La Jolla, CA: California Underwater Glider Network.

Rudnick, D. L. (2016a). Ocean research enabled by underwater gliders. Annu. Rev. Mar. Sci. 8, 519-541. doi: 10.1146/annurev-marine-122414-033913

Rudnick, D. L., Zaba, K. D., Todd, R. E., and Davis, R. E. (2017). A climatology of the California current system from a network of underwater gliders. Prog. Oceanogr. 154, 64-106. doi: 10.1016/j.pocean.2017.03.002

Sánchez-Velasco, L., Godínez, V. M., Ruvalcaba-Aroche, E. D., Márquez-Artavia, A., Beier, E., Barton, E. D., et al. (2019). Larval fish habitats and deoxygenation in the northern limit of the oxygen minimum zone off Mexico. J. Geophys. Res. Oceans 124, 9690-9705. doi: 10.1029/2019JC015414

Sasano, D., Takatani, Y., Kosugi, N., Nakano, T., Midorikawa, T., and Ishii, M. (2018). Decline and bidecadal oscillations of dissolved oxygen in the Oyashio region and their propagation to the western North Pacific. Glob. Biogeochem. Cycles 32, 909-931. doi: 10.1029/2017GB005876

Saunders, P. M. (1986). The accuracy of salinity, oxygen in the deep ocean. J. Phys. Ocean. 16, 189-195. doi: 10.1175/1520-0485(1986)016<0189:TAOMOS $>2.0$. $\mathrm{CO} ; 2$

Savchuk, O. P. (2018). Large-scale nutrient dynamics in the Baltic Sea, 1970-2016. Front. Mar. Sci. 5:95. doi: 10.3389/fmars.2018.00095

Schmidtko, S., Stramma, L., and Visbeck, M. (2017). Decline in global oceanic oxygen content during the past five decades. Nature 542, 335-339. doi: 10.1038/ nature 21399

Seibel, B. A., and Deutsch, C. (2020). Oxygen supply capacity in animals evolves to meetmaximum demand at the current oxygen partial pressure regardless of size or temperature. J. Exp. Biol. 223:jeb210492. doi: 10.1242/jeb.210492

Seibel, B. A., Andres, A., Birk, M. A., Shaw, C. T., Timpe, A., and Welsh, C. (2021). Oxygen supply capacity breathes new life into the critical oxygen partial pressure (Pcrit). J. Exper. Biol. 224:jeb242210. doi: 10.1242/jeb.242210

Seitzinger, S. P., Mayorga, E., Bouwman, A. F., Kroeze, C., Beusen, A. H. W., Billen, G., et al. (2010). Global river nutrient export: A scenario analysis of past and future trends. Glob. Biogeochem. Cycles 24:GB0A08. doi: 10.1029/ 2009GB003587 
Smith, K. L. Jr., Sherman, A. D., McGill, P. R., Henthorn, R. G., Ferreira, J., and Huffard, C. L. (2017). Evolution of monitoring an abyssal time- series station in the northeast Pacific over 28 years. Oceanography 30, 72-81. doi: 10.5670/ oceanog.2017.425

Soetaert, K., and Grégoire, M. (2011). Estimating marine biogeochemical rates of the carbonate pH system-A Kalman filter tested. Ecol. Modell. 222, 1929-1942. doi: 10.1016/j.ecolmodel.2011.03.012

Staudinger, C., Strobl, M., Fischer, J. P., Thar, R., Mayr, T., Aigner, D., et al. (2018). A versatile optode system for oxygen, carbon dioxide, and $\mathrm{pH}$ measurements in seawater with integrated battery and logger. Limnol. Oceanogr. Meth. 16, 459-473. doi: 10.1002/lom3.10260

Steinhoff, T., Gkritzalis, T., Lauvset, S. K., Jones, S., Schuster, U., Olsen, A., et al. (2019). Constraining the oceanic uptake and fluxes of greenhouse gases by building an ocean network of certified stations: The Ocean Component of the Integrated Carbon Observation System, ICOS-Oceans. Front. Mar. Sci. 6:544. doi: 10.3389/fmars.2019.00544

Stramma, L., Johnson, G. C., Sprintall, J., and Mohrholz, V. (2008). Expanding oxygen-minimum zones in the tropical oceans. Science 320, 655-658. doi: $10.1126 /$ science. 1153847

Stramma, L., Prince, E. D., Schmidtko, S., Luo, J., Hoolihan, J. P., Visbeck, M., et al. (2012). Expansion of oxygen minimum zones may reduce available habitat for tropical pelagic fishes. Nat. Climate Change 2, 33-37. doi: 10.1038/nclimate1304

Stratmann, T., Soetaert, K., Wei, C.-L., Lin, Y.-S., and van Oevelen, D. (2019). The SCOC database, a large, open, and global database with sediment community oxygen consumption rates. Sci. Data 6:242. doi: 10.1038/s41597-019-0 259-3

Sumaila, U. R., Ebrahim, N., Schuhbauer, A., Skerritt, D., Li, Y., Kim, H., et al. (2019). Updated estimates and analysis of global fisheries subsides. Mar. Policy 109:103695. doi: 10.1016/j.marpol.2019.103695

Swartz, W., Sumaila, U. R., and Watson, R. (2013). Global Ex-Vessel Fish Price Database revisited: a new approach for estimating 'missing' prices. Environ. Resour. Econ. 56, 467-480. doi: 10.1007/s10640-012-9611-1

Takeshita, Y., Jones, B., Johnson, K. S., Chavez, F. P., Rudnick, D., Blum, M., et al. (2021). Accurate $\mathrm{pH}$ and $\mathrm{O} 2$ measurements from Spray underwater gliders. J. Atmosp. Ocean. Technol. 38, 181-195. doi: 10.1175/JTECH-D-20-0095.1

Takeshita, Y., Martz, T. R., Johnson, K. S., Plant, J. N., Gilbert, D., Riser, S. C., et al. (2013). A climatology-based quality control procedure for profiling float oxygen data. J. Geophys. Res. Oceans 118, 5640-5650. doi: 10.1002/jgrc.20399

Tanhua, T., van Heuven, S., Key, R., Velo, A., Olsen, A., and Schirnick, C. (2010). Quality control procedures and methods of the CARINA database. Earth Syst. Sci. Data 2, 35-49. doi: 10.5194/essd-2-35-2010

Tengberg, A., De Bovee, F., Hall, P., Berelson, W., Cicceri, G., Crassous, P., et al. (1995). Benthic chamber and profile landers in oceanography - A review of design, technical solutions and functioning. Prog. Oceanogr. 35, 253-294. doi: 10.1016/0079-6611(95)00009-6

Testor, P., de Young, B., Rudnick, D. L., Glenn, S., Hayes, D., Lee, C. L., et al. (2019). OceanGliders: A component of the integrated GOOS. Front. Mar. Sci. 6:422. doi: 10.3389/fmars.2019.00422

Thierry, V., and Bittig, H. (2018). Argo Quality Control Manual for Dissolved Oxygen Concentration, v2.0. France: IFREMER for Argo BGC Group.

Thierry, V., Gilbert, D., Kobayashi, T., and Schmid, C. (2018). Processing argo oxygen data at the DAC level, v2.3.1. Brest, France: IFREMER.

Thomas, P., and Rahman, M. S. (2010). Region-wide impairment of Atlantic croaker testicular development and sperm production in the northern Gulf of Mexico hypoxic dead zone. Mar. Env. Res. 69, S59-S62. doi: 10.1016/j. marenvres.2009.10.017

Tiano, L., Garcia-Robledo, E., Dalsgaard, T., Devol, A. H., Ward, B. B., Ulloa, O., et al. (2014). Oxygen distribution and aerobic respiration in the north and south eastern tropical pacific oxygen minimum zones. Deep-Sea Res Part I-Oceanogr. Res. Pap. 94, 173-183. doi: 10.1016/j.dsr.2014.10.001

Tomasetti, S. J., and Gobler, C. J. (2020). Dissolved oxygen and pH criteria leave fisheries at risk. Science 368, 372-373. doi: 10.1126/science.aba4896

Toussaint, F., Rabouille, C., Cathalot, C., Bombled, B., Abchiche, A., Aouji, O., et al. (2014). A new device to follow temporal variations of oxygen demand in deltaic sediments: the LSCE benthic station. Limnol. Oceanogr. Methods 12, 729-741. doi: 10.4319/lom.2014.12.729

Townhill, B. L., van der Molen, J., Metcalfe, J. D., Simpson, S. D., Farcas, A., and Pinnegar, J. K. (2017). Consequences of climate-induced low oxygen conditions for commercially important fish. Mar. Ecol. Prog. Ser. 580, 191-204. doi: 10. 3354/meps12291

Troupin, C., Barth, A., Sirjacobs, D., Ouberdous, M., Brankart, J.-M., Brasseur, P., et al. (2012). Generation of analysis and consistent error fields using the Data Interpolating Variational Analysis (DIVA). Ocean Model. 52-53, 90-101. doi: 10.1016/j.ocemod.2012.05.002

Tyler, R., Brady, D. C., and Targett, T. E. (2009). Temporal and spatial dynamics of diel-cycling hypoxia in estuarine tributaries. Estuaries Coasts 32:145. doi: 10.1007/s12237-008-9108-x

Uchida, H., Johnson, G. C., and McTaggart, K. E. (2010). "CTD oxygen sensor calibration procedures," in The GO-SHIP Repeat Hydrography Manual: A Collection of Expert Reports and Guidelines, eds E. M. Hood, C. L. Sabine, and B. M. Sloyan (Brest, France: ICPO Publication).

Ulses, C., Estournel, C., Fourrier, M., Coppola, L., Kessouri, F., Lefèvre, D., et al. (2021). Oxygen budget of the north-western Mediterranean deep- convection region. Biogeosciences 18, 937-960. doi: 10.5194/bg-18-937-2021

UNESCO (2012). FOO: Framework for Ocean Observing By the Task Team for an Integrated Framework for Sustained Ocean Observing, UNESCO 2012, IOC/INF1284. Paris: UNESCO.

Vaquer-Sunyer, R., and Duarte, C. M. (2008). Thresholds of hypoxia for marine biodiversity. Proc. Natl. Acad. Sci. 105, 15452-15457. doi: 10.1073/pnas. 0803833105

Vergara, O., Dewitte, B., Montes Torres, I., Garçon, V., Ramos, M., Paulmier, A., et al. (2016). Seasonal variability of the oxygen minimum zone off Peru in a high-resolution regional coupled model. Biogeosciences 13, 4389-4410. doi: $10.5194 /$ bg-13-4389-2016

Vinci, M., Giorgetti, A., and Lipizer, M. (2017). The role of EMODnet chemistry in the european challenge for good environmental status. Nat. Hazards Earth Syst. Sci. 17, 197-204. doi: 10.5194/nhess-17-197-2017

Wang, Z. A., Moustahfid, H., Mueller, A. V., Michel, A. P. M., Mowlem, M., Glazer, B. T., et al. (2019). Advancing observation of ocean biogeochemistry, biology, and ecosystems with cost-effective in-situ sensing technologies. Front. Mar. Sci. 6:519. doi: 10.3389/fmars.2019.00519

Wanninkhof, R., Pickers, P. A., Omar, A. M., Sutton, A., Murata, A., Olsen, A., et al. (2019). A surface ocean CO2 reference network, SOCONET and associated marine boundary layer CO2 measurements. Front. Mar. Sci. 6:400. doi: 10.3389/fmars.2019.00400

Wei, Y., Jiao, Y., An, D., Li, D., Li, W., and Wei, Q. (2019). Review of dissolved oxygen detection technology: from laboratory analysis to online intelligent detection. Sensors 19:3995. doi: 10.3390/s19183995

Wenzhöfer, F., and Glud, R. N. (2002). Benthic carbon mineralization in the Atlantic: A synthesis based on in situ data from the last decade. Deep-Sea Res. (I) 49, 1255-1279. doi: 10.1016/S0967-0637(02)00025-0

Wenzhöfer, F., Oguri, K., Middelboe, M., Turnewitsch, R., Toyofuku, T., Kitazato, H., et al. (2016). Benthic carbon mineralization in hadal trenches: Assessment by in situ O2 microprofile measurements. Deep-Sea Res. I 116, 276-286. doi: 10.1016/j.dsr.2016.08.013

Wilkinson, M., Dumontier, M., Aalbersberg, I., Appleton, G., Axton, M., Baak, A., et al. (2016). The FAIR guiding principles for scientific data management and stewardship. Sci. Data 3:160018. doi: 10.1038/sdata.2016.18

Winkler, L. W. (1888). Die Bestimmung des im Wasser gelösten Sauerstoffes. Chem. Ber. 21, 2843-2855. doi: 10.1002/cber.188802102122

Wishner, K. F., Seibel, B. A., Roman, C., Deutsch, C., Outram, D., Shaw, C. T., et al. (2018). Ocean deoxygenation and zooplankton: Very small oxygen differences matter. Sci. Adv. 4:eaau5180. doi: 10.1126/sciadv.aau5180

Wong, G. T. F., and Cheng, X.-H. (1998). Dissolved organic iodine in marine waters: Determination, occurrence and analytical implications. Mar. Chem. 59, 271-281. doi: 10.1016/S0304-4203(97)00078-9

Wong, G. T. F., and Li, K.-Y. (2009). Winkler's method overestimates dissolved oxygen in seawater: Iodate interference and its oceanographic implications. Mar. Chem. 115, 86-91. doi: 10.1016/j.marchem.2009.06.008

Wu, R. S. (2002). Hypoxia: from molecular responses to ecosystem responses. Mar. Pollut. Bull. 45, 35-45. doi: 10.1016/S0025-326X(02)00061-9

Wu, R. S. (2009). "Effects of hypoxia on fish reproduction and development," in Fish physiology, Vol. 27, eds J. G. Richards, A. P. Farrell, and C. J. Brauner (Cambridge: Academic Press), 79-141. doi: 10.1016/S1546-5098(08)00003-4

Yang, B., Emerson, S. R., and Bushinsky, S. M. (2017). Annual net community production in the subtropical Pacific Ocean from in situ oxygen measurements 
on profiling floats. Glob. Biogeochem. Cycles 31, 728-744. doi: 10.1002/ 2016GB005545

Yasuhara, M., Hunt, G., Breitburg, D., Tsujimoto, A., and Katsuki, K. (2012). Human-induced marine ecological degradation: micropaleontological perspectives. Ecol. Evol. 2, 3242-3268. doi: 10.1002/ece3.425

Yasuhara, M., Tittensor, D. P., Hillebrand, H., and Worm, B. (2017). Combining marine macroecology and palaeoecology in understanding biodiversity: microfossils as a model. Biol. Rev. 92, 199-215. doi: 10.1111/brv.12223

Zhai, W. D., Dai, M., and Cai, W. J. (2009). Coupling of surface pCO2 and dissolved oxygen in the northern South China Sea: impacts of contrasting coastal processes. Biogeosciences 6, 2589-2598. doi: 10.5194/bg-6-2589-2009

Zhang, Q., Tango, P. J., Murphy, R. R., Forsyth, M. K., Tian, R., Keisman, J., et al. (2018). Chesapeake Bay dissolved oxygen criterion attainment deficit: three decades of temporal and spatial patterns. Front. Mar. Sci. 5:422. doi: 10.3389/fmars.2018.00422

Conflict of Interest: The authors declare that the research was conducted in the absence of any commercial or financial relationships that could be construed as a potential conflict of interest.

Publisher's Note: All claims expressed in this article are solely those of the authors and do not necessarily represent those of their affiliated organizations, or those of the publisher, the editors and the reviewers. Any product that may be evaluated in this article, or claim that may be made by its manufacturer, is not guaranteed or endorsed by the publisher.
Citation: Grégoire M, Garçon V, Garcia H, Breitburg D, Isensee K, Oschlies A, Telszewski M, Barth A, Bittig HC, Carstensen J, Carval T, Chai F, Chavez F, Conley D, Coppola L, Crowe S, Currie K, Dai M, Deflandre B, Dewitte B, Diaz R, Garcia-Robledo E, Gilbert D, Giorgetti A, Glud R, Gutierrez D, Hosoda S, Ishii M, Jacinto G, Langdon C, Lauvset SK, Levin LA, Limburg KE, Mehrtens H, Montes I, Naqvi W, Paulmier A, Pfeil B, Pitcher G, Pouliquen S, Rabalais N, Rabouille C, Recape V, Roman M, Rose K, Rudnick D, Rummer J, Schmechtig C, Schmidtko S, Seibel B, Slomp C, Sumalia UR, Tanhua T, Thierry V, Uchida H, Wanninkhof $R$ and Yasuhara M (2021) A Global Ocean Oxygen Database and Atlas for Assessing and Predicting Deoxygenation and Ocean Health in the Open and Coastal Ocean. Front. Mar. Sci. 8:724913. doi: 10.3389/fmars.2021.724913

Copyright ( 2021 Grégoire, Garçon, Garcia, Breitburg, Isensee, Oschlies, Telszewski, Barth, Bittig, Carstensen, Carval, Chai, Chavez, Conley, Coppola, Crowe, Currie, Dai, Deflandre, Dewitte, Diaz, Garcia-Robledo, Gilbert, Giorgetti, Glud, Gutierrez, Hosoda, Ishii, Jacinto, Langdon, Lauvset, Levin, Limburg, Mertens, Montes, Naqvi Paulmier, Pfeil, Pitcher, Pouliquen, Rabalais, Rabouille, Recape, Roman, Rose, Rudnick, Rummer, Schmechtig, Schmidtko, Seibel, Slomp, Sumalia, Tanhua, Thierry Uchida, Wanninkhof and Yasuhara. This is an open-access article distributed under the terms of the Creative Commons Attribution License (CC BY). The use, distribution or reproduction in other forums is permitted, provided the original author(s) and the copyright owner(s) are credited and that the original publication in this journal is cited, in accordance with accepted academic practice. No use, distribution or reproduction is permitted which does not comply with these terms. 


\section{APPENDIX}

TABLE A1 | Characteristics of each generation of floats: type of sensors, known issues, drift correction, number of floats equipped with $\mathrm{O}_{2}$ sensors, number of profiles (in June 2020) and data streams.

\begin{tabular}{|c|c|c|c|c|c|c|c|c|}
\hline $\begin{array}{l}\text { Generation of } \\
\text { floats }\end{array}$ & Sensors type & Known issues & Drift correction & \# floats & \# profiles & \# RT (1) & \# A (2) & \# DM (3) \\
\hline First Generation & SBE43 sensors & $\begin{array}{l}\text { Sensor stability and } \\
\operatorname{drift}^{(4)}\end{array}$ & $\begin{array}{l}\text { A gain and offset formulation } \\
\text { established in stable deep } \\
\text { waters }^{(5)}\end{array}$ & 160 & 26921 & 9972 & 0 & 16949 \\
\hline $\begin{array}{l}\text { Second } \\
\text { Generation }\end{array}$ & $\begin{array}{l}\text { Aanderaa } 3830 / 3835 \\
4330 / 4831\end{array}$ & $\begin{array}{l}\text { Inadequate } \\
\text { temperature } \\
\text { compensation and/or } \\
\text { distorted, incorrect } \mathrm{O}_{2} \\
\text { response especially at } \\
\text { low to intermediate } \mathrm{O}_{2} \\
\text { levels }\end{array}$ & $\begin{array}{l}\text { Either a gain and offset } \\
\text { formulation established in } \\
\text { stable deep waters }{ }^{(5)} \text { or a } \\
\text { temperature-dependent } \mathrm{O}_{2} \\
\text { gain }{ }^{(6)}\end{array}$ & 598 & 111520 & 41929 & 2730 & 66861 \\
\hline $\begin{array}{l}\text { Third } \\
\text { Generation }\end{array}$ & $\begin{array}{l}\text { Aanderaa } \\
4330 / 4831-S B E 63, \\
\text { RINKO, ARO-FT }\end{array}$ & $\begin{array}{l}\text { Linear } \mathrm{O}_{2} \text { sensitivity } \\
\text { drift }^{(6)}\end{array}$ & $\begin{array}{l}\text { Drift correction by an } \mathrm{O}_{2} \text { gain } \\
\text { factor using the surface } \mathrm{p}_{2} \\
\text { estimated either from in-air } \\
\text { measurement or estimated } \\
\text { from climatologies at the } \\
\text { ARGO-measured Temperature } \\
\text { and salinity }{ }^{(6,7)}\end{array}$ & 498 & 50464 & 22187 & 4883 & 23394 \\
\hline
\end{tabular}

(1) Real-Time, available $24 \mathrm{~h}$ after profiling; (2) Adjusted, RT data after automated QC; (3) Delayed-Mode, best quality data including realistic error estimates, sophisticated data adjustments and QC procedures, manual inspection by either the float's PI or pre-identified Delayed Mode (DMQC) expert (e.g. Bittig et al., 2019); (4) Gruber et al., 2010; (5) Takeshita et al., 2013; (6) Bittig et al., 2018; (7) Thierry and Bittig, 2018. 